UNIVERSIDADE DE SÃO PAULO

FACULDADE DE ECONOMIA, ADMINISTRAÇÃO E CONTABILIDADE DEPARTAMENTO DE ADMINISTRAÇÃO PROGRAMA DE PÓS-GRADUAÇÃO EM ADMINSTRAÇÃO

AVALIAÇÃO DE DESEMPENHO ORGANIZACIONAL - UM ESTUDO EM UM HOSPITAL UNIVERSITÁRIO PÚBLICO

Joice Chiareto

Orientador: Prof. Dr. Hamilton Luiz Corrêa

SÃO PAULO

2014 
Prof. Dr. Marco Antonio Zago

Reitor da Universidade de São Paulo

Prof. Dr. Adalberto Américo Fischmann

Diretor da Faculdade de Economia, Administração e Contabilidade

Prof. Dr. Roberto Sbragia

Chefe do Departamento de Administração

Prof. Dr. Moacir de Miranda Oliveira Júnior

Coordenador do Programa de Pós-Graduação em Administração 
JOICE CHIARETO

\title{
AVALIAÇÃO DE DESEMPENHO ORGANIZACIONAL - UM ESTUDO EM UM HOSPITAL UNIVERSITÁRIO PÚBLICO
}

\author{
Dissertação apresentada ao \\ Departamento de Administração da \\ Faculdade de Economia, Administração \\ e Contabilidade da Universidade de São \\ Paulo como requisito para a obtenção do \\ título de Mestre em Ciências.
}

Orientador: Prof. Dr. Hamilton Luiz Corrêa

\section{Versão Corrigida}

(versão original disponível na Faculdade de Economia, Administração e Contabilidade)

\section{SÃO PAULO}




\section{FICHA CATALOGRÁFICA}

\section{Elaborada pela Seção de Processamento Técnico do SBD/FEA/USP}

\section{Chiareto, Joice}

Avaliação de desempenho organizacional - um estudo em um hospital universitário público / Joice Chiareto. -- São Paulo, 2014.

$123 \mathrm{p}$.

Dissertação (Mestrado) - Universidade de São Paulo, 2014.

Orientador: Hamilton Luiz Corrêa.

1. Avaliação de desempenho organizacional 2. Atenção à saúde 3. Indicadores de desempenho I. Universidade de São Paulo. Faculdade de Economia, Administração e Contabilidade. II. Título.

CDD - 658.4013 
"You don't need to be a fantastic hero to do certain things. You can be just an ordinary chap, sufficiently motivated to reach challenging goals."

Sir Edmund Hillary (1919-2008) Montanhista e aventureiro Neozelandês 
Neste momento me faltam palavras para agradecer a todos que me apoiaram durante o mestrado. Agradeço oaos meus pais por tudo fizeram por mim até hoje e por me apoiarem na ideia pouco ortodoxa de sair de casa e largar tudo para ir estudar. Aos meus tios por terem me tratado como uma filha e aos quais eu considero como também como pai e mãe.

Ao meu orientador Professor Hamilton Luiz Corrêa por seu apoio e orientação neste período. Aos professores Flavio Hourneaux Junior e Julio Carneiro da Cunha, por suas participações na banca de qualificação e defesa e por suas contribuições a este trabalho. Agradeço também a minha orientadora de iniciação científica da Universidade Paranaense a Professora Fátima Maria Pegorini Gimenes, pois cheguei ao mestrado graças a seus incentivos.

A todos os colegas que tive o privilégio de conhecer na pós-graduação por seu apoio, amizade e incentivo. Aos funcionários das instituições participantes que colaboraram com minha pesquisa. Pois sem o apoio deles a conclusão deste trabalho não teria sido possível. Por fim, agradeço aos colaboradores da secretaria do PPGA, da graduação e da pós-graduação por sempre me atenderem e esclarecerem minhas dúvidas. 


\section{RESUMO}

Este trabalho teve como objetivos verificar se existe um sistema de avaliação de desempenho organizacional no hospital universitário estudado, caracterizá-lo e identificar os benefícios trazidos e as dificuldades enfrentadas pela avaliação de desempenho organizacional na instituição. Na fundamentação teórica foram abordados os conceitos principais de avaliação e indicadores de desempenho, avaliação de desempenho em organizações públicas e hospitais. Para atingir os objetivos de pesquisa foi utilizada a metodologia de estudo de caso único, tendo como fontes de dados uma entrevista com o gestor responsável pela avaliação de desempenho e pesquisa documental. O objeto de pesquisa foi o Hospital das Clínicas da Faculdade de Medicina de Ribeirão Preto (HCFMRP-USP). Os resultados encontrados demonstraram que a avaliação de desempenho na instituição estudada apresenta grande parte das características que, segundo a literatura, um sistema de avaliação deve conter. Nesse ponto, recebe destaque a relação direta da avaliação de desempenho com os resultados financeiros da instituição, o alto nível de participação da alta administração e dos setores da instituição na avaliação de desempenho. Quanto a problemas na avaliação de desempenho, destacam-se alguns aspectos relacionados aos desalinhamentos na escolha e categorização de alguns indicadores quando confrontados com a missão e objetivos do HCFMRP-USP. Desde modo, este trabalho visa contribuir para melhoria da compreensão da avaliação de desempenho organizacional em hospitais universitários públicos. 


\begin{abstract}
This work aimed verify the existence of a performance measurement system in the teaching hospital studied, characterize it and brought identify the benefits and the difficulties faced by measurement of organizational performance in the institution. In the theoretical foundation the core concepts of evaluation and performance indicators, performance measurement in public organizations and hospitals were approached. To achieve the objectives of this research, the methodology of single case study was used, and as data sources an interview with the manager responsible for performance evaluation and documentary research. The research object was the Hospital das Clínicas da Faculdade de Medicina de Ribeirão Preto (HCFMRP-USP). The results demonstrated that the performance evaluation in the institution studied has much of the characteristics that, according to the literature, an evaluation system should contain. At this point, get highlighted the direct relationship of the performance measurement results with the financial results of the institution, the high level of involvement of senior management and departments of the institution with the performance measurement. As for problems in the performance measurement process, are highlighted misalignments in the selection and categorization of some indicators when faced with the mission and goals of HCFMRP-USP. This work aims to contribute to improving the understanding of evaluation of organizational performance in public teaching hospitals.
\end{abstract}




\section{Sumário}

LISTA DE ABREVIATURAS E SIGLAS ....................................................................... 9

LISTA DE QUADROS..................................................................................................... 10

LISTA DE TABELAS .......................................................................................... 11

LISTA DE ILUSTRAÇÕES .............................................................................................. 12

1 INTRODUÇÃO ........................................................................................................ 13

1.1 Pergunta de pesquisa e objetivos ............................................................................................ 14

1.1.1 Pergunta de pesquisa ................................................................................................................. 14

1.1.2 Objetivo Geral .......................................................................................... 14

1.1.3 Objetivos Específicos................................................................................................ 14

1.2 Definições operacionais................................................................................................ 14

1.3 Estrutura do trabalho ........................................................................................... 15

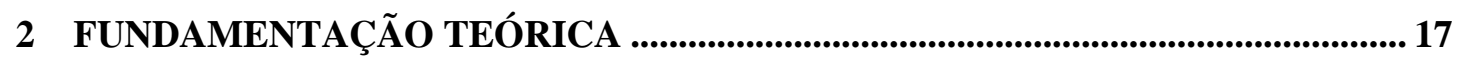

2.1 Avaliação de desempenho organizacional ................................................................. 17

2.2 MADE-O - Modelo de avaliação de desempenho organizacional ................................. 20

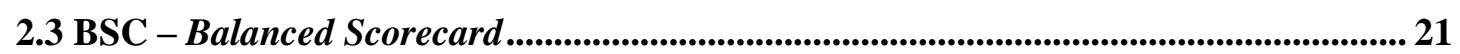

2.4 Indicadores de desempenho .............................................................................................................. 24

2.5 Tipos de indicadores de desempenho ...................................................................... 26

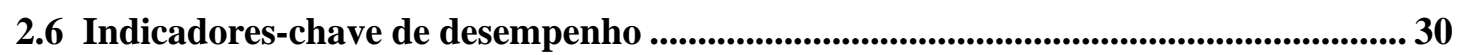

2.6 Avaliação de desempenho em organizações públicas.................................................... 31

2.7 Avaliação de desempenho em organizações de saúde ......................................................33

2.8 Indicadores de desempenho na saúde............................................................................... 36

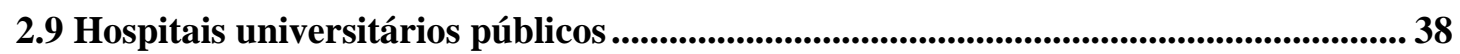

2.10 Avaliação de desempenho em hospitais...................................................................... 41

2.11 Avaliação de desempenho organizacional em hospitais universitários ....................... 44

2.12 EBSERSH - Empresa brasileira de serviços hospitalares e REHUF - Programa nacional de reestruturação dos hospitais universitários federais ........................................ 46

2.13 SAHE - Sistema de avaliação dos hospitais de ensino.................................................. 49

2.14 CQH - Compromisso com a qualidade hospitalar .....................................................50

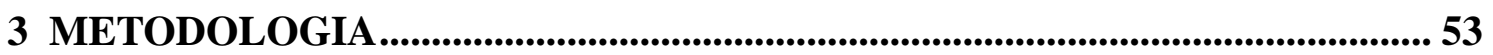

3.1 Natureza da pesquisa ......................................................................................................5

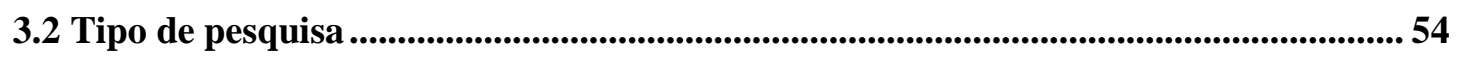

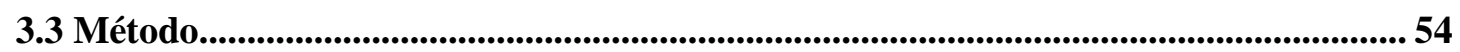

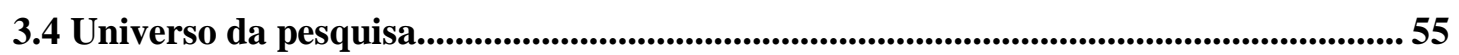

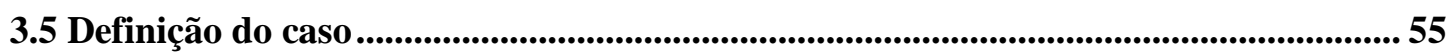


3.6 Definiç̧̃̃o das variáveis .................................................................................................................... 56

3.7 Coleta de dados............................................................................................................................... 57

3.8 Pré-teste do instrumento de coleta de dados.........................................................................60

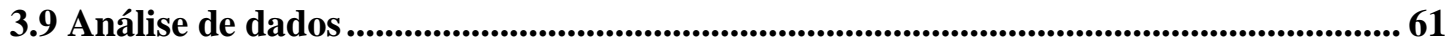

3.10 Limitações ......................................................................................................................................62 62

4 DESCRIÇÃO E ANÁLISE DOS RESULTADOS ................................................. 63

4.1 Processo de seleção do caso ........................................................................................................ 63

4.2 Hospital das Clínicas da Faculdade de Medicina de Ribeirão Preto - USP ............... 64

4.2.1 Assistência no HCFMRP-USP ......................................................................................... 66

4.2.2 Ensino e pesquisa.................................................................................................................... 66

4.2.3 Estrutura Organizacional................................................................................................... 68

4.2.4 Planejamento estratégico do HCFMRP-USP ........................................................... 69

4.3 A avaliação de desempenho organizacional no HCFMRP-USP .................................... 73

4.4 Indicadores-chave de avaliação de desempenho ............................................................. 77

4.5 Indicadores de desempenho no nível operacional ............................................................. 79

4.6 Metas da avaliação de desempenho organizacional .............................................................. 83

4.7 Comparação dos resultados da avaliação com outras instituições ................................. 83

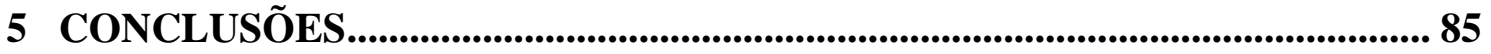

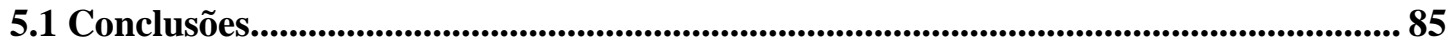

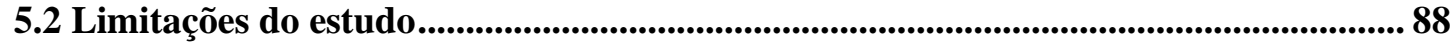

5.3 Recomendações para a avaliação de desempenho para hospitais universitários

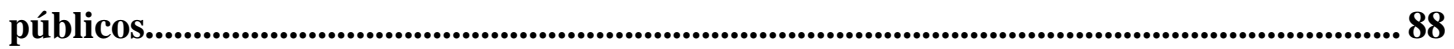

5.4 Recomendações para estudos futuros.................................................................................... 89

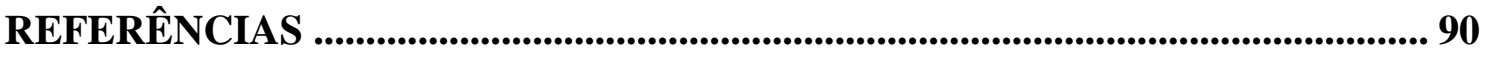

APÊNDICE 1 - INSTRUMENTO DE COLETA DE DADOS .................................. 101

APÊNDICE 2 - TERMO DE CONSENTIMENTO.................................................... 104

ANEXO 1 - AUTORIZAÇÃO DO COMITÊ DE ÉTICA HU-USP ...................... 107

ANEXO 2 - AUTORIZAÇÃO DO COMITÊ DE ÉTICA HCFMRP-USP ........... 109

ANEXO 3 - INDICADORES-CHAVE DO HCFMRP-USP .................................... 110

ANEXO 4 - INDICADORES OPERACIONAIS DO HCFMRP-USP.................. 114 


\section{LISTA DE ABREVIATURAS E SIGLAS}

Abrahue: Associação Brasileira de Hospitais Universitários e de Ensino

ADO: Avalição de Desempenho Organizacional

AIH: Autorização de Internação Hospitalar

CCIH: Competências para Controle de Infecções Hospitalares

CEAPS: Centro de Educação e Aperfeiçoamento Profissional em Saúde

CECEn: Comissão de Educação Continuada em Enfermagem

CNES: Cadastro Nacional de Estabelecimentos de Saúde

CPAC: Comissão Permanente de Acompanhamento do Contrato

CPS: Coordenadoria de Planejamento de Saúde

CQH: Compromisso com a Qualidade Hospitalar

DEA: Data Envelopment Analysis

DRS: Departamento Regional de Saúde

EBSESH: Empresa Brasileira de Serviços Hospitalares

FAEPA: Fundação de Apoio ao Ensino Pesquisa e Assistência do Hospital das Clínicas da Faculdade de Medicina de Ribeirão Preto da Universidade de São Paulo

FMRP: Faculdade de Medicina de Ribeirão Preto

GAD: Grupo de Avaliação de Desempenho

HCFMRP-USP: Hospital das Clínicas da Faculdade de Medicina de Ribeirão Preto -

Universidade de São Paulo

HU-USP: Hospital Universitário da Universidade de São Paulo

MEC: Ministério da Educação

REHUF: Programa de Reestruturação dos Hospitais Universitários Federais

SAHE: Sistema de Avaliação dos Hospitais de Ensino

SES-SP Secretaria de Estado da Saúde de São Paulo

SIH/SUS: Sistema de Informações Hospitalares do Sistema Único de Saúde

UE: Unidade de Emergência

UNIFESP: Universidade Federal de São Paulo

USP: Universidade de São Paulo

WHO: World Health Organization 


\section{LISTA DE QUADROS}

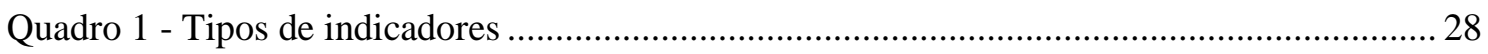

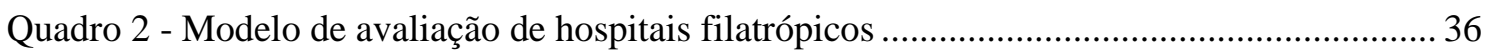

Quadro 3 - Declarações de missão de hospitais universitários................................................... 44

Quadro 4 - Estudos anteriores relacionados a hospitais universitários ........................................ 45

Quadro 5 - Aspectos considerados, grupos de variáveis e autores .............................................. 56

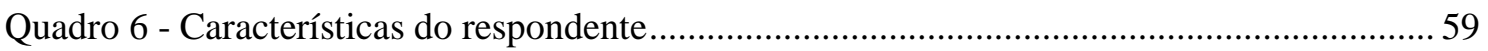

Quadro 7 - Instrumento de coleta de dados versus objetivos da pesquisa................................... 59

Quadro 8 - Planejamento estratégico: categorias, perspectivas e objetivos ................................. 69

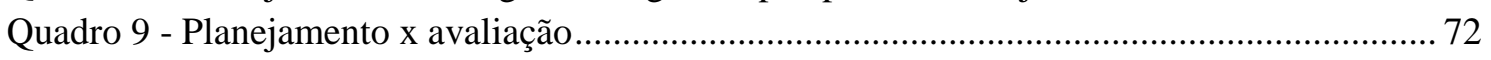

Quadro 11 - Exemplos de indicadores operacionais do HCFMRP-USP .................................... 80

Quadro 12 - Indicadores-chave e metas HCFMRP-USP ..............Error! Bookmark not defined. 


\section{LISTA DE TABELAS}

Tabela 1 - Estágios oferecidos para estudantes de graduação e pós-graduação em 2013 ............ 67

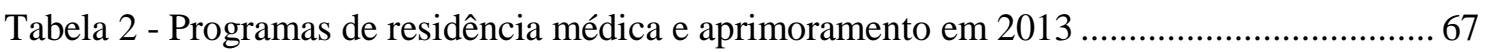

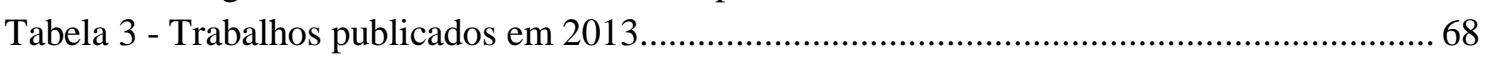

Tabela 4 - Dimensões e pontuações da avaliação de desempenho no HCFMRP-USP................ 74

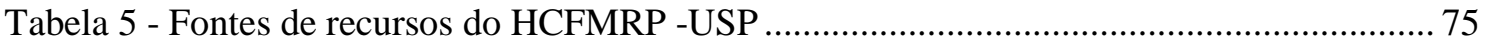

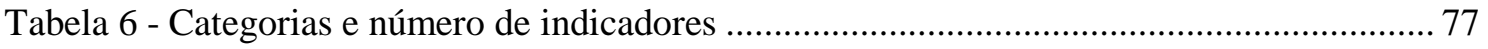

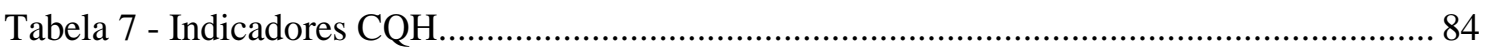




\section{LISTA DE ILUSTRAÇÕES}

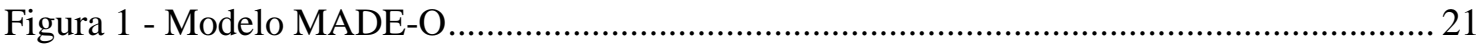

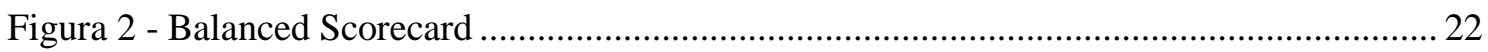

Figura 3 - Representação de um sistema de avaliação de desempenho organizacional ............... 25

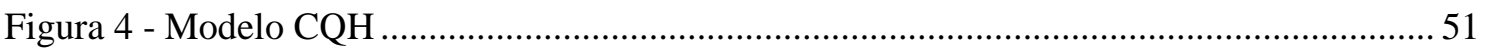

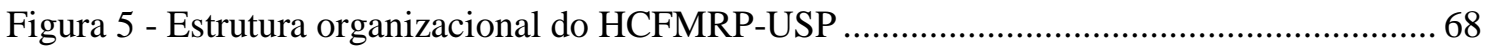




\section{INTRODUÇÃO}

Os hospitais universitários são centros de formação de profissionais na área da saúde e também de desenvolvimento de tecnologia. A prestação de serviços à população permite o aprimoramento contínuo do atendimento e a elaboração de novos protocolos técnicos. E programas como os de educação conitnuada oferecem oportunidades de atualização técnica aos profissionais do sistema de saúde (MINISTÉRIO DA SAÚDE, 2014). Nessas insituições são formados os profissionais que prestam serviços à população, lecionam e fazem pesquisas na área de saúde. Essas características tornam o papel dos hospitais universitários (HUs) crítico para o presente e o futuro do sistema de saúde.

Dentre os diversos aspectos relevantes no funcionamento dos HUs um que tem recebido grande atenção governamental é a avaliação de desempenho organizacional. Os HUs brasileiros têm sofrido pressões para melhorar suas práticas de avaliação de desempenho organizacional, inclusive tendo sua viabilidade financeira questionada (BONACIM; ARAUJO, 2009).

Segundo a World Health Organization (2003), a mensuração é um conceito fundamental para a melhoria da qualidade hospitalar. Ela oferece um meio para definir o papel real dos hospitais e comparar resultados com as metas originais. Além de que a avaliação de desempenho é reconhecida como uma metodologia que colabora com a melhoria da qualidade na prestação de serviços de saúde (BALLARD, 2003).

O desempenho em HUs já foi estudado anteriormente por diversos ângulos, como econômico-financeiro (BONACIM; ARAUJO, 2011), resultados de indicadores isolados (ZUCCHI; BITTAR, 2002), gestão de custos (BONACIM; ARAUJO, 2010), produtividade (OZCAN et al., 2010), relação entre ensino e assistência (LOBO, et al., 2010), entre outros. Mas não foi encontrado nenhum trabalho que estudasse como a avaliação de desempenho organizacional é realizada nesse tipo de organização. Assim, levando em consideração a importância dos HUs para a para a ciência e para a sociedade e a lacuna de estudos sobre o tema, justifica-se estudar como a avaliação de desempenho organizacional (ADO) tem sido realizada nos Hospitais Universitários (HUs) Públicos do Brasil. 


\subsection{Pergunta de pesquisa e objetivos}

\subsubsection{Pergunta de pesquisa}

Como é realizada a avaliação de desempenho organizacional no hospital universitário estudado? Quais as características dessa avaliação?

\subsubsection{Objetivo Geral}

- Descrever as características da avaliação de desempenho organizacional no hospital universitário estudado.

\subsubsection{Objetivos Específicos}

- Identificar os benefícios trazidos pelo uso de avaliação de desempenho organizacional.

- Identificar as dificuldades enfrentadas pela avaliação de desempenho organizacional.

\subsection{Definições operacionais}

O uso de definições operacionais na pesquisa busca evitar confusões sobre significados e conceitos na pesquisa (COOPER; SCHINDLER, 2003). São conceitos muito restritos que se dirigem diretamente às características de um objeto e têm como objetivo possibilitar a mensuração e/ou observação das variáveis envolvidas (RICHARDSON, 1999). Abaixo seguem as definições operacionais utilizadas neste trabalho:

Sistema de avaliação de desempenho organizacional: conjunto de indicadores utilizados para quantificar eficácia e eficiência (NEELY, 1994), o qual geralmente está relacionado a um sistema de informação (HALACHMI, 2005). 
Modelo de avaliação de desempenho: modo como às dimensões de avaliação de desempenho estão estruturadas (NEELY; GREGORY; PLATTS, 2005). Neste trabalho para ser considerado um modelo essa estruturação deverá estar formalizada na literatura.

Indicadores de avaliação de desempenho organizacional: valores físicos usados para medir, comparar e gerenciar o desempenho global da organização (GOSSELIN, 2005). Os termos medida, métrica e indicador de desempenho serão utilizados como sinônimos durante esse trabalho. Conforme o trabalho de Hourneaux Junior (2010) não existe uma distinção clara entre os termos.

Hospitais universitários públicos: instituições listadas no CNES (2014) como hospital de ensino e que pertençam a uma instituição de ensino superior federal, estadual ou municipal.

\subsection{Estrutura do trabalho}

Esta dissertação está dividida em cinco capítulos. O Capítulo 1 é composto pela introdução, pergunta e objetivos de pesquisa e definições operacionais.

O Capítulo 2 apresenta a fundamentação teórica do trabalho, traz os principais conceitos relacionados aos temas de avaliação de desempenho organizacional, indicadores, avaliação de desempenho na área de saúde e também estudos anteriores relacionados ao tema.

O Capitulo 3 é composto pela metodologia de pesquisa, aborda o método de pesquisa, critérios para escolha do caso, procedimento de análise de dados e limitações da pesquisa.

No Capítulo 4 é apresentado o caso estudado e discutidos os resultados da pesquisa.

O Capítulo 5 apresenta as conclusões sobre os objetivos de pesquisa, limitações do estudo e sugestões para estudos futuros. Após o capítulo final encontram-se as referências e os apêndices. 


\section{FUNDAMENTAÇÃO TEÓRICA}

Neste trabalho a fundamentação teórica aborda os principais conceitos relacionados à avaliação de desempenho organizacional, avaliação de desempenho em organizações

públicas, indicadores de desempenho, avaliação e indicadores desempenho em organizações de saúde, avaliação de desempenho em hospitais e HUs.

\subsection{Avaliação de desempenho organizacional}

Olson e Slater (2002) afirmam que o processo de gestão estratégica compreende pelo menos cinco elementos: desenvolver uma missão, analisar a situação da empresa, formar uma estratégia competitiva, implementar a estratégia e monitorar o desempenho (OLSON; SLATER, 2002). Entre estes elementos o foco deste trabalho é a avaliação/mensuração do desempenho organizacional.

Inicialmente a avaliação de desempenho organizacional baseou-se apenas nos resultados financeiros das empresas. Porém, nas décadas de 1970 e 1980, havia uma insatisfação em relação ao modo como a avaliação de desempenho vinha sendo realizada (BOURNE et al., 2000). Eram necessários novos sistemas de mensuração, onde dados financeiros fossem tratados como parte de um conjunto maior de medidas (ECCLES, 1991).

Isso levou a elaboração de modelos de avaliação de desempenho equilibrados e multidimensionais que apresentassem ênfase não financeira, medidas externas e que pudessem indicar o desempenho futuro (BOURNE et al., 2000). Os novos modelos de avaliação de desempenho organizacional deveriam também poder monitorar áreas como operações, marketing e recursos humanos (CHENHALL; LANGFIELD-SMITH, 2007).

Então devido à necessidade de se mensurar o desempenho de modo multidimensional, muitos novos modelos de avaliação de desempenho organizacional foram criados, como: a) Método da avaliação global de desempenho (CORRÊA, 1986); b) BSC Balanced scorecard (KAPLAN; NORTON, 1992); c) Skandia navigator (EDVINSSON, 1997); d) Sigma sustainability scorecard (THE SIGMA PROJECT, 2003); e) Prisma de 
Desempenho (NEELY; ADAMS; CROWE, 2001), além de muitos outros. Lugoboni (2010) levantou 19 modelos de avaliação de desempenho da literatura.

É importante definir a diferença entre modelo (framework, model or schemes) e sistema (system) de avaliação de desempenho organizacional. Um sistema de avaliação de desempenho pode ser definido como conjunto de indicadores utilizados para quantificar eficácia e eficiência em uma organização (NEELY, 1994), e está geralmente está relacionado a um sistema de informação (HALACHMI, 2005). Mas não necessariamente se encaixa em um modelo de avaliação descrito na literatura.

Já o termo modelo de avaliação de desempenho organizacional está mais relacionado a estruturação das dimensões/perspectivas de avaliação (financeira, clientes, recursos humanos, inovação, entre outras) dentro da organização (NEELY; GREGORY; PLATTS, 2005). Porém não existe um consenso sobre a separação entre sistema e modelo. O BSC, por exemplo, é tratado em muitos trabalhos como modelo (NEELY; GREGORY; PLATTS, 2005, NEELY; ADAMS; CROWE, 2001), mas em outros é tratado como sistema (KAPLAN; NORTON, 1992).

Neste trabalho, sistema de avaliação será tratado como um conjunto de indicadores (NEELY, 1994) e o termo modelo será utilizado para descrever as abordagens para estruturação da avaliação que estão formalizadas na literatura.

Essa abordagem foi escolhida porque muitos sistemas de avaliação são adaptações de modelos existentes e não estão formalizados na literatura, ocasionalmente não estão formalizados nem mesmo da organização em que são utilizados. Pois mesmo que a avaliação de desempenho de uma organização não esteja formalizada, ela ainda pode ocorrer.

Segundo Neeely, Gregory e Platts (2005) a mensuração do desempenho é o processo de quantificar as ações. Ela determina o quão bem uma organização está atingindo seus objetivos (CUNHA, 2013). A avaliação de desempenho organizacional é também um dos modos pelo qual as partes interessadas (sócios, governo, sociedade, entre outros) podem saber como os recursos estão sendo utilizados pela organização. 
Uma das principais razões para a realização da avaliação de desempenho organizacional é a necessidade das empresas de gerir o desempenho. A medição do desempenho e a gestão de desempenho não podem ser separadas (LEBAS, 1995). A relação estreita com controle organizacional torna a avaliação um dos aspectos centrais da organização. Sem possuir informações sobre o quanto os objetivos organizacionais estão sendo atingidos não há como cobrar performance. Consequentemente, fica aberta uma grande lacuna para ineficiências (HALACHMI, 2002).

Além da relação da avaliação de desempenho organizacional (ADO) com a gestão do desempenho é possível listar ao menos cinco outras razões pelas quais deve-se mensurar o desempenho nas organizações: a) saber como a organização chegou onde está: a avaliação relacionada ao passado apoia o sistema de recompensas e ajuda a construir as informações que irão prever os valores dos parâmetros utilizados nas análises; b) saber qual é o status dos processos que definem a organização: qual é o seu potencial de realização no futuro; c) saber para onde a organização quer ir: a avaliação ajuda a apoiar a definição de objetivos, metas e apoiar a elaboração de planos de ação;d) saber como chegará lá: a avaliação também pode apoiar as atividades de orçamento e planejamento e melhoria contínua; e) saber se chegou lá: a avaliação não pode ser separada do feedback (LEBAS, 1995).

Corrêa (2012), recomenta algumas questões que a ADO deve responder. 1) para que: por qual motivo a avaliação é realizada? 2) Para quem: quem precisa dos resultados da avaliação? Gerentes, controllers, sócios? 3) O quê: quais as variáveis e dimensões mensuradas? 4) Como: quais as fases da avaliação? 5) Quem: quem realiza a avaliação de desempenho? Empregados, consultores? 6) Quando: Qual a frequência em que a avaliação é realizada? (CORRÊA, 2012).

O mesmo autor afirma que um sistema de ADO seja considerado completo, deve possuir ao menos 5 características: ser global: 1) abranger todas as dimensões da organização; 2) ser histórico: registrar os resultados de vários anos; 3) ser comparativo: permitir comparar os resultados com outras empresas e setores (benchmarking); 4) mostrar relações de causa e efeito; e 5) ter a capacidade de antecipação: utilizar indicadores cujos resultados possam ajudar a prever o desempenho futuro. 
Existem muitos modelos de avaliação de desempenho organizacional na literatura, com características próprias e adaptados aos mais diversos contextos organizacionais. Nos tópicos 2.1 e 2.2 são abordados os dois modelos de avaliação de desempenho organizacional considerados mais relevantes para este estudo.

\subsection{MADE-O - Modelo de avaliação de desempenho organizacional}

O Modelo Corrêa ou MADE-O foi criado inicialmente como um modelo de avaliação de desempenho global para empresas estatais. As devido a sua flexibilidade pode ser aplicado também em outros tipos de organização, incluindo até mesmo organizações privadas (CUNHA, 2011).

Este modelo apresenta um conjunto de 10 módulos, que buscam abranger toda a empresa: econômico-financeiro, operacional, recursos humanos, satisfação dos usuários/clientes, inovação tecnológica, adaptação/ambiente, avaliação técnica, clima organizacional, benefícios sociais, potencialidade gerencial (CORRÊA, 1986). A organização dos módulos pode ser vista na Figura 1: 


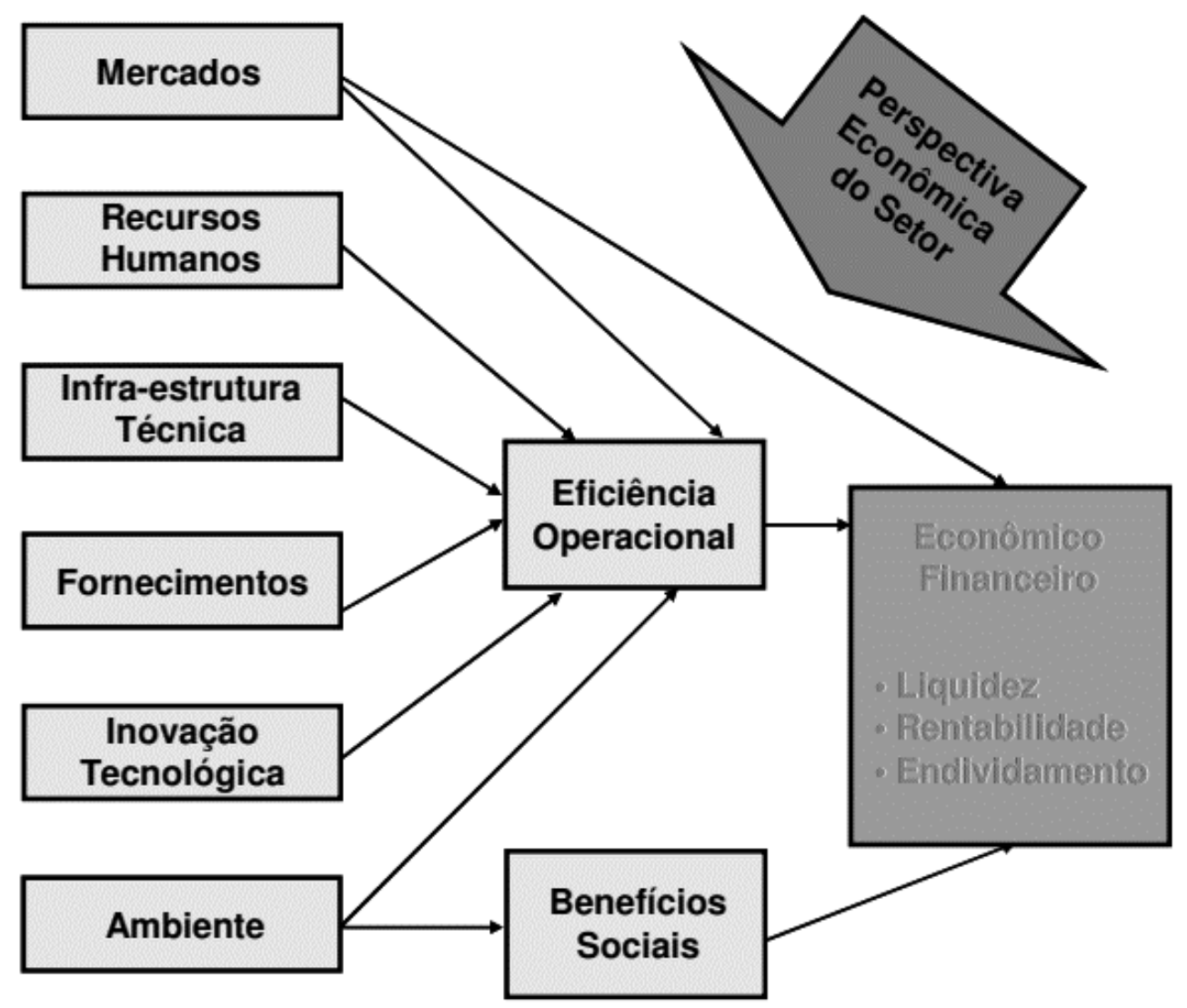

Figura 1 - Modelo MADE-O

Fonte: Adaptado de Corrêa, 1986.

No MADE-O assume-se que existem relações entre o desempenho dos módulos, como por exemplo, entre os resultados do módulo operacional e do módulos de clima organizacional. Além de que alguns dos módulos como o de potencialidade gerencial apresentam maioor impacto resultados organizacionais no médio e longo prazo (CORRÊA, 1986). Anterior ao BSC, o MADE-O já recomendava que a avaliação de desempenho deveria partir da estratégia e dos objetivos organizacionais (CORRÊA, 1986).

\subsection{BSC - Balanced Scorecard}

O Balanced Scorecard, criado por Kaplan e Norton (1992) é um dos modelos de avaliação de desempenho mais difundidos tanto na esfera acadêmica quanto nas empresas. 
Essa metodologia possui algumas características que a destacam entre os modelos de ADO. Dentre elas podemos citar a ligação da avaliação de desempenho com a estratégia organizacional e a avaliação de desempenho multidimensional, considerando outros aspectos além dos resultados financeiros. O BSC tem como premissa que os resultados financeiros são consequências dos resultados em outros aspectos da organização, numa relação de causa e efeito. Por isso o modelo utiliza quatro perspectivas para avaliar a performace de uma organização: aprendizado e crescimento, processos internos, clientes e financeira (KAPLAN; NORTON, 1992). As perspectivas do BSC são apresentadas na Figura 2 :

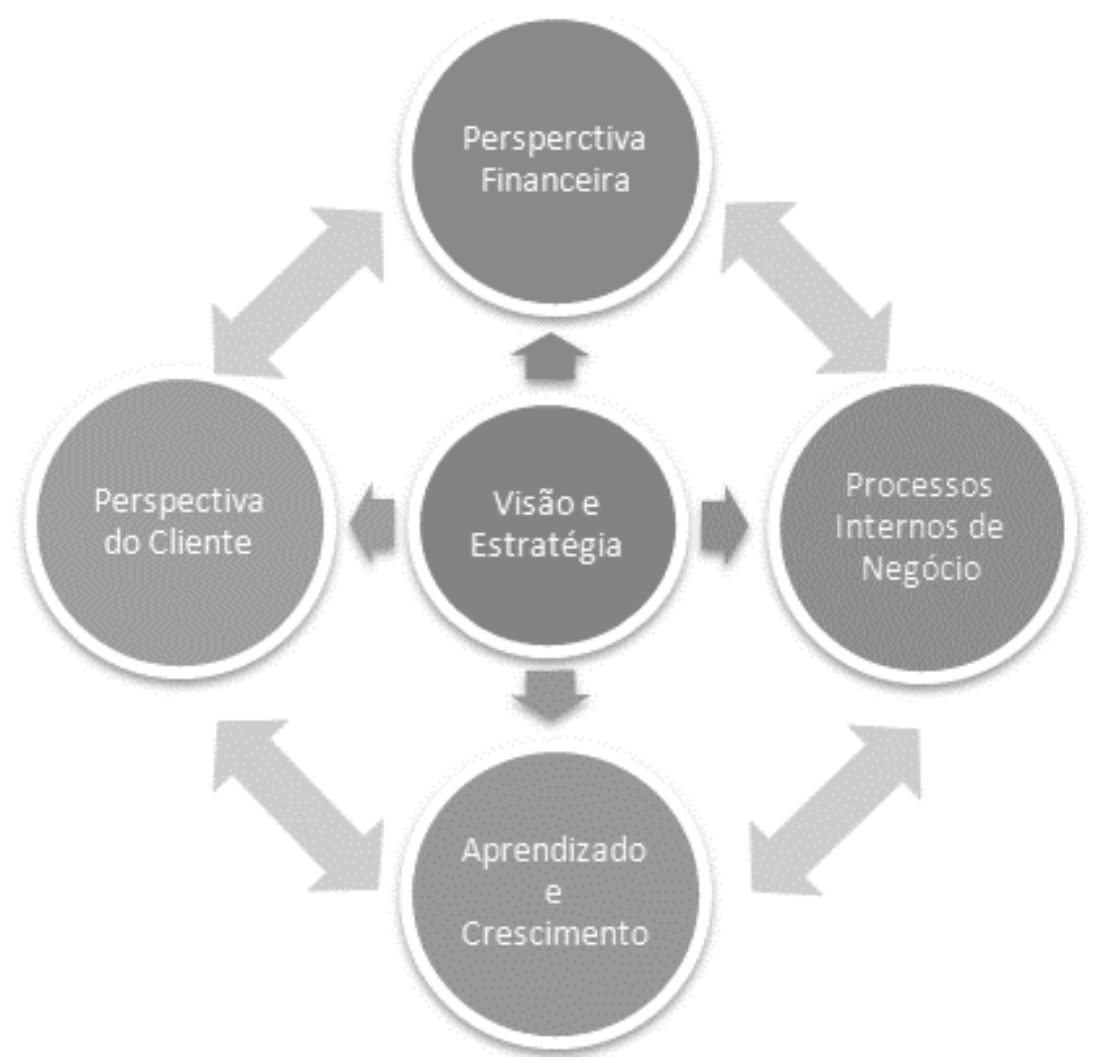

Figura 2 - Balanced Scorecard

Fonte: Adaptado de Kaplan e Norton, 1992.

O Balanced Scorecard permite que uma organização traduza sua missão e visão em objetivos estratégicos espefícos dentro de suas quatro perspectivas. Uma vez que os objetivos são identificados estabelecidos os indicadores de desempenho, metas e ações (WACHTEL; HARTFORD; HUGHES, 1999). 
O sistema estabelece um equilíbrio entre financeiro / operacional e outras medidas e fornece um conjunto de indicadores de desempenho prospectivas ligando estratégia para ações específicas. Estas medidas e indicadores, quando corretamente desenvolvido, proporcionar uma visão abrangente do desempenho organizacional (VOELKER; RAKICH; FRENCH, 2001).

O BSC também pode ser considerado uma salvaguarda contra a sub-otimização, forçando os gestores a considerar todas as medidas operacionais importantes juntas A principal tarefa de uma empresa ou divisão ao introduzir o balanced scorecard é elaborar um conjunto de medidas explicitamente ligadas a sua estratégia. Esta é uma condição essencial para que a estratégia seja amplamente compreendida e aceita dentro da organização (BUTLER; LETZA; NEALE, 1997).

Após seu lançament o modelo BSC teve grande aceitação entre acadêmicos e gestores. Já que resultados insatisfatórios nas medidas não financeiras poderiam oferecer um aviso de problemas futuros no desempenho financeiro e permitir ações corretivas a tempo de minimizar os danos (BUTLER; LETZA; NEALE, 1997).

O interesse em usar medidas não financeiras, como a satisfação do cliente, satisfação do empregado ou a inovação, como indicadores para o desempenho futuro da empresa levou gestores a olhar para a implementação do Balanced Scorecard como um meio de superar as limitações dos sistemas de mensuração de desempenho tradicionais (SIM; $\mathrm{KOH}, 2001)$.

Por ser derivado da estratégia organizaiconal o BSC leva os gestores a considerar todas as medidas operacionais importantes juntas, colocando a estratégia e a visão organizacional base do modelo (BUTLER; LETZA; NEALE, 1997).

Uma vez que a maioria das ações localiza-se no nível operacional os gestores precisam decompor medidas globais ao nível local. Desse modo, a mensuração liga o julgamento da alta administração sobre os processos internos e as competências às ações tomadas por indivíduos (KAPLAN; NORTON, 1992). 
Outra premissa do modelo é o uso de um número reduzido de indicadores. Eles devem estar alinhados com a missão e as estratégias, de modo que proporcionem uma imagem rápida e abrangente do desempenho organizacional. Ao limitar o número de indicadores o BSC auxilia o gestor a decidir o que é realmente importante (SELF, 2004). As principais vantagens do BSC são: adaptar-se à estratégia do negócio, comunicar os objetivos estratégicos e melhorar o feedback e aprendizado (OLSON; SLATER, 2002)

Apesar das contribuições do BSC para a avaliação de desempenho é importante destacar que o modelo também recebeu muitas críticas. Norreklit (2000) questiona a relação de causa e efeito levantada pelo BSC, pois segundo ele relações de causa e efeito podem ser testadas empiricamente, mas isso não ocorre. O autor considera que existe uma relação lógica, mas não de causa e efeito entre as perspectivas do modelo. E também levanta que para haver uma relação de causa e efeito deve haver uma sequência temporal, onde a causa precede o efeito, mas a dimensão de tempo não é levada em conta no BSC.

\subsection{Indicadores de desempenho}

Os modelos citados no tópico 2.1e 2.2 utilizam os mais diversos tipos de indicadores para a mensuração de desempenho organizacional, desde aqueles facilmente mensuráveis, como os referentes aos resultados financeiros da empresa, até outros mais subjetivos como o de potencialidade gerencial (CORRÊA, 1986).

O objetivo desses modelos de mensuração de desempenho é assegurar que a grande variedade de eventos e resultados ocorridos na organização sejam capturados de forma útil para os tomadores de decisão (WATTS; MCNAIR-CONNOLLY, 2012). O ato de medir o desempenho e coletar dados só tem utilidade quando essas informações são utilizadas (BEHN, 2003).

Segundo Neely, Gregory e Platts (2005), um sistema de avaliação de desempenho pode ser analisado basicamente por três ângulos: 1) as medidas de desempenho de modo individual; 2) o conjunto de medidas de desempenho - o sistema de medição de 
desempenho como uma entidade; 3) a relação entre o sistema de medição de desempenho e do ambiente em que ele opera.

Na Figura 3 está representado graficamente como é organizado um sistema de avaliação de desempenho:

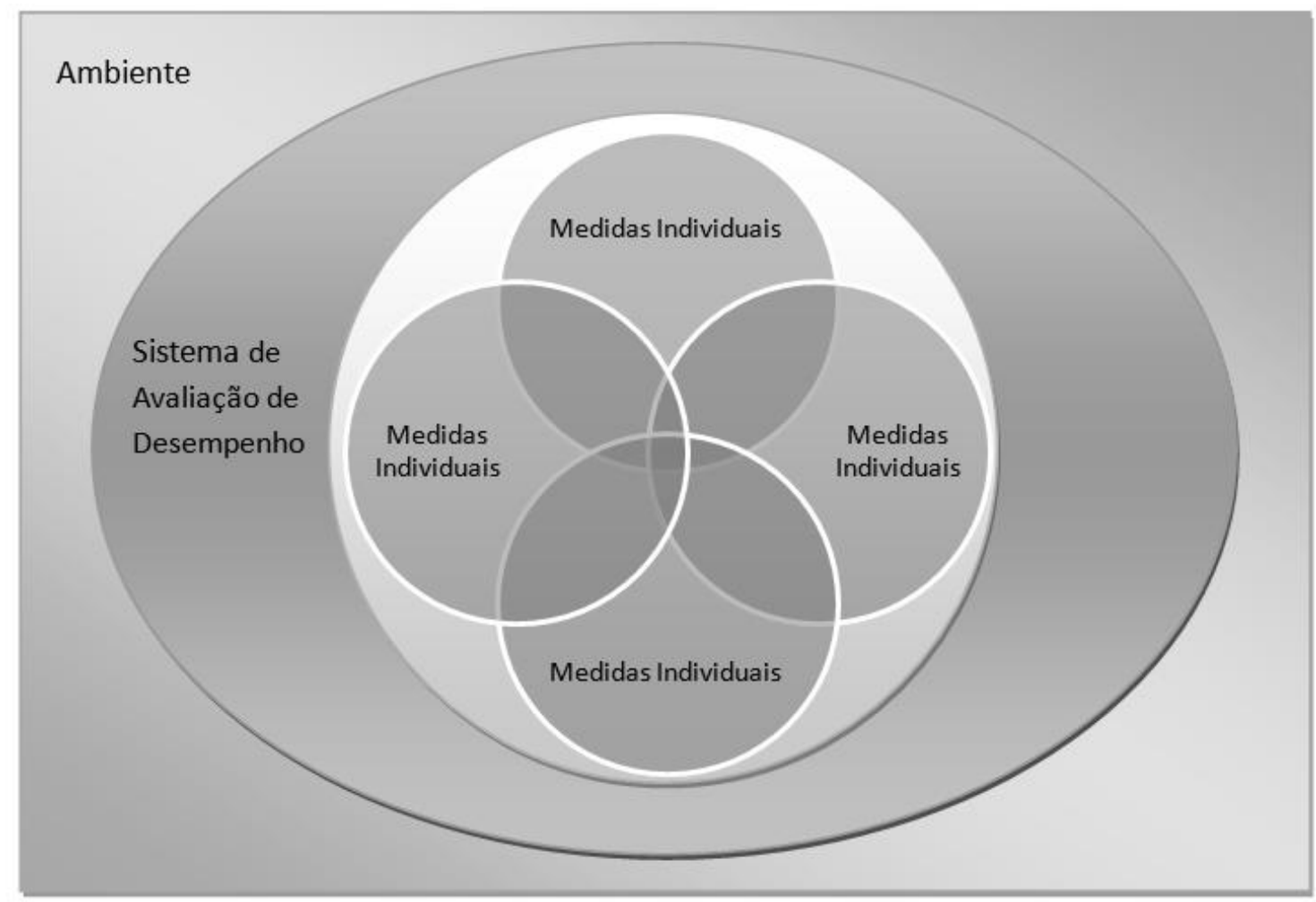

Figura 3 - Representação de um sistema de avaliação de desempenho organizacional Fonte: Adaptado de NEELY; GREGORY;PLATTS, 2005, p. 1229.

Ao analisar a Figura 3 é possível visualizar que um sistema de avaliação de desempenho é basicamente um conjunto de indicadores relacionados dentro de um ambiente organizacional. A avaliação de desempenho começa com a identificação de indicadores que permitam mensurar o desempenho da organização (BHATTI; AWAN; RAZAQ, 2013).

Geralmente um sistema de ADO consiste em uma série de medidas de desempenho individuais (NEELY, GREGORY, PLATTS, 2005). Os indicadores são os elementos básicos de um sistema de avaliação de desempenho (MIKUŠOVÁ; JANEČKOVÁ, 2010). Como citado anteriormente, neste trabalho os termos indicador e medida são tratados como sinônimos. 
Os indicadores são ferramentas objetivas que analisam e avaliam os principais componentes (produtos, serviços, processos e operações) de uma organização, estabelecem metas de desempenho em cada nível e acompanham o desempenho ao longo do tempo (MOSSE; ROGERS, 1996 apud ONDATEGUI-PARRA, et al., 2004). Um dos objetivos dos indicadores é dar à seus usuários sinais sobre o que é importante e sobre o que é esperado dentro da organização (MIKUŠOVÁ; JANEČKOVÁ,2010).

Alguns fatores podem indicar a qualidade de um indicador. Um bom indicador deve ter: possuir uma definição suficientemente detalhada, clara e compreensível; ser útil; seu custo de obtenção deve ser aceitável; e deve se destinar a facilitar a obtenção da informação necessária para o processo de tomada de decisão (MIKUŠOVÁ; JANEČKOVÁ, 2010).

A qualidade dos indicadores escolhidos para fazer parte de um sistema de avaliação de desempenho é importante por várias razões, mas uma que se destaca é a limitação do número de indicadores que devem ser utilizados. Adicionar mais e mais medidas de desempenho só cria dificuldades. Gasta-se muito tempo na coleta de dados e monitoramento de suas atividades e não o suficiente com o trabalho real (DENTON, 2005).

\subsection{Tipos de indicadores de desempenho}

Indicadores de desempenho podem ter diferentes classificações dependendo dos critérios utilizados. Um dos meios utilizados para classificar os indicadores é em medidas financeiras e não financeiras.

Segundo Otley (2007) há três principais funções das medidas financeiras:ser uma ferramenta para a gestão financeira, ser o maior objetivo organizacional e ser um mecanismo de motivação e controle organizacional.

Qualquer organização, pública ou privada, tem que viver com restrições financeiras e entregar valor aos seus stakeholders. Nesse contexto o papel das medidas financeiras é 
auxiliar no gerenciamento dos recursos financeiros da organização e garantir que as restrições financeiras da organização não sejam ultrapassadas (OTLEY, 2007).

Indicadores financeiros são medidas de resultado que relatam o desempenho passado, mas não são bons para prever o futuro. Medidas de desempenho financeiras por si só raramente fornecem aos gestores todas as informações que precisam para tomar decisões estratégicas. A dependência de indicadores financeiros apenas, muitas vezes leva a um foco estreito e de curto prazo e pode servir como um obstáculo para ver oportunidades de longo prazo ou lidar com as ameaças no futuro (VOELKER; RAKICH; FRENCH, 2001). Por isso existe a necessidade de se utilizar indicadores não financeiros.

Os indicadores não financeiros são responsáveis por mensurar grande parte da gestão no nível operacional, onde muitas ocorrências não são mensuráveis monetariamente de modo imediato (OTLEY, 2007). Por isso existe a necessidade do uso de medidas não financeiras para medir o real desempenho da organização. Neely (2007) cita os cinco objetivos de desempenho operacional propostos por Skinner (1969): qualidade, confiança, velocidade, custo e flexibilidade.

Medidas relacionadas com a qualidade, participação de mercado, satisfação do cliente e do empregado podem produzir maior conhecimento sobre os fatores que impulsionam o desempenho financeiro. Um déficit nessas medidas pode fornecer um aviso antecipado de uma iminente escassez de desempenho financeiro e permitir ações corretivas em tempo de moderar os danos aos resultados financeiros (BUTLER; LETZA; NEALE, 1997).

Além de classificados em financeiros e não financeiros, outro critério utilizado para a classificação de indicadores é o impacto do indicador e o uso das informações que ele fornece para o gestor (TANGEN, 2005). Esse conceito utiliza como base a premissa de que as várias medidas de desempenho disponíveis para o gestor fornecem informações diferentes e são usadas para diversos fins (TANGEN, 2005). Algumas medidas são de grande importância para a organização e serão frequentemente utilizadas, enquanto outras são menos importantes e podem até mesmo não ter utilidade (TANGEN, 2005). 
Um resumo da classificação de indicadores por uso e benefícios das informações fornecidas pode ser visto no Quadro 1:

Quadro 1 - Tipos de indicadores

\begin{tabular}{|c|c|c|c|}
\hline $\begin{array}{l}\text { Tipo de } \\
\text { Medida }\end{array}$ & Descrição & $\begin{array}{r}\text { Benefício das } \\
\text { Informações }\end{array}$ & $\begin{array}{c}\text { Uso das } \\
\text { Informações }\end{array}$ \\
\hline $\begin{array}{c}\text { Tipo A: } \\
\text { Indispensável }\end{array}$ & $\begin{array}{l}\text { Esse é o melhor tipo de medida de desempenho e } \\
\text { representa medidas indispensáveis e com alto } \\
\text { impacto na organização. As informações dessas } \\
\text { medidas são utilizadas frequentemente e são } \\
\text { consideradas de alto valor. }\end{array}$ & Alto & Alto \\
\hline Tipo B: Útil & $\begin{array}{l}\text { As informações desse tipo de medida são } \\
\text { significativas, mas não vitais. O uso dessas } \\
\text { medidas ainda é bom, mas as informações } \\
\text { provenientes delas tem um impacto limitado na } \\
\text { organização. }\end{array}$ & Médio & Médio \\
\hline $\begin{array}{c}\text { Tipo C: } \\
\text { Informativa }\end{array}$ & $\begin{array}{l}\text { São utilizadas em um menor grau e têm baixo } \\
\text { impacto. O uso está relacionado a razões } \\
\text { informativas. }\end{array}$ & Baixo & Baixo \\
\hline $\begin{array}{c}\text { Não se } \\
\text { qualifica }\end{array}$ & $\begin{array}{l}\text { Medidas de desempenho sem propósito } \\
\text { específico. Fornecem informações desnecessárias } \\
\text { e sem impacto na organização. Incluí-las na } \\
\text { avaliação de desempenho é um desperdício de } \\
\text { recursos. }\end{array}$ & Nenhum & - \\
\hline $\begin{array}{c}\text { Não se } \\
\text { qualifica }\end{array}$ & $\begin{array}{l}\text { Medidas que fornecem informações distorcidas } \\
\text { ou inexatas. Essas medidas tem impacto negativo } \\
\text { na organização e podem levar a decisões } \\
\text { equivocadas. }\end{array}$ & Subutilizada & - \\
\hline
\end{tabular}

Fonte: Adaptado de TANGEN, 2005.

Além das já citadas, indicadores podem ser divididos em indicadores de lagging e de leading. Indicadores de lagging são dados históricos ou de um evento ou de um conjunto eventos que já ocorreram, indicadores financeiros geralmente são medidas de lagging (DENTON, 2005). Já um indicador leading é qualquer variável cujo resultado conhecido ocorre antes do que se deseja prever (EMERSON, 1996), são medidas de natureza preventiva. Medidas de leading, como acompanhamento de um processo, visam antecipar ou impactar no futuro. Mudanças em indicadores como rotatividade de 
funcionários ou taxas de defeito podem indicar que o desempenho financeiro será prejudicado no futuro (DENTON, 2005).

Outros autores como Mikusová e Janecková (2010) sugerem a classificação em indicadores de eficiência e indicadores de eficácia e/ou entre indicadores de resultado e indicadores de processo:

- Indicadores de eficiência (economia): mensuram as fontes consumidas na fabricação de um produto ou prestação de um serviço;

- Indicadores de eficácia: avaliam os resultados na visão do cliente, em que medida as suas necessidades e requisitos foram cumpridos com êxito;

- Indicadores de resultado (indicadores de output, delay, retrospectiva, externo, etc.): caracterizam saída do processo;

- Indicadores do processo (indicadores de entrada, gestão, liderança, interno, preditiva, dinâmica, causal, futuro, independente, etc.): são indicadores internos vindos do interior do processo de apuração dos resultados, capturam eventos internos do processo (MIKUŠOVÁ; JANEČKOVÁ,2010).

Com todas essas classificações e nomenclaturas possíveis, muitos indicadores se encaixam em mais de uma categoria. Uma mesma medida pode ser considerada um indicador não financeiro, de leading, operacional e de processo.

Existem ainda outros modos de classificar os indicadores de desempenho, como pelob nível organizacional em que é utilizado (operacional, tático ou estratégico) (MIKUŠOVÁ; JANEČKOVÁ, 2010). No nível operacional a avaliação de desempenho mede diretamente as entradas, processamentos e saídas de vários processos da organização (CHENHALL; LANGFIELD-SMITH, 2007). No nível estratégico se encontram os indicadores-chave (DENTON, 2005). Um bom sistema de avaliação de ADO deve incluir indicadores de diversas naturezas, sendo a escolha dessas medidas uma das decisões cruciais de ADO (DENTON, 2005). 


\subsection{Indicadores-chave de desempenho}

A mensuração do desempenho começa a partir da identificação dos indicadores de desempenho que serão utilizados (BHATTI; AWAN; RAZAQ , 2013). E os indicadores de desempenho estão em toda a parte, quase qualquer atividade pode ser mensurada via indicador (FORTUIN, 1988).

Apesar dos mais diversos aspectos da organização serem mensuráveis via indicador, não é viável que todos eles sejam medidos (LEBAS, 1995), é recomendável que se mesure apenas o que é realmente importante (DENTON, 2005). Dentre todos os indicadores possíveis de serem utilizados, é necessário que a organização faça escolhas e preze pela qualidade dos indicadores (MIKUŠOVÁ; JANEČKOVÁ,2010).

Principalmente quanto trata-se do nível estratégico da organização, o uso de um número menor de indicadores se torna ainda mais crítico. Contudo, não existe muita discussão na literatura em português sobre os indicadores estratégicos, também chamados de indicadores-chave.

Mesmo a definição de indicadores-chave de desempenho não é muito discutida na literatura de mensuração ou gestão do desempenho organizacional. Em geral não são encontrados trabalhos na literatura em português que utilizem essa nomenclatura. Mesmo quando pesquisados como indicadores estratégicos de desempenho, não são encontrados muitos trabalhos que tratem do assunto diretamente.

$\mathrm{Na}$ literatura estrangeira em inglês, existem poucos trabalhos que tratem dos keyperformance indicators, podendo ser citados os trabalhos de Mikusová e Janecková (2010) e de Bhatti, Awan e Razaq (2013) que tratam dos KPIs de forma geral. Outros trabalhos tratam de indicadores-chave em setores ou áreas específicas como keyperformance indicators financeiros (PINK et al., 2007), key-performance indicators em organizações de saúde (SORENSEN, et al., 1987, TOOR; OGUNLANA, 2010), e keyperformance indicators organizações de pesquisa e desenvolvimento (GEISLER, 1994). 
Contudo é frequente na literatura em inglês o uso do termo performance indicators para tratar dos indicadores mais importantes da organização que estão ligados diretamente como os objetivos organizacionais. Como afirmado por Fortuin (1988) de que bons indicadores de desempenho (performance indicators) são derivados dos objetivos organizacionais (FORTUIN, 1988). Sendo essa também a definição dos indicadoreschave, esses termos podem ser considerados como sinônimos.

$\mathrm{O}$ uso de performance indicators ou indicadores-chave permite que a organização mensure a estratégia quantitativamente e estabeleça as metas de desempenho desejadas (FORTUIN, 1988). A mensuração do desempenho nas áreas estratégicas são são importantes não só para a expansão da empresa, mas mais freqüentemente e em primeiro lugar para a sua sobrevivência (MIKUŠOVÁ; JANEČKOVÁ, 2010).

Os indicadores-chave devem indicar claramente, de modo rápido e objetivo o nível de desempenho do negócio. Se as ações tomadas obtiveram os resultados desejados e em que nível (FORTUIN, 1988). A possibilidade de avaliar o desempenho da organização rapidamente auxilia as organizações a sobreviver em um ambiente que muda rapidamente (MIKUŠOVÁ; JANEČKOVÁ, 2010).

\subsection{Avaliação de desempenho em organizações públicas}

O setor público tem muitos atributos econômicos do setor privado, porém também tem obrigações não-econômicas, como os benefícios ambientais e sociais, e precisa definir metas de desempenho para equilibrar esses múltiplos objetivos (ZHONGHUA; YE, 2012). A empresa pública, por atingir geralmente uma grande parcela da população, deveria ser avaliada primeiramente por seu papel na sociedade (ainda que ele seja difícil de mensurar), diferente da empresa privada, que atende as necessidades de grupos mais específicos (CORRÊA, 1986), mesmo que ainda possua obrigações sociais/ambientais.

Uma vez que o desempenho do setor público tem essas peculiaridades cabe aos governos mensurar o sucesso de seus programas. Sucesso, neste contexto, se relaciona à eficácia na realização dos objetivos definidos nos programas e serviços financiados com o dinheiro público. Exige-se que os resultados obtidos sejam eficientes, de modo a 
evitar o desperdício de recursos públicos (BARRADOS; BLAIN, 2013). As considerações financeiras podem facilitar ou dificultar o andamento das atividades, mas raramente serão o principal objetivo (KAPLAN, 2001).

Além de mensurar eficácia e eficiência de programas governamentais a avaliação de desempenho no setor público tem outro objetivo muito importante: comunicar os stakeholders. As organizações públicas possuem uma grande variedade de partes interessadas, muitas vezes com interesses conflitantes e com a capacidade exercer influência significativa sobre a sobrevivência da organização (JARRAR; SCHIUMA, 2007). Segundo Corrêa (1986, p. 140) "a avaliação de uma empresa pública deve ser resultante de consenso interno, reunir as sugestões e contribuições de todos os envolvidos, de forma que a metodologia adotada por uma dada empresa reflita claramente as suas características".

Entre os stakeholders que utilizam as informações resultantes da ADO no setor público, pode-se citar três importantes stakeholders e os usos que fazem da ADO: 1) profissionais e responsáveis pela prestação de serviços públicos: podem usar os dados da avaliação para verificar o seu próprio desempenho e buscar possibilidades de melhoria (BIRD, et al., 2005); 2) gestores públicos: usam os dados para verificar se suas organizações estão cumprindo sua missão, para estabelecer metas e usar como base para recompensas de desempenho e para a prestar contas (BIRD, et al., 2005); 3) população: para verificar a qualidade do uso dos recursos públicos por meio da prestação de contas (JARRAR; SCHIUMA, 2007).

A avaliação de desempenho organizacional em insituições públicas já é estudada a algum tempo, como exemplo disso é possível citar o MADE-O (CORRÊA, 1986), que é uma metodologia de ADO criada especificamente para empresas estatais. Esse método apresenta um conjunto de dez módulos (dimensões) para a avaliação de empresas estatais: 1) econômico-financeiro;2) operacional; 3) recursos humanos; 4) satisfação dos usuários/clientes; 5) inovação tecnológica; 6) adaptação/ambiente; 7) avaliação técnica; 8) clima organizacional; 9) benefícios sociais; e 10) potencialidade gerencial.

Esses módulos buscam abranger todas as áreas de uma empresa estatal, desde que realizados alguns ajustes para atender às necessidades de cada empresa. Alguns 
módulos, como o de potencialidade gerencial, não estão ligados diretamente aos resultados no curto prazo. Mas resultados ruins nesses módulos podem levar a um mau desempenho no futuro (CORRÊA, 1986).

\subsection{Avaliação de desempenho em organizações de saúde}

As organizações de prestação de serviços de saúde de têm enfrentado diversas mudanças em seu ambiente. O desenvolvimento de novas políticas de saúde, aumento da responsabilidade social, aumento das exigências em qualidade dos serviços, mudanças na demanda, competição por fornecimento de serviços e novas tecnologias médicas (IOAN; NESTIAN; TIŢĂ, 2012), têm tornado a gestão dessas organizações mais complexa. Essas organizações também sofrem pressões do governo, operadoras de planos de saúde, segurados, comunidade e consumidores individuais para reduzir o custo e melhorar a qualidade do atendimento (LI; BENTON, 1996).

Em especial o atendimento com qualidade tem sido uma exigência crescente na área da saúde. Pacientes têm demandado maiores níveis de desempenho da instituição que os atende (BONACIM; ARAÚJO, 2009). Donabedian (1990) levanta que a qualidade em prestação de serviços de saúde é definida por sete atributos: (1) eficácia: a capacidade de atendimento, em sua melhor execução, para melhorar a saúde, (2) efetividade: o grau em que a melhoria do estado de saúde atingível é realizada, (3) eficiência: a capacidade de obter a maior melhora no estado de saúde ao menor custo; (4) otimização: o balanceamento de custos e benefícios mais vantajoso; (5) aceitabilidade: conformidade com as preferências do paciente em relação à acessibilidade, relação paciente-médico, comodidades, efeitos do tratamento e custo dos cuidados; (6) legitimidade: conformidade com as preferências sociais sobre todos os itens acima, e (7) equidade: equidade na distribuição dos cuidados de saúde.

Para decidir sobre a alocação de recursos nas organizações de saúde os gestores precisam estar atentos a todos estes atributos de qualidade ao mesmo tempo em que se preocupam com as questões de viabilidade do negócio (VOELKER, RAKICH, FRENCH, 2001). Diversos fatores tornam a gestão de serviços de saúde é muito 
desafiadora quando comparada com outros setores mais convencionais, entre eles é possível citar:

- Grandes problemas para mensurar a saídas (resultados) das atividades dos cuidados de saúde;

- Hospitais e outras organizações de serviços de saúde são normalmente formas de governança e organizacionais complexas;

- Mesmo quando assalariados, médicos demandam certo grau de autonomia profissional;

- Extensivo treinamento e educação necessitam ser acomodados;

- A tecnologia e as práticas clínicas mudam rapidamente;

- O produto dos serviços de saúde é altamente complexo e geralmente precisa ser cuidadosamente ajustado às necessidades individuais dos pacientes (OZCAM; SMITH, 1998).

Todo contexto de crescimento da demanda por qualidade do atendimento e aumento complexidade da gestão tornou a mensuração de desempenho um elemento fundamental para a gestão de organizações de saúde (LI; BENTON, 1996). Elas necessitam de ferramentas gerenciais que possibilitem a avaliação de suas ações e que lhes permitam melhorar a gestão dos recursos utilizados na prestação de serviços (SOUZA et al., 2009).

O desempenho é a extensão em que os objetivos organizacionais são atingidos (CUNHA, 2013). Nos serviços de saúde, a gestão do desempenho representa um instrumento para buscar qualidade, eficiência e eficácia juntos, sendo um conceito multidimensional (IOAN; NESTIAN; TIŢĂ, 2012). Organizações prestadoras de serviços de saúde passaram a concentrar atenção considerável sobre a definição e utilização de indicadores de qualidade clínica, para identificar oportunidades de melhoria de serviços de saúde, para medir a eficácia de intervenções específicas e fornecer uma ligação quantitativa entre qualidade do atendimento e rentabilidade (BALLARD, 2003).

Entretanto ainda é difícil para essas instituições mensurar e gerenciar o desempenho. Um dos motivos por trás disso é o fato de cada fornecedor, consumidor e contribuinte 
definir o desempenho dos serviços de saúde com base em seus objetivos, interesses e interpretações (LI; BENTON, 1996).

Os critérios para definir o que é um bom desempenho dependem diretamente dos envolvidos. Para um paciente o critério de desempenho é a qualidade do serviço, para um médico é a obtenção de resultados clínicos desejáveis, para um hospital é a solidez da sua viabilidade financeira e para quem paga pelos serviços é o reconhecimento dos cuidados de baixo custo e satisfação do cliente (LI; BENTON, 1996).

Pode-se concluir que apesar da importância da ADO (LI; BENTON, 1996), da atenção que tem recebido (BALLARD, 2003), e da necessidade de seu uso em organizações de saúde (SOUZA, et al., 2009), sua execução ainda é um desafio para a área da saúde (LI; BENTON, 1996). Em busca de solucionar ou ao menos amenizar esse problema alguns modelos de ADO têm sido adaptados para orgaizações de saúde, como o BSC (VOELKER; RAKICH; FRENCH, 2001) ou criados especificamente para um tipo de organização de prestação de serviços de saúde, como os hospitais filantrópicos (CUNHA, 2013). O modelo de avaliação de hospitais filantrópicos pode ser visto no Quadro 2: 
Quadro 2 - Modelo de avaliação de hospitais filatrópicos

\begin{tabular}{|l|l|}
\hline Perspectivas & Variáveis \\
\hline Financeira & Viabilidade financeira por custos e despesas \\
\hline & Viabilidade financeira por atendimento \\
\hline & Eficiência operacional \\
\hline & Liquidez financeira \\
\hline & Margem de contribuição \\
\hline & Tempo médio de faturamento \\
\hline Qualidade & Quantidade de acreditações \\
\hline Acessibilidade & Grau de percepção da qualidade dos serviços prestados \\
\hline & Atendimentos realizados - cirurgias \\
\hline & Atendimentos realizados - internações \\
\hline & Atendimentos realizados \\
\hline & Exames \\
\hline & Relação de atendimentos filantrópicos \\
\hline Processos internos & Tempo médio de espera \\
\hline & Tempo médio de permanência \\
\hline & Taxa de rotatividade - saídas \\
\hline & Taxa de rotatividade - dias de internação \\
\hline & Taxa de ocupação - pacientes-dia \\
\hline & Taxa de retorno com o mesmo CID \\
\hline & Capacidade de atendimento - quadro de funcionários \\
\hline & Capacidade de infraestrutura - leitos \\
\hline & Investimento em tecnologia \\
\hline & Retenção de pacientes \\
\hline Capacidades & Taxa de infecção hospitalar \\
\hline & Score para descarte do lixo hospitalar \\
\hline & Reutilização demateriais hospitalares. \\
\hline &
\end{tabular}

Adaptado de Cunha, 2013.

\subsection{Indicadores de desempenho na saúde}

Indicadores são medidas-síntese que contêm informações relevantes sobre determinados atributos e dimensões do desempenho do sistema de saúde (OPAS, 2008). Avaliação de desempenho na área da saúde pode incluir uma grande variedade de indicadores. Hermann et al. (2000) avaliaram nos Estados Unidos o Inventário Nacional de Medidas de Saúde Mental e Qualidade e identificaram 86 medidas de desempenho nas seguintes categorias: adequação do tratamento ( $65 \%$ de todos os indicadores), continuidade do tratamento, acessibilidade dos cuidados, coordenação dos cuidados, detecção e prevenção (LUIJSTERBURG, et al., 2008).

Geralmente os indicadores clássicos utilizados pelos hospitais podem ser agrupados basicamente em três grupos: 1) indicadores de saúde: por exemplo, taxas de mortalidade 
e fatores de risco; 2) indicadores de utilização dos serviços: como taxas de consultas médicas, intervenções cirúrgicas, exploração e diagnósticos, dias de internação hospitalar e tempo médio de permanência por paciente; 3) indicadores de recursos hospitalares: como número de leitos disponíveis, internações hospitalares, o número de admissões anuais, as taxas de ocupação por serviço e rotação média de leitos / quartos (URRUTIA, ERIKSEN, 2005).

Contudo, classificar os indicadores por tipo não é suficiente. É necessário saber o propósito do uso desses indicadores e também se eles estão aptos a cumprir seu papel.

Uma das justificativas para a introdução de indicadores de desempenho em uma organização assume que a presença deles promoverá mudanças na qualidade dos processos dentro da organização, trará melhores resultados e uma redução de custos (PERERA et al., 2007).

O uso de indicadores pode servir a muitos propósitos em uma organização de saúde: documentar a qualidade do atendimento, fazer comparações ao longo do tempo e entre organizações, melhorar da qualidade do apoio, apoiar as escolhas dos pacientes, julgar e definir prioridades. Além de serem muito úteis para ajudar a cumprir regulamentos e possibilitar acreditações (MAINZ, 2003).

Não é por acaso que ocorreu um explosão em número de indicadores de desempenho utilizados pelas organizações (DAVIES; LAMPEL, 1998). Todavia esse aumento do uso e do número de indicadores de desempenho na área da saúde se baseia na premissa de que os indicadores utilizados possuem os atributos necessários para refletir os resultados organizacionais tanto da assistência quanto econômicos (PERERA et al., 2007).

Segundo a Organização Pan-Americana de Saúde (2008) a qualidade de um indicador para a saúde depende principalmente de dois aspectos: as propriedades dos componentes utilizados em sua formulação e a precisão dos sistemas de informação (OPAS, 2008). A elaboração de um indicador também é afetada pela instuição que está sendo estudada, como hospitais, asilos, grupos de médicos, departamentos 
especializados e médicos. Uma medida adequada para uma entidade pode não funcionar para outra (EDDY, 1998).

Diversos autores definem as características essencias ou atributos para a elaboração de bons indicadores de avaliação de desempenho na área da saúde, mostrando diferentes visões sobre o assunto. Kruk e Freedman (2008) estabelecem que as medidas utilizadas numa organização de saúde devam ser: localmente relevantes, confiáveis, válidas e viáveis de implementar.

Já a OPAS (2008) repete alguns dos conceitos destes autores, mas adiciona outros aos atributos desejáveis de um indicador: a)validade: capacidade de medir o que pretende; b) confiabilidade: reproduzir os mesmos resultados quando aplicado em condições similares; c) sensibilidade: capacidade de detectar o fenômeno analisado; d) especificidade: capacidade de detectar somente o fenômeno analisado; e) mensurabilidade: basear-se em dados disponíveis ou fáceis de conseguir; f) relevância: responder às prioridades de saúde; g) custo-efetividade: os resultados justificam o investimento de tempo e recursos; h) ser interpretável: ser passível de análise e interpreção com facilidade pelo usuário (OPAS, 2008).

Além de apresentar os atributos citados, os indicadores de desempenho também precisam estar diretamente ligados à estratégia organizacional. Segundo OndateguiParra et al. (2004) eles devem prover informações sobre os objetivos operacionais essenciais a serem alcançados. É necessária a implementações cuidadosa de regras e sistemas de informação para assegurar confiabilidade dos indicadores (LUIJSTERBURG et al., 2008).

\subsection{Hospitais universitários públicos}

Os hospitais universitários além de prestar assistência de média e alta complexidade, contribuem para a formação de profissionais na área de saúde, sediam cursos de pósgraduação e são fontes de geração do conhecimento (BONACIM; ARAUJO, 2009). 
Em seu estudo Medici (2001) analisou a realidade dos hospitais universitários/hospitais de ensino em 22 países (de alto, médio e baixo nível de desenvolvimento) e mostrou que um HU geralmente é entendido como um centro de atenção médica de alta complexidade que: (a) tem importante papel no atendimento médico de nível terciário; (b) apresenta forte envolvimento em atividades de ensino e pesquisa relacionada ao tipo de atendimento médico que dispensa; (c) atrai alta concentração de recursos físicos, humanos e financeiros em saúde; (d) exerce um papel político importante na comunidade que está inserido, dada sua escala, dimensionamento e custos.

É comum encontrar hospitais de ensino e hospitais universitários sendo tratados sinônimos na literatura, principalmente na literatura de administração. Esses dois tipos de instituições de saúde realmente são muito semelhantes; entretanto existem algumas diferenças que devem ser destacadas. Um hospital universitário é necessariamente considerado um hospital de ensino, porém um hospital de ensino pode não ser um hospital universitário. Um hospital de ensino, apesar de também ser responsável pela formação de estudantes, não necessariamente é um prolongamento de uma universidade ou faculdade. Geralmente os hospitais de ensino formam residentes e outros profissionais vindos de instituições de ensino superior.

No Brasil os hospitais universitários públicos são os recursos de saúde mais complexos do SUS, produto de grandes investimentos e realizam os procedimentos mais custosos ao sistema (BARATA; MENDES; BITTAR, 2010). Na realidade brasileira um hospital universitário (HU) é definido como uma instituição que: (a) é um prolongamento de um estabelecimento de ensino em saúde; (b) prove treinamento universitário na área de saúde; (c) é reconhecido oficialmente como hospital de ensino, estando submetido à supervisão das autoridades competentes e (d) propicia atendimento médico de maior complexidade (nível terciário) a uma parcela da população (MEDICI, 2001).

Segundo a legislação essas organizações desempenham as funções de: atender as necessidades do ensino de graduação na área de saúde, desenvolver programas de pósgraduação stricto sensu e lato sensu, definir a oferta anual de vagas dos programas de residência médica, implementar a residência multiprofissional nas áreas estratégicas para o SUS e estimular o desenvolvimento de linhas de pesquisa de interesse do SUS. Sendo também centros de referência em atendimentos de média e alta complexidade. 
O Conselho Federal de Medicina - CFM (2014) define os hospitais universitários como centros de formação de recursos humanos e de desenvolvimento de tecnologia na área de saúde. Responsáveis pela elaboração e aprimoramento de protocolos técnicos para diversas patologias e por oferecer oportunidade de atualização técnica aos profissionais de todo o sistema de saúde.

Todas essas características dos HUs citadas acima podem ser agrupadas em três funções principais dos HUs: ensino, pesquisa e assistência. Segundo Lobo et al. (2010) um fator importante na caracterização dos HUs está no reconhecimento da existência dessas múltiplas dimensões dentro de cada hospital - assistência, ensino e pesquisa - cujo desempenho e qualidade influenciam umas às outras. No entanto justamente uma consequiência das responsabilidades adicionais que um HU carrega é que seus custos usualmente são maiores quando comparados com insitituições não-docentes (GROSSKOPF; MARFARITIS;VALDMANIS, 2001).

Quanto à assistência, os HUs são centros de referência de média e alta complexidade, para a rede pública de serviços de saúde (EBSERH, 2014) e também têm responsabilidade para com o avanço da tecnologia médica, pois as equipes médicas dessas insituições determinam a forma de incorporação de novas tecnologias no país, gerando grande impacto no financiamento do sistema público de saúde e no atendimento à população (BARATA; MENDES; BITTAR, 2010).

Outro fator que torna a administração desse tipo de instituição mais complexa do que de um hospital puramente assistencial é o fato de que cada uma de suas áreas (ensino, pesquisa e extensão) se reporta a instituições governamentais diferentes, Ministério da Saúde (assistência), Ministério da Educação (ensino), Ministério da Ciência e Tecnologia (pesquisa). Além de estarem submetidos às normas da Instituição de Ensino Superior (IES) à qual pertencem. A gestão dos HUs é muito dependente das normas e da legislação sob as quais as IES operam.

Aspectos como a baixa produtividade, falta de informações gerenciais confiáveis, falta de informações sobre a gestão de recursos, deficiente capacitação de recursos humanos de apoio, inexistência de planos diretores de expansão e modernização, conhecimento insuficiente das políticas públicas de saúde e desintegração com os 
demais recursos de saúde do SUS dificultam a gestão dos HUs (BARATA; MENDES; BITTAR, 2010).

Segundo Lobo et al. (2010), a partir de 2004 houve alguma melhoria na situação dos HUs, como a melhora na integração entre seus três objetivos maiores, por meio da Política de Reestruturação dos Hospitais de Ensino. Onde foi iniciado um processo de certificação dos hospitais universitários e de ensino, mediante visitas de representantes do MEC e Ministério da Saúde.

Mas de todos os desafios enfrentados pelos HUs talvez o maior avanço a ser dado seja o fortalecimento da sua sustentabilidade organizacional (MACHADO; KUCHENBECKER, 2007). Nessas instituições a sustentabilidade é definida como equilíbrio financeiro ao mesmo tempo em que a organização exerce sua missão e cumpre seu compromisso social (MACHADO; KUCHENBECKER, 2007).

A necessidade de mensurar o cumprimento da missão organizacional e manter o equilíbrio financeiro estão entre os motivos pelos quais a avaliação de desempenho organizacional desempenha um papel crucial nessas organizações. Isto porque os principais objetivos de um sistema de avaliação de desempenho em uma organização sem fins lucrativos são determinar o quão bem ela está cumprindo sua missão (GRIGOROUDIS; ORFANOUDAKI; ZOPOUNIDIS, 2012) e melhorar o seu desempenho (BEHN, 2003).

Para atingir o equilíbrio financeiro, por exemplo, podem-se implantar mecanismos de saneamento financeiro dos HUs, desenvolver sistemas de indicadores de avaliação e gestão, incorporar questões relativas à qualidade dos serviços prestados, transparência e responsabilidade social (MACHADO; KUCHENBECKER, 2007).

\subsection{Avaliação de desempenho em hospitais}

Após os anos 70 a administração hospitalar passou a enfrentar novos desafios em seu ambiente com: a) a atenção primária passa a ser associada ao conceito de democratização da saúde; b) as técnicas de prevenção que ganham força como 
instrumento para prolongar a vida e reduzir custos dos sistemas de saúde; c) o crescimento da atenção médica baseada no conceito de seguro; d) o aumento do conhecimento e da regulação do setor; e) a multidisciplinaridade crescente da atenção à saúde; f) o crescimento dos mecanismos de defesa do consumidor (MEDICI, 2001).

Além de um hospital ter que lidar com esses fatores externos, as características desse tipo de organização o tornam um exemplo clássico de organização complexa (MARINHO, 2001). Dentre estas características três tem o maior impacto na gestão dessas organizações: sua natureza de burocracia profissional (DENIS; LANGLEY; LUXEAU, 1991), a existência de pelo menos duas entidades separadas que interagem (administração e equipe médica) dentro da mesma organização (HARRIS, 1977 apud ELDENBURG et al., 2004), e a gama diversificada de stakeholders com os quais um hospital interage (MCDONALD, 2012).

A natureza de burocracia profissional, segundo a definição de Mintzberg (1979), devese ao fato de que nos hospitais o principal trabalho de operação é realizado por profissionais qualificados que mantêm considerável autonomia sobre as suas atividades (DENIS; LANGLEY; LUXEAU, 1991). Isso faz com que muitas decisões relativas à orientação estratégica dessas organizações sejam fortemente influenciadas pelas atividades e aspirações de profissionais-chave, como a equipe médica. As atividades dessa equipe, por exemplo, afetam diretamente os serviços oferecidos pelo hospital por meio de suas redes de referência pessoais, sua escolha de pacientes e tratamentos prescritos (DENIS; LANGLEY; LUXEAU, 1991).

As duas entidades que interagem dentro do hospital são: a sua administração, que gerencia funcionários e recursos, e a equipe médica, diretor médico e chefes de departamento médico, que gerenciam os médicos (HARRIS, 1977). Para o bom funcionamento da organização ambas devem se equilibrar para manter a viabilidade econômica e a qualidade do atendimento ao paciente (ELDENBURG et al., 2004).

Já o conjunto de stakeholders do hospital pode incluir: pacientes e seus cuidadores / familiares, comunidades, médicos, funcionários, órgãos reguladores, estado e departamentos nacionais de saúde, outros departamentos do governo, por exemplo, 
educação e serviços comunitários, universidades, acionistas ou mantenedores, entre outros (MCDONALD, 2012).

Em resumo, os fatores externos citados por Medici (2001) natureza de burocrática profissional dos hospitais (DENIS; LANGLEY; LUXEAU, 1991) existência de pelo menos duas entidades separadas em uma mesma organização (HARRIS, 1977, ELDENBURG, et al., 2004) e o conjunto diversificado de stakeholders (MCDONALD, 2012), são fatores que limitam o poder dos administradores (DENIS; LANGLEY; LUXEAU, 1991) e tornam a administração destas organizações muito complexa (MARINHO, 2001).

A administração precisa equilibrar os interesses dos profissionais, que clamam por desenvolvimento, e do governo, que clama por racionalização de gastos, no caso de hospitais públicos (DENISS; LANGLEY; LOXEAU, 1991) e a necessidade de assegurar que os recursos disponíveis sejam distribuídos equitativamente e utilizados de forma eficaz e eficiente (MCDONALD, 2012).

É justamente nessa lacuna que se encaixa a avaliação de desempenho organizacional. Desde que um sistema de avaliação de desempenho organizacional consiste em um conjunto de indicadores utilizados para quantificar eficácia e eficiência (NEELY, 1994), e o uso de indicadores de desempenho e mensuração de resultados são um bom meio de avaliar a adequação dos serviços prestados por instituições de saúde (MAINZ, 2003).

Estar ciente do nível de desempenho de um hospital é compreender se ele está cumprindo sua missão (IOAN; NESTIAN; TIŢĂ, 2012). Segundo a Organização Mundia da Saúde (WHO, 2003), a mensuração é fundamental para o conceito de melhoria da qualidade hospitalar e oferece um meio para definir o que realmente fazem os hospitais e comparar resultados com as metas originais.

Em termos práticos a avaliação de desempenho organizacional é utilizada em muitos hospitais para fins de acreditação e/ou para melhorar a gestão. Na Austrália, por exemplo, para atender as normas do Conselho Australiano de Normas de Saúde e seu programa de acreditação, é necessário que os hospitais coletem e avaliem indicadores clínicos e não-clínicos regularmente (MCDONALD, 2012). No Brasil existe o 
Programa de Reestruturação dos Hospitais Universitários Federais (REHUF) que utiliza indicadores para distribuir recursos governamentais.

Sistemas de avaliação de desempenho como o BSC e similares têm sido aplicados em instituições de saúde, como um centro médico acadêmico em Taiwan (CHEN; HOU; CHANG, 2012), para comparar indicadores de hospitais públicos no Japão e na China (CHEN et al., 2006). Outras metodologias, como a Análise Envoltória de Dados (DEA) também tem sido utilizadas para avaliar o desempenho de hospitais públicos das capitais brasileiras (GONÇALVES et al., 2007) e para mensurar a eficiência em hospitais filantrópicos (CUNHA, 2013).

\subsection{Avaliação de desempenho organizacional em hospitais universitários}

A missão de qualquer hospital ao prestar serviços de saúde é resolver os problemas de saúde dos pacientes (eficácia), da melhor forma (qualidade) da forma mais econômica possível (eficiência) (IOAN; NESTIAN; TITA, 2012). Os HUs devem atender a esses objetivos em sua missão e cumprir outros objetivos, principalmente relacionados ao ensino e pesquisa.

Esse fato pode ser evidenciado pelas declarações de missão de alguns hospitais universitários, inclusive a instituição participante dessa pesquisa, demonstrado no Quadro 3:

Quadro 3 - Declarações de missão de hospitais universitários.

\begin{tabular}{|l|l|}
\hline Instituição & Missão \\
\hline $\begin{array}{l}\text { Pospital Universitário da Universidade de São } \\
\text { Paulo }\end{array}$ & $\begin{array}{l}\text { Desenvolver atividades de ensino e pesquisa na } \\
\text { área de saúde e assistência hospitalar de média } \\
\text { complexidade, preferencialmente às populações } \\
\text { do Distrito de Saúde do Butantã e da Comunidade } \\
\text { Universitária da USP prestando um serviço } \\
\text { diferenciado com atendimento de excelência. }\end{array}$ \\
\hline $\begin{array}{l}\text { Hospital São Paulo - Hospital Universitário da } \\
\text { UNIFESP }\end{array}$ & $\begin{array}{l}\text { Prestar assistência à saúde da população com } \\
\text { qualidade, visando seu bem estar e oferecendo } \\
\text { condições ótimas para ensino e pesquisa. }\end{array}$ \\
\hline $\begin{array}{l}\text { Hospital das Clínicas da Faculdade de } \\
\text { de São Paulo. }\end{array}$ & $\begin{array}{l}\text { Desenvolver e praticar assistência, ensino e } \\
\text { pesquisa em saúde, por meio da busca permanente } \\
\text { da excelência, contribuindo para a melhoria da } \\
\text { qualidade de vida da população. }\end{array}$ \\
\hline
\end{tabular}


Pode-se perceber que em todas as declarações de missão é enfatizado o papel do HU como um centro de atendimento à população, ensino e pesquisa. Essas insituições têm a necessidade de equilibrar suas três dimensões (ensino, pesquisa e atendimento). Sendo que a viabillidade financeira e a baixa produtividade dos HUs ainda é um desafio que precisa ser superado (BONACIM; ARAÚJO, 2009).

A gestão de HUs tem sido estudada por diversos ângulos até o momento, como pode ser visto no Quadro 4:

Quadro 4 - Estudos anteriores relacionados a hospitais universitários

\begin{tabular}{|c|c|c|}
\hline Título do Trabalho & Objetivo do Estudo & Autores \\
\hline \begin{tabular}{lrr} 
Hospitais & \multicolumn{2}{c}{ Universitários: } \\
avaliação & de & eficiência \\
técnica & &
\end{tabular} & $\begin{array}{l}\text { Comparar a eficiência de } 43 \\
\text { hospitais universitários federais } \\
\text { brasileiros (HUs) por meio da } \\
\text { análise de envoltória de dados } \\
\text { [Data Envelopment Analysis } \\
\text { (DEA)] }\end{array}$ & (MARINHO, 2001) \\
\hline $\begin{array}{l}\text { Hospitais Universitários: } \\
\text { passado, presente e futuro }\end{array}$ & $\begin{array}{l}\text { Discutir a evolução dos hospitais } \\
\text { universitários, suas } \\
\text { características, funcionamento e } \\
\text { financiamento, e seu papel no } \\
\text { ensino e pesquisa médicos. }\end{array}$ & (MEDICI, 2001) \\
\hline $\begin{array}{llr}\text { Desafios } & \text { e } & \text { perspectivas } \\
\text { futuras } & \text { dos } & \text { hospitais } \\
\text { universitários no } & \text { Brasil }\end{array}$ & $\begin{array}{l}\text { Promover uma reflexão crítica } \\
\text { acerca dos desafios e } \\
\text { perspectivas dos HU brasileiros } \\
\text { em relação à assistência à saúde, } \\
\text { ensino e pesquisa acadêmica. }\end{array}$ & $\begin{array}{l}\text { (MACHADO; } \\
\text { KUCHENBECKER, 2007) }\end{array}$ \\
\hline $\begin{array}{l}\text { Valor econômico agregado } \\
\text { por Hospitais Universitários } \\
\text { Públicos }\end{array}$ & $\begin{array}{l}\text { Demonstrar como pode ser } \\
\text { mensurado o valor econômico } \\
\text { agregado à sociedade por } \\
\text { Hospitais Universitários Públicos }\end{array}$ & (BONACIM; ARAÚJO, 2009) \\
\hline $\begin{array}{l}\text { Avaliação de desempenho e } \\
\text { integração } \\
\text { assistencial nos hospitais } \\
\text { universitários }\end{array}$ & $\begin{array}{l}\text { Avaliar o desempenho e a } \\
\text { integração entre as dimensões de } \\
\text { assistência e de ensino dos } \\
\text { hospitais } \\
\text { brasileiros. }\end{array}$ & $\overline{(\mathrm{LOBO} \text { et } \text { al., 2010) }}$ \\
\hline 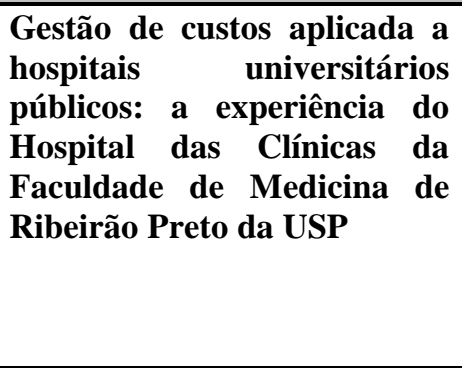 & $\begin{array}{l}\text { Analisar a situação do sistema de } \\
\text { custos do Hospital das Clínicas } \\
\text { da Faculdade de Medicina de } \\
\text { Ribeirão Preto da Universidade } \\
\text { de São Paulo } \\
\text { (HCFMRP-USP) e a proposta de } \\
\text { mudança para do método } \\
\text { absorção para o custeio baseado } \\
\text { em atividades (ABC). }\end{array}$ & (BONACIM; ARAÚJO, 2010) \\
\hline
\end{tabular}

Perebe-se que apenas dois dos trabalhos destacados tratam de alguma forma a avaliação de desempenho em HUs. O estudo de Lobo et al. (2010), está relacionado com a avaliação de desempenho em HUs. Porém ele dirige-se mais à integração entre a assistência e o ensino do que à mensuração dos resultados da instituição como um todo. 
Já o trabalho de Marinho (2001) mensura a eficiência dos HUs por meio do DEA (Data Envelopment Analysis), mas não se preocupa com o funcionamento interno dessas organizações.

Após compreender a relevância dos HUs e a falta de estudos sobre a gestão destas instuições é possível perceber a necessidade da realização de avaliação de desempenho em HUs e também a natureza dos programas criados pelo Governo Federal e pelo Governo do Estado de São Paulo para melhorar a gestão dos HUs.

Os programas citados declaram ter como principais objetivos avaliar o cumprimento da missões dos HUs e também melhorar o desempenho destas instituições. Por exemplo, o Sistema de Avaliação dos Hospitais de Ensino (SAHE) - inicialmente nomeado Sistema de Avaliação dos Hospitais Universitários (SAHU) - é um sistema coordenado pela Assessoria de Hospitais de Ensino do Gabinete da SES-SP e foi desenhado e desenvolvido pela Coordenadoria de Planejamento de Saúde (CPS) da Secretaria de Estado da Saúde de São Paulo (SES-SP) em 2005, com o objetivo de coletar eletronicamente dados de relatórios mensais e anuais de hospitais de ensino do Estado de São Paulo (SAHE, 2014).

Esse sistema é útil principalmente para os gestores do sistema de saúde, por poderem comparar os resultados entre diferentes instituições. Mas a comparação entre HUs também é útil para os gestores destes, aos poderem comparar os resultados entre si. Mas o SAHE aparentemente ainda necessita de ajustes, como a criação de indicadores para mensurar objetivos de ensino e pesquisa dos HUs.

\subsection{EBSERSH - Empresa brasileira de serviços hospitalares e REHUF - Programa nacional de reestruturação dos hospitais universitários federais}

A EBSERSH (Empresa Brasileira de Serviços Hospitalares) foi criada pela lei $\mathrm{N}^{\mathrm{o}}$ 12.550 de Dezembro de 2011, sendo uma organização com personalidade jurídica de direito privado e patrimônio próprio, vinculada ao Ministério da Educação. Ela tem como objetivo prestar de serviços de assistência médico-hospitalar, ambulatorial, de apoio diagnóstico e terapêutico gratuitos à comunidade e também a prestação de 
serviços de apoio nas áreas de ensino, pesquisa e extensão, vinculados à área da saúde em instituições públicas federais de ensino.

A criação da EBSERSH fez parte de um conjunto de medidas do Governo Federal para gerenciar o REHUF (Programa Nacional de Reestruturação dos Hospitais de Universitários Federais). Os objetivos da EBSERSH facilmente se confundem com os do REHUF e dos próprios hospitais universitários. A Missão da EBSERSH é "Prestar serviços de atenção à saúde com excelência, criar condições para a formação profissional de qualidade e promover o desenvolvimento científico e tecnológico, mediante a gestão dos hospitais universitários federais e congêneres". Sua Visão é "Ser reconhecida pela sociedade brasileira como referência na atenção à saúde e em gestão hospitalar" (EBSERSH, 2014).

Já seus objetivos estratégicos são:

- Atenção à Saúde - Assegurar a excelência dos serviços de atenção à saúde nos Hospitais Universitários e congêneres.

- Operações - Garantir as condições operacionais necessárias para que a EBSERH se torne referência na gestão de Hospitais Universitários e congêneres.

- Formação profissional - Apoiar as Instituições Federais de Ensino Superior na formação de profissionais da saúde (EBSERSH, 2014).

Apesar do grande envolvimento da EBSERSH com os hospitais universitários ela, a princípio, não busca ferir a autonomia universitária, a qual é garantida pelo artigo 207 da Constituição Federal de 1988. Em termos práticos a EBSERSH tem como função prestar serviços de apoio por meio de contrato aos HUs na execução dos planos do REHUF. Atualmente a EBSERSH atua ou irá iniciar sua atuação em 19 dos 47 hospitais universitários federais do Brasil.

Já o Programa Nacional de Reestruturação dos Hospitais Universitários Federais (REHUF), que é apoiado pela EBSERSH, foi criado pelo Decreto $\mathrm{N}^{\circ} 7.802$, de 27 de 
Janeiro de 2010, e regulamentado pela Portaria Interministerial $\mathrm{N}^{\circ} 883$, de 5 de julho de 2010.

Segundo a lei o REHUF tem como objetivo "criar condições materiais e institucionais para que os hospitais universitários federais possam desempenhar plenamente suas funções em relação às dimensões de ensino, pesquisa e extensão e à dimensão da assistência à saúde".

O programa é orientado por algumas diretrizes, são elas:

I - Instituição de mecanismos adequados de financiamento, igualmente compartilhados entre as áreas da educação e da saúde;

II - Melhoria dos processos de gestão;

III - Adequação da estrutura física;

IV - Recuperação e modernização do parque tecnológico;

V - Reestruturação do quadro de recursos humanos dos hospitais universitários federais;

VI - Aprimoramento das atividades hospitalares vinculadas ao ensino, pesquisa e extensão, bem como à assistência à saúde, com base em avaliação permanente e incorporação de novas tecnologias em saúde (BRASIL, 2010).

Para atingir seus objetivos o REHUF também adota algumas medidas, as quais são desdobramentos das diretrizes. Em resumo essas medidas são:

a) Modernizar a gestão dos hospitais universitários federais, padronizar de insumos e melhorar o custo-benefício dos procedimentos;

b) Implantar um sistema gerencial de informações e indicadores de desempenho a ser disponibilizado pelo Ministério da Educação, com o cumprimento de metas;

c) Reformar prédios e/ou construir unidades hospitalares novas;

d) Adquirir novos equipamentos de saúde e substituição dos equipamentos obsoletos;

e) Implantar processos de melhoria de gestão de recursos humanos; 
f) Promover incremento do potencial tecnológico e de pesquisa dos hospitais universitários federais;

g) Instituir processos permanentes de avaliação das atividades de ensino, pesquisa, extensão, inovação tecnológica e atenção à saúde;

h) Criar mecanismos de governança com a participação de representantes externos às universidades (BRASIL, 2010).

O programa pretende atender a toda a rede de hospitais universitários federais que é formada por 47 hospitais vinculados a 33 universidades federais (EBSERSH, 2014). Pode-se perceber que tanto o REHUF quanto a EBSERSH têm como seus principais objetivos melhorar praticamente todos os aspectos relacionados à gestão do ensino, pesquisa e atendimento dentro do HUs Federais.

\subsection{SAHE - Sistema de avaliação dos hospitais de ensino}

O Sistema de Avaliação dos Hospitais de Ensino (SAHE) - inicialmente nomeado Sistema de Avaliação dos Hospitais Universitários (SAHU) - é um sistema coordenado pela Assessoria de Hospitais de Ensino do Gabinete da SES-SP e foi desenhado e desenvolvido pela Coordenadoria de Planejamento de Saúde (CPS) da Secretaria de Estado da Saúde de São Paulo (SES-SP) em 2005, com o objetivo de coletar eletronicamente dados de relatórios mensais e anuais de hospitais de ensino do Estado de São Paulo (SAHE, 2014).

No início de 2014 o SAHE contava com 45 hospitais de ensino certificados no Estado de São Paulo, sendo oito Hospitais Universitários (públicos), 26 Hospitais vinculados ou conveniados a Faculdades de Medicina (filantrópicos, organizações sociais, administração direta) e 11 Hospitais Especializados (filantrópicos, universitários, administração direta e associados à Universidade de São Paulo). Todos os HUs participantes da pesquisa de campo neste trabalho são HUs certificados pelo SAHE.

Um dos objetivos do SAHE é comparar os resultados dos indicadores entre os HUs para que estes e as secretarias regionais de saúde possam melhorar o ajuste das metas 
(SAHE, 2014). Esse sistema trabalha com indicadores de produtividade, qualidade, consumo e distribuição de funcionários por áreas (SAHE, 2009).

Os HUs participantes do SAHE também deveriam ter acesso, por meio do Observatório SAHE, aos resultados dos indicadores de produção, produtividade e qualidade de outras instituições, visando ajudar os HUs a comparar seus resultados entre eles (SAHE, 2014). Em relação à pesquisa e ensino nos HUs o sistema, no momento, é capaz apenas de quantificar as ações realizadas pelas instituições (SAHE, 2013).

É possível perceber que esse sistema é útil principalmente para os gestores do sistema de saúde, por poderem comparar os resultados entre diferentes instituições. Mas a comparação entre HUs também é útil para os gestores destes, aos poderem comparar os resultados entre si. Mas o SAHE aparentemente ainda necessita de ajustes, como a criação de indicadores para mensurar objetivos de ensino e pesquisa dos HUs.

\subsection{CQH - Compromisso com a qualidade hospitalar}

$\mathrm{O} \mathrm{CQH}$ é um programa relacionado a qualidade dos serviços hospitalares. A missão do $\mathrm{CQH}$ é "contribuir para a melhoria contínua da qualidade do atendimento nos serviços de saúde mediante metodologia específica" (CQH, 2014). O CQH é mantido pela Associação Paulista de Medicina e pelo Conselho Regional de Medicina do Estado de São Paulo e conta também com o apoio de outras instituições. Atualmente o programa abrange aproximadamente 200 insituições hospitalares, sendo a maioria situada no estado de São Paulo.

Em sua estrutura o $\mathrm{CQH}$ é bem semelhante a outras metodologias de avaliação de desempenho organizacional. Ela utiliza vários tipos de indicadores separados em critérios para mensurar o desempenho organizacional das insituições seladas. A representação gráfica do modelo pode ser vista na Figura 4: 


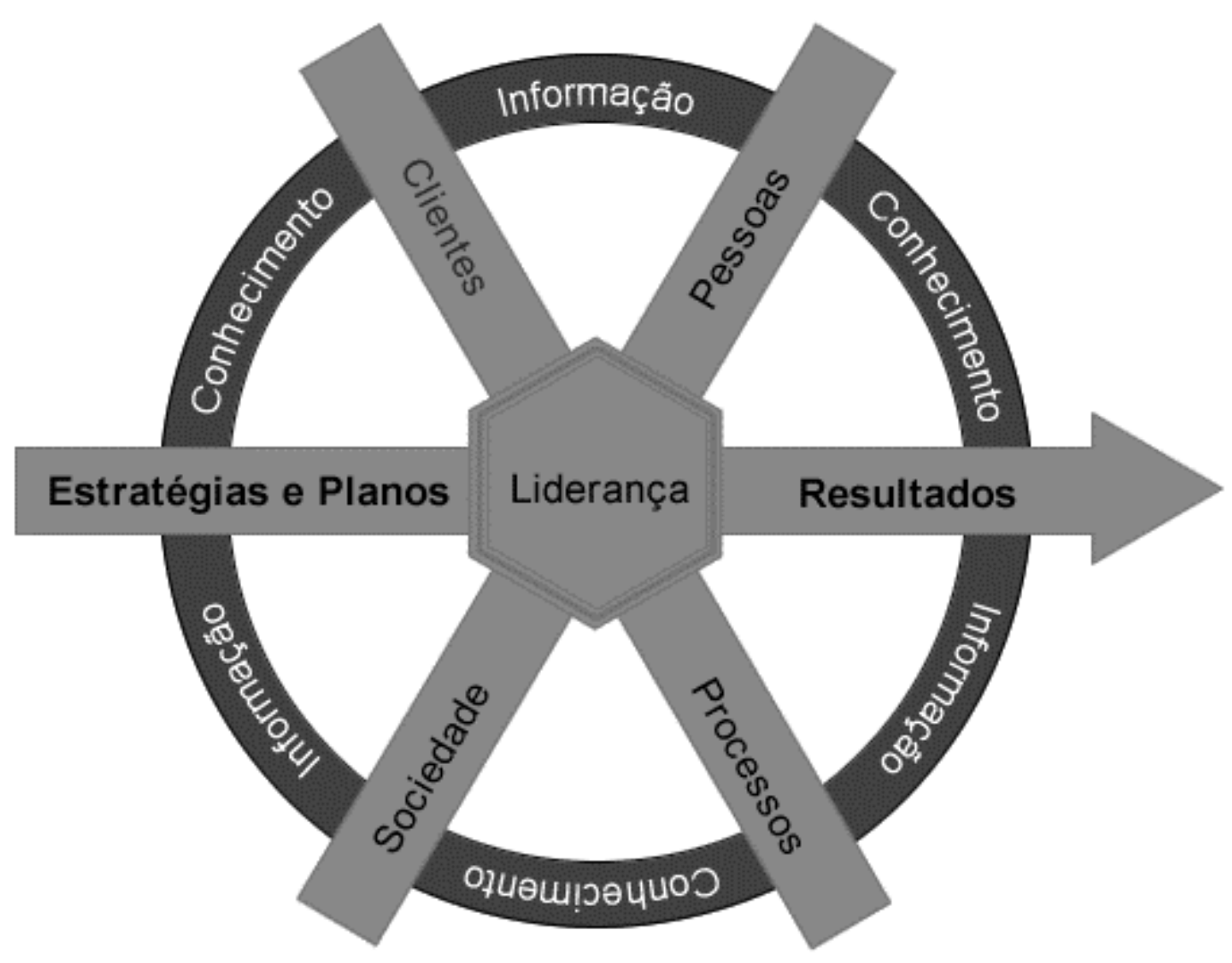

Figura 4 - Modelo CQH

Fonte: Compromisso com a Qualidade Hospitalar, 2014.

Cada critério busca avaliar o desempenho em um aspecto diferente da instituição. O critério Estratégias e Planos examina o processo de formulação e implementação das estratégias, definição de indicadores, desdobramento das metas e planos para as áreas e o acompanhamento dos ambientes internos e externos (CQH, 2014).

O critério Informação examina a gestão das informações na instituição (internas e comparativas) e também a gestão dos ativos intangíveis. O critério Clientes levanta como a organização trata dos aspectos relacionados aos clientes e ao mercado, como segmentação de mercado, divulgação, satistação, expectativas e necessidades dos clientes (CQH, 2014).

O critério Sociedade avalia o cumprimento das responsabilidades sociais e ambientais da organização, como a realização ou apoio a projetos sociais. $\mathrm{O}$ critério Processos relaciona-se aos principais processos do negócio. O cirtério Pessoas relaciona-se a organização do trabalho na organização e aos processos de seleção, capacitação e 
desemvolvimento de pessoas. O último critério, o de Resultados, trata dos resultados relevantes para a organização como econômicos - financeiros, clientes e mercados, sociedade, pessoas, processos do negócio, de apoio e de relacionamento com fornecedores (CQH, 2014). 


\section{METODOLOGIA}

Pesquisa baseia-se na resolução de problemas por meio do método científico. Partindo de um problema ou dúvida, emprega-se um método para tentar encontrar uma solução (CERVO; BERVIAN, 1996). Nas ciências sociais a pesquisa busca adquirir novos conhecimentos sobre o ser humano e seus múltiplos relacionamentos com outros seres humanos e instituições (GIL, 1999).

Este capítulo descreve a natureza e tipo de pesquisa realizada, o método, o universo da pesquisa, a definição do caso e das variáveis, as estratégias e instrumentos de coleta de dados e as limitações do método. Como apresentado anteriormente, os objetivos deste trabalho são: 1) verificar se existe um sistema de avaliação de desempenho organizacional no hospital universitário estudado; 2) identificar as características da avaliação de desempenho organizacional; 3) identificar os benefícios trazidos pelo uso de avaliação de desempenho organizacional; 4) identificar as dificuldades enfrentadas pela avaliação de desempenho organizacional.

\subsection{Natureza da pesquisa}

A natureza da pesquisa, também chamada de abordagem, enfoque ou método, pode ser dividida em duas grandes classificações: pesquisas quantitativas e pesquisas qualitativas. A classificação de uma pesquisa em qualitativa ou quantitativa depende das características do problema de pesquisa (RICHARDSON, 1999).

Num primeiro momento pode-se diferenciar a pesquisa quantitativa da qualitativa pelo modo como os métodos estatísticos são utilizados. Normalmente, na pesquisa quantitativa, o instrumental estatístico é base do processo de análise do problema (RICHARDSON, 1999). Já a pesquisa qualitativa relaciona-se muito mais com os significados que as pessoas dão para um determinado fenômeno (DENZIN; LINCOLN, 2008). Dentro dessa classificação o presente trabalho caracteriza-se como uma pesquisa qualitativa. 


\subsection{Tipo de pesquisa}

Existem basicamente três tipos de pesquisas: estudos exploratórios, estudos experimentais (também chamados de estudos explicativos) e estudos descritivos (TRIVIÑOS, 2008). Cada abordagem exige diferentes enfoques e níveis aprofundamento, dependendo do objeto estudado, dos objetivos da pesquisa e das qualificações do pesquisador (CERVO; BERVIAN, 1996).

A pesquisa descritiva observa, registra, analisa e correlaciona fatos ou fenômenos (variáveis) sem manipulá-los. O objetivo das pesquisas descritivas é descobrir, com o maior nível de exatidão possível, a frequência, as características, a natureza de um fenômeno e sua relação e/ou conexão com outros (CERVO; BERVIAN; SILVA, 1996).

Já na pesquisa experimental o pesquisador manipula diretamente as variáveis relacionadas ao objeto de estudo, com o objetivo de estudar as causas e efeitos de um fenômeno (CERVO; BERVIAN, 1996) a preocupação principal é identificar o que contribui ou determina a sua ocorrência (GIL, 1999).

Por último, nos estudos exploratórios o objetivo é aprofundar o conhecimento sobre um tema ou problema pouco estudado (SAMPIERI; COLLADO; LUCIO, 2006) esses estudos permitem aumentar a experiência do pesquisador em relação ao problema (TRIVIÑOS, 2008). O presente trabalho é um estudo exploratório, pois visa ampliar o conhecimento a respeito de como é realizada a avaliação de desempenho nos HUs.

\subsection{Método}

Em uma definição ampla método de pesquisa é a ordem em que determinados procedimentos são realizados para atingir um resultado (CERVO; BERVIAN, 1996).

Para selecionar um método (também chamado de delineamento ou estratégia de pesquisa) três condições devem ser consideradas: (a) o tipo de pesquisa, (b) a extensão de controle que o pesquisador tem sobre os eventos, (c) o grau de enfoque em acontecimentos históricos e/ou contemporâneos (YIN, 2010). 
O método selecionado para este trabalho foi o estudo de caso. Questões do tipo 'como' e 'por que' geralmente levam ao uso de estudos de caso, o qual é preferível para estudar eventos contemporâneos que não podem ser manipulados e onde os limites entre fenômeno e contexto não estão claramente definidos. O estudo de caso é utilizado nessas ocasiões por permitir que o pesquisador retenha as características holísticas dos eventos (YIN, 2010). Outras características dos estudos de casos são:

- Existência de muitas variáveis de interesse;

- Utilizar múltiplas fontes de evidência, sendo necessária a triangulação;

- Utilizar a teoria como base para as proposições e para orientar a coleta e análise de dados (YIN, 2010).

Além de apresentar essas características os estudos de caso podem ser divididos em estudos de casos único e múltiplo, ambos podendo ser holísticos ou integrados (YIN, 2010). Neste trabalho foi realizada uma pesquisa do tipo exploratória por meio do método de estudo de caso único.

\subsection{Universo da pesquisa}

Neste trabalho serão pesquisados os hospitais universitários públicos do Brasil (federais, estaduais e municipais), devendo estes estar cadastrados no CNES como hospitais de ensino, o Brasil possui 190 hospitais de ensino (CNES, 2014).

Dentro desse universo o Hospital das Clínicas da Faculdade de Medicina de Ribeirão Preto - HCFMRP-USP foi selecionados devido a sua grande capacidade de atendimento e facilidade de acesso do pesquisador.

\subsection{Definição do caso}

O caso para esta pesquisa foi selecionado por conveniência. Esse tipo de seleção é a mais simples, onde o pesquisador escolhe os casos ou o caso para estudo de acordo com o acesso que possui (YIN, 2010). Para a pesquisa foi escolhido um hospital universitário 
pertencente a uma universidade estadual: o Hospital das Clínicas da Faculdade de Medicina de Ribeirão Preto - HCFMRP-USP.

Para a escolha do caso foram utilizados alguns critérios: 1) estar listado no CNES (2014) como hospital de ensino e pertencer a uma instituição de ensino superior municipal, estadual ou federal; 2) autorização da pesquisa via Plataforma Brasil e pelo comitê de ética em pesquisa da instituição em tempo hábil; 3) acessível ao pesquisador.

Um dos requisitos para estudar esta organização foi a aprovação da pesquisa pelo comitê de ética da instituição, bem como o anonimato dos respondentes.

\subsection{Definição das variáveis}

Variáveis são características observáveis de um fenômeno. Na pesquisa qualitativa as variáveis são descritas e na pesquisa quantitativa as variáveis são medidas (TRIVIÑOS, 1987). Variáveis apresentam duas características fundamentais: (a) são aspectos observáveis de um fenômeno; (b) apresentam variações ou diferenças em relação ao mesmo ou a outros fenômenos (RICHARDSON, 1999).

No Quadro 5 estão relacionados os grupos de variáveis levantadas, os aspectos de avaliação considerados e os autores consultados para este trabalho:

Quadro 5 - Aspectos considerados, grupos de variáveis e autores

\begin{tabular}{|c|c|c|}
\hline Grupo de Variáveis & Aspecto Considerado & Autores \\
\hline \multirow[t]{3}{*}{$\begin{array}{l}\text { Avaliação de } \\
\text { Desempenho } \\
\text { Organizacional }\end{array}$} & $\begin{array}{l}\text { Uso do Sistema de avaliação de } \\
\text { desempenho organizacional }\end{array}$ & $\begin{array}{l}\text { CORREA, 1986, KAPLAN; NORTON, } \\
\text { 1992, EDVINSSON; MALONE, 1998, } \\
\text { ADAMS; NEELY, } 2000 .\end{array}$ \\
\hline & $\begin{array}{l}\text { Uso de indicadores de avaliação } \\
\text { de desempenho isolados }\end{array}$ & NEELY; GREGORY; PLATTS, 2005 \\
\hline & $\begin{array}{c}\text { Objetivos da realização de } \\
\text { avaliação de desempenho } \\
\text { organizacional }\end{array}$ & $\begin{array}{lr}\text { KAPLAN; NORTON, } & \text { 1992, EDDY, 1998, } \\
\text { GRIGOROUDIS; } & \text { ORFANOUDAKI; } \\
\text { ZOPOUNIDIS, 2012. } & \end{array}$ \\
\hline \multirow{3}{*}{$\begin{array}{l}\text { Indicadores de } \\
\text { Avaliação de } \\
\text { Desempenho } \\
\text { Organizacional }\end{array}$} & $\begin{array}{l}\text { Uso de indicadores-chave de } \\
\text { avaliação de desempenho }\end{array}$ & 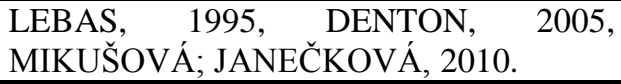 \\
\hline & $\begin{array}{c}\text { Relação entre indicadores e } \\
\text { objetivos organizacionais }\end{array}$ & $\begin{array}{l}\text { EDDY, 1998, KAPLAN; NORTON, 1992, } \\
\text { SELF, } 2004 .\end{array}$ \\
\hline & $\begin{array}{l}\text { Participação dos setores na } \\
\text { elaboração e revisão dos } \\
\text { indicadores }\end{array}$ & $\begin{array}{lcc}\text { LEBAS, } & 1995, \quad \text { EDDY, } & 1998, \\
\text { ONDATEGUI-PARRA, et al., } 2004 . & \end{array}$ \\
\hline
\end{tabular}




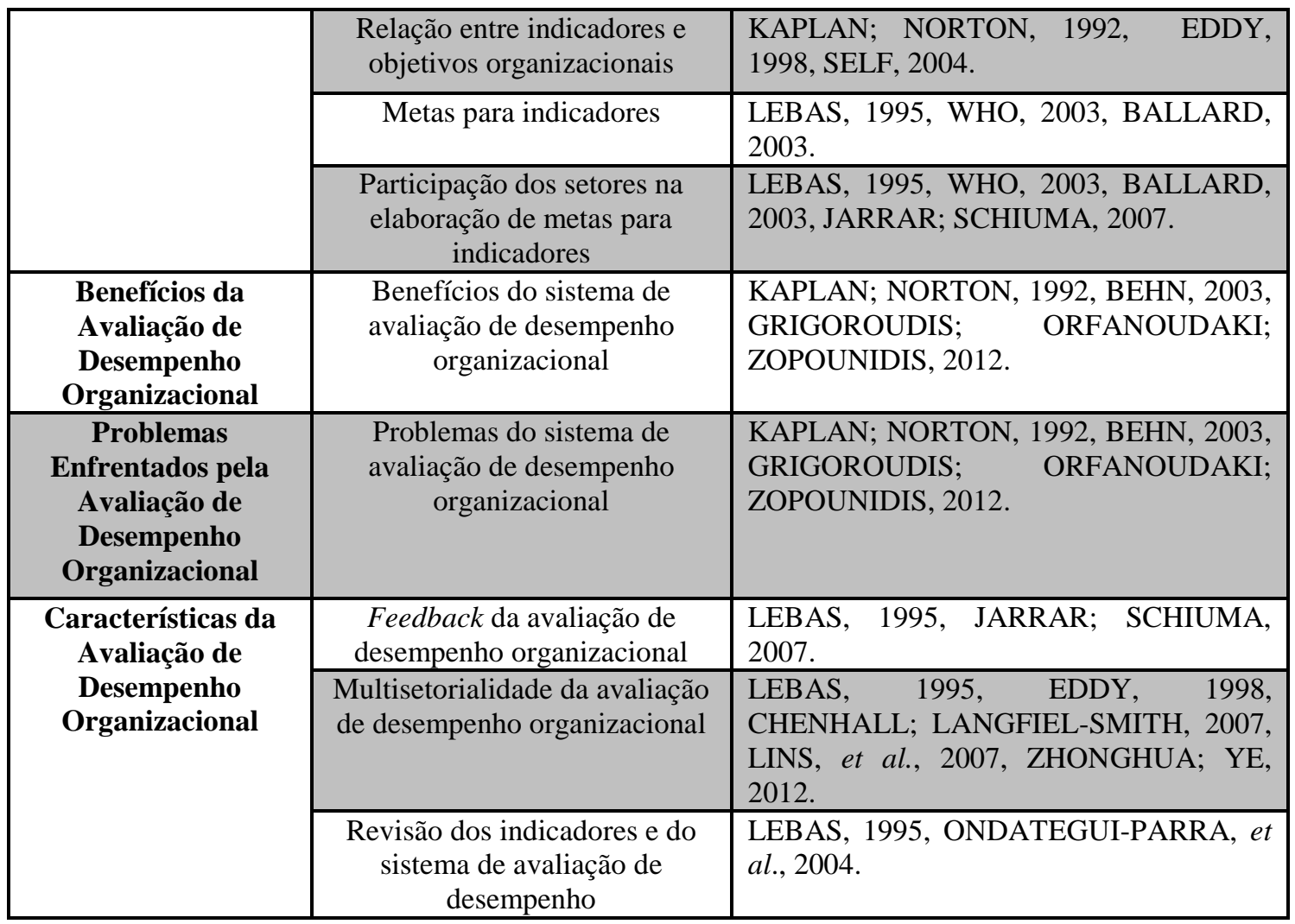

Nem todos os aspectos considerados nesta seção estão presentes no roteiro de entrevista. Isso ocorre porque muitas informações foram obtidas por meio da pesquisa documental e da triangulação de dados.

A pesquisa documental concentrou-se em levantar listas de indicadores e as práticas de avaliação registradas pela instituição estudada. A entrevista buscou levantar as impressões do gestor quanto à avaliação e outros aspectos não registrados, como as barreiras e problemas relacionados à avaliação.

\subsection{Coleta de dados}

Uma das características marcantes do estudo de caso é o uso de múltiplas fontes de evidência, isso permite ao pesquisador visualizar uma variação maior de aspectos históricos e comportamentais. Mas a maior contribuição deste processo é a convergência dos resultados de diversas fontes. Um resultado é considerado mais acurado se for baseado em mais de uma fonte de evidência (YIN, 2010).

O processo de convergir dados de mais de uma fonte é chamado de triangulação de dados. A triangulação colabora com a validade do constructo, pois apresenta várias 
avaliações do mesmo fenômeno (YIN, 2010) e ajuda a ter um entendimento mais profundo do fenômeno estudado (DENZIN; LINCOLN, 2008). O presente trabalho utilizará três fontes de dados: documentos de circulação livre e outras informações disponíveis no website da instituição em estudo; documentos de circulação interna fornecidos pela organização; entrevista com gestor da organização.

Os documentos utilizados como fonte de dados foram: o relatório de atividades 2013 do HCFMRP-USP, os resultados CQH (Compromisso com a Qualidade Hospitalar) 2013, a planilha de metas para indicadores 2013 e o quadro de propostas de indicadores 2014 .

Os documentos foram utilizados principalmente para corroborar e ampliar as evidências provenientes da entrevista. $\mathrm{O}$ uso de documentos também serve proporcionar outros detalhes e melhorar a qualidade da informação de outras fontes (YIN, 2010).

Por meio da entrevista em profundidade o pesquisador pode acessar informações que, de outro modo, ficariam inacessíveis, como experiências pessoais e atitudes (DENZIN; LINCOLN; 2008), a entrevista também é um modo de obter dados que não podem ser encontrados em registros e fontes documentais, mas podem ser fornecidos por determinados indivíduos (CERVO; BERVIAN; SILVA, 1996). Neste trabalho a entrevista serviu principalmente para levantar as impressões do gestor sobre a avaliação de desempenho e aspectos práticos (como assuntos discutidos em reuniões) que não estão registrados em outros meios.

O estilo aberto desse tipo de técnica de coleta de dados permite que seja obtida uma grande riqueza de informações (GODOI; BANDEIRA-DE-MELO; SILVA, 2006). A entrevista foi realizada com um profissional da média gerência do HU pesquisado, que participa diretamente do processo de avaliação de desempenho da instituição.

Na primeira parte do instrumento, que é composto principalmente de perguntas abertas, estão questões referentes às características do respondente, como pode ser visto no Quadro 6: 
Quadro 6 - Características do respondente

\begin{tabular}{|c|c|c|c|c|}
\hline \multicolumn{5}{|c|}{ Características do Respondente } \\
\hline Nível hierárquico na organização & & & & \\
\hline Área de atuação dentro da organização & & & & \\
\hline Tempo no setor & & & & \\
\hline Formação & & & & \\
\hline Escolaridade & \begin{tabular}{l|l} 
Graduação & Pós-graduação
\end{tabular} & Mestre & Doutor & Pós-doutor \\
\hline
\end{tabular}

A segunda parte é composta apenas de questões abertas, as quais foram elaboradas de acordo com os objetivos da pesquisa e a literatura consultada. O objetivo desta parte do instrumento é levantar informações sobre as características da avaliação de desempenho na organização estudada e as impressões do entrevistado sobre as práticas de ADO na organização a qual pertence. A relação entre as questões do instrumento de coleta de dados e os objetivos de pesquisa pode ser vista no Quadro 7:

Quadro 7 - Instrumento de coleta de dados versus objetivos da pesquisa

\begin{tabular}{|c|c|}
\hline \multicolumn{2}{|r|}{ Tema 1 - Avaliação de desempenho organizacional } \\
\hline 1 & $\begin{array}{l}\text { O sistema de avaliação de desempenho utilizado abrange todas as áreas do Hospital } \\
\text { Universitário? Quais setores fazem parte e quais não? }\end{array}$ \\
\hline 2 & $\begin{array}{l}\text { Qual a relação entre avaliação de desempenho organizacional e o planejamento estratégico da } \\
\text { organização? }\end{array}$ \\
\hline 3 & As áreas recebem feedbacks sobre seus resultados na avaliação? \\
\hline 4 & Se sim, como é realizado esse feedback? \\
\hline 5 & $\begin{array}{l}\text { Como é a divisão entre ensino, pesquisa, extensão e atendimento em termos de avaliação de } \\
\text { desempenho organizacional? Elas são avaliadas separadamente ou em conjunto? }\end{array}$ \\
\hline 6 & $\begin{array}{l}\text { O hospital universitário compara seus resultados (ensino, pesquisa e atendimento) com os de } \\
\text { outras instituições? }\end{array}$ \\
\hline \multicolumn{2}{|r|}{ Tema 2 - Benefícios e problemas da avaliação de desempenho organizacional } \\
\hline 7 & $\begin{array}{l}\text { Quais são os principais benefícios trazidos pelo sistema de avaliação de desempenho } \\
\text { organizacional para o Hospital Universitário? }\end{array}$ \\
\hline 8 & $\begin{array}{l}\text { Quais são os principais problemas e/ou dificuldades que a avaliação de desempenho enfrenta na } \\
\text { organização? }\end{array}$ \\
\hline \multicolumn{2}{|r|}{ Tema 3 - Indicadores de avaliação de desempenho organizacional } \\
\hline 9 & $\begin{array}{l}\text { Quais são os principais indicadores de desempenho (os mais importantes) utilizados pelo hospital } \\
\text { universitário? }\end{array}$ \\
\hline 10 & $\begin{array}{l}\text { Como é realizada a revisão do sistema de avaliação de desempenho organizacional e dos } \\
\text { indicadores? }\end{array}$ \\
\hline 11 & $\begin{array}{l}\text { Com que frequência o sistema de avaliação de desempenho organizacional e os indicadores são } \\
\text { revistos? }\end{array}$ \\
\hline 12 & $\begin{array}{l}\text { Existe um bom alinhamento entre os objetivos organizacionais e indicadores de avaliação e } \\
\text { desempenho? Existem indicadores diretamente relacionados a cada objetivo? }\end{array}$ \\
\hline 13 & $\begin{array}{l}\text { O Hospital Universitário utilizava algum tipo de indicador anteriormente ao início da implantação } \\
\text { do sistema de avaliação de desempenho organizacional? }\end{array}$ \\
\hline
\end{tabular}




\begin{tabular}{|r|l|}
\hline $\mathbf{1 4}$ & Existem metas para os indicadores de avaliação de desempenho organizacional? \\
\hline $\mathbf{1 5}$ & As áreas participantes da avaliação de desempenho organizacional têm metas separadas? \\
\hline $\mathbf{1 6}$ & $\begin{array}{l}\text { Qual a participação dos setores na elaboração e revisão das metas de avaliação de desempenho } \\
\text { organizacional? }\end{array}$ \\
\hline
\end{tabular}

O modo como o conteúdo da entrevista é registrado também tem influência na qualidade e detalhamento dos dados (GODOI; BANDEIRA-DE-MELO; SILVA, 2006). Por esse motivo, com autorização do entrevistado, a entrevistas foi gravada e posteriormente transcrita.

Outro dos requisitos para o estudo de caso é o uso do protocolo, qual ajuda a garantir a uniformidade da coleta de dados nos casos (YIN, 2010).

Adaptado de Yin (2010) o protocolo a ser utilizado neste estudo de caso contém:

I. Visão geral do projeto de estudo de caso: objetivos e assunto do estudo;

II. Procedimentos de campo: apresentação de credenciais, acesso aos locais, termos de consentimento e fontes de dados;

III. Questões do estudo de caso: questões para a coleta de dados, planilha para dados específicos e potenciais fontes de dados;

IV. Guia para o relatório do estudo de caso: esboço, formato dos dados e outras informações.

Neste trabalho todas essas condições do protocolo foram cumpridas, destaca-se que o uso de um protocolo e apresentação prévia do projeto de pesquisa é exigência do comitê de ética da instituição participante. Outra exigência foi o cadastro do projeto na Plataforma Brasil (PLATAFORMA BRASIL, 2014).

\subsection{Pré-teste do instrumento de coleta de dados}

O pré-teste ou estudo preliminar teve como objetivo verificar a adequação das perguntas. Também são funções do pré-teste encontrar perguntas que possam conter ambiguidades, pedir informações de caráter muito pessoal, solicitar informações desconhecidas, convidar a uma resposta socialmente desejável, ter uma gama de 
respostas muito restrita, apresentar respostas alternativas inadequadas, entre outros (HILL; HILL 2008).

Neste estudo o pré-teste foi realizado com um gestor de um hospital de ensino. O participante do pré-teste foi entregvistado pelo pesquisador e assim que a entrevista foi finalizada o entrevistado questionado sobre possíveis dúvidas quanto às perguntas, inadequações do instrumento e outros comentários sobre o instrumento. O instrumento de pesquisa foi ajustado e aplicado ao entrevistado participante da pesquisa.

\subsection{Análise de dados}

O processo de análise de dados visa extrair o sentido dos dados recolhidos (CRESWELL, 2007). A metodologia de análise de dados utilizada neste trabalho foi a análise de conteúdo. Ela assume que a mensagem contida num texto pode ser compreendida por meio da fragmentação do texto em palavras, termos ou frases menores e mais simples (CHIZZOTI, 2006).

Neste trabalho, a análise de dados foi realizada seguindo os passos sugeridos por Creswell (2007):

1) Organização e preparação dos dados: transcrição das entrevistas, leitura superficial do material, classificação e organização dos dados;

2) Leitura de todos os dados: obtenção de um sentido geral dos dados, identificação das informações principais, registro das primeiras considerações gerais do pesquisador;

3) Início da análise detalhada e codificação: organização dos materiais em grupos e criação de categorias;

4) Descrição: separação dos temas de acordo com a codificação e análise dos temas nos casos; 
5) Representação: elaboração de passagens e tabelas para representar as descrições dos casos;

6) Interpretação final e extração dos significados: comparação dos resultados com a teoria e levantamento de novas questões.

As categorias criadas para agrupar os termos, palavras ou frases (passo 3) foram criadas de acordo com os objetivos da pesquisa e da particularidade dos dados (CHIZZOTI, 2006).

\subsection{Limitações}

Uma das limitações deste trabalho é não permitir generalizações estatísticas e sua grande dependência das habilidades do pesquisador (YIN, 2010). Outra limitação é o anonimato dos respondentes. Apesar de não preferível o anonimato é aceitável, por exemplo, para proteger o caso real e seus respondentes (YIN, 2010). O anonimato dos respondentes foi um dos requisitos para a aprovação da pesquisa pelo comitê de ética da instituição estudada. Além disso, por ser um estudo de caso único, os resultados encontrados são considerados menos robustos que os de estudos de casos múltiplos (YIN, 2010). 


\section{DESCRIÇÃO E ANÁLISE DOS RESULTADOS}

Neste capítulo são apresentados e discutidos os resultados obtidos após a realização da pesquisa descrita na metodologia.

\subsection{Processo de seleção do caso}

Por este trabalho estudar a avaliação de desempenho organizacional em hospitais universitários, que são instituições de saúde, a pesquisa teve de passar por todos os processos burocráticos necessários a uma pesquisa com seres humanos. Ainda que o único contato da pesquisa com seres humanos seriam entrevistas com gestores quanto às práticas de avaliação de desempenho nos hospitais estudados.

Inicialmente para a pesquisa de campo foram selecionados três hospitais universitários do Estado de São Paulo. Sendo estes:

- Hospital São Paulo - Hospital Universitário da Universidade Federal de São Paulo - UNIFESP;

- Hospital Universitário da Universidade de São Paulo - USP;

- Hospital das Clínicas da Faculdade de Medicina de Ribeirão Preto (HCFMRPUSP).

Para a realização da pesquisa com esses HUs foi necessário o preenchimento/elaboração de uma série de documentos e autorizações, como: termo de consentimento livre e esclarecido, convite de participação na pesquisa, assinatura da folha de rosto pelo diretor da faculdade, autorização da coordenadoria de ensino e pesquisa, cronograma de execução, declaração de compromisso do pesquisador responsável, declaração de benefícios resultantes da pesquisa, cadastro do protocolo de pesquisa, orçamento financeiro, entre outros.

Também foi necessário o cadastro do projeto de pesquisa na Plataforma Brasil e a aprovação do projeto pelo comitê de ética em pesquisa de cada uma das instituições 
participantes (somente a aprovação leva entre 15 e 30 dias, de acordo com a instituição). Processos os quais geralmente não são aplicados às pesquisas na área de administração.

Inicialmente o projeto de pesquisa não foi aprovado para execução no Hospital São Paulo por falta de documentação, posteriormente os documentos necessários foram enviados pelo pesquisador. Porém a Plataforma Brasil, devido a uma característica do sistema, impede que o pesquisador inclua novamente essa instituição como parte da pesquisa. Após várias tentativas de contato com o suporte da Plataforma Brasil via Atendimento Telefônico (o número não existe) e via Atendimento online (os atendentes estão sempre todos ocupados ou a pagina está fora do ar), o pesquisador entrou em contato via e-mail. Foi aberto um chamado para possível resolução do problema, contudo devido ao grande período de tempo necessário, sem que fosse encontrada uma solução, não foi possível aguardar e o Hospital São Paulo não pôde fazer parte deste trabalho.

Já no Hospital Universitário da Universidade de São Paulo (HU-USP) a pesquisa foi aprovada pelo comitê de ética em pesquisa da instituição, o que era requisito obrigatório para realização da pesquisa nos outros hospitais, e a entrevista com um gestor foi realizada. Porém a pesquisa documental não pôde ser concluída, devido ao fato de que o HU-USP entrou em greve durante a execução do trabalho. Isso impossibilitou a conclusão da coleta de dados, então o HU-USP também teve de ser excluído desta pesquisa.

O Hospital das Clínicas da Faculdade de Medicina de Ribeirão Preto (HCFMRP-USP) foi a única, entre as três instituições, em que a pesquisa foi aprovada pelo comitê de ética e a coleta de dados concluída. Sendo assim o HCFMRP-USP foi o objeto de estudo deste trabalho.

\subsection{Hospital das Clínicas da Faculdade de Medicina de Ribeirão Preto - USP}

O Hospital das Clínicas da Faculdade de Medicina de Ribeirão Preto (HCFMRP-USP) iniciou suas atividades em junho de 1956. Ele é uma autarquia pública estadual 
vinculada administrativamente à Secretaria de Estado da Saúde de São Paulo e associado à Universidade de São Paulo para fins de Ensino, Pesquisa e prestação de serviços médico-hospitalares. Regulamentado pelo Decreto $\mathrm{n}^{\circ}$. 13.297 de 05 de março de 1979, desde 1988 o hospital está integrado ao Sistema Único de Saúde - SUS (HCFMRP-USP, 2013).

O complexo do HCFMRP-USP dispõe de três prédios: o HC-Campus, o Hemocentro (ambos situados no Campus Universitário de Ribeirão Preto - SP) e a Unidade de Emergência - UE (no centro de Ribeirão Preto - SP). A instituição tem como principais atividades proporcionar Assistência Médico Hospitalar e servir de campo de Ensino e de Pesquisa, na área da saúde. Sua missão é "Desenvolver e praticar assistência, ensino e pesquisa em saúde, por meio da busca permanente da excelência, melhoria da qualidade de vida da população" (HCFMRP-USP, 2013).

Ele é considerado um hospital de grande porte, alta complexidade e referência terciária para a região nordeste do Estado de São Paulo. Ele realiza diariamente cerca de 2500 consultas, 60 cirurgias, 90 internações, 6 mil exames laboratoriais, 2 mil exames especializados, 500 exames radiológicos, realiza em média 220 transfusões de sangue e fornece 9500 refeições. A instituição também está inserida no SUS como referência terciária/quaternária e os usuários do Sistema Único de Saúde representam cerca de 95\% dos atendimentos realizados. Apesar de ser uma instituição voltada para atendimentos de alta complexidade, devido à carência regional de serviços de saúde, muitas vezes ocupa grande parte de sua capacidade com atendimentos de média complexidade (HCFMRP-USP, 2013).

Em 2013 o HCFMRP-USP possuía 4. 668 servidores contratados por processo seletivo, 1.105 servidores contratados pela FAEPA (Fundação de Apoio ao Ensino, Pesquisa e Assistência do HCFMRP-USP), totalizando 5.773 funcionários. Esta força de trabalho é representada por $8,18 \%$ servidores de nível básico, 42,84\% de nível médio e 48,98\% de nível superior (HCFMRP-USP, 2013).

Os cargos de confiança (diretores, assistentes, chefes e encarregados) representam $8,71 \%$. Quanto às categorias profissionais, o quadro de pessoal é composto, percentualmente, por: $37,74 \%$ enfermagem, 10,67\% médicos, 8,85\% técnicos, 19,07\% 
administrativo e 23,66\% operacional. O hospital conta também com serviços terceirizados, tais como: limpeza hospitalar, lavagem de roupa, vigilância, serviço de manutenção de elevadores e serviço de manutenção de equipamentos médicohospitalares (HCFMRP-USP, 2013).

O HCFMRP-USP mantém um estreito relacionamento com a FAEPA. A fundação gerencia os recursos do faturamento SUS, convênios com agências públicas de fomento à pesquisa científica, entre outros. Ela é uma entidade anexa HCFMRP-USP, de caráter privado, sem fins lucrativos e com autonomia administrativa e financeira. Seu objetivo principal é oferecer financiamento para atividades de ensino, pesquisa e assistência a instituições educacionais, principalmente o HCFMRP-USP (FAEPA, 2014).

\subsubsection{Assistência no HCFMRP-USP}

O HCFMRP-USP oferece assistência à saúde para toda região de Ribeirão Preto em unidades ambulatoriais e hospitalares. Suas atividades abrangem cuidados de prevenção, tratamento e recuperação, de natureza clínica e/ou cirúrgicas, serviços complementares de diagnóstico e tratamento, nas especialidades: psiquiatria, pediatria, otorrinolaringologia, ortopedia, oftalmologia, neurologia, ginecologia/obstetrícia , genética, clínica médica, cirurgia de cabeça/pescoço e clínica cirúrgica.

A assistência é prestada por equipe multiprofissional que compreende: médicos, pessoal de enfermagem, psicólogos, fisioterapeutas, terapeutas ocupacionais, fonoaudiólogos, nutricionistas, assistentes sociais, dentre outras. Os principais produtos da assistência são: atendimento ambulatorial, atendimento de urgência e emergência, internações, hospital-dia, cirurgias, transplantes, exames auxiliares ao diagnóstico e ao tratamento, reabilitação física, motora e sensório-motora.

\subsubsection{Ensino e pesquisa}

Na área de ensino o HCFMRP-USP oferece residência médica e multiprofissional, aprimoramento profissional, estágio de capacitação em serviços diversos na área da saúde, cursos profissionalizantes na área da saúde, ensino à distância, pós-graduação 
nos níveis de mestrado e doutorado, local de estágio para os alunos dos cursos de medicina, enfermagem, terapia ocupacional, fisioterapia, nutrição, fonoaudiologia e informática biomédica da USP de Ribeirão Preto e da Faculdade de Ciências Farmacêuticas de Ribeirão Preto. A Tabela 1 contém o número de alunos de estágio do HCFMRP-USP:

Tabela 1 - Estágios oferecidos para estudantes de graduação e pós-graduação em 2013

\begin{tabular}{|l|l|}
\hline Graduação & Número de Alunos \\
\hline Medicina & 600 \\
\hline Enfermagem & 410 \\
\hline Fisioterapia & 200 \\
\hline Fonoaudiologia & 120 \\
\hline Informática Biomédica & 160 \\
\hline Nutrição e Metabolismo & 150 \\
\hline Terapia Ocupacional & 100 \\
\hline Pós-Graduação & Número de Alunos \\
\hline Medicina & 990 \\
\hline Enfermagem & 30 \\
\hline
\end{tabular}

Na Tabela 2 são apresentados o número de programas de residência médica e aprimoramento do HCFMRP-USP:

Tabela 2 - Programas de residência médica e aprimoramento em 2013

\begin{tabular}{|l|l|}
\hline Residência Médica & Valores \\
\hline $\mathbf{N}^{\circ}$. de Programas & 63 \\
\hline $\mathbf{N}^{\circ}$. de Residentes & 670 \\
\hline $\mathbf{N}^{\circ}$ de Residentes Multiprofissionais & 27 \\
\hline Aprimoramento & Valores \\
\hline $\mathbf{N}^{\circ}$. de Programas & 24 \\
\hline $\mathbf{N}^{\circ}$. de Alunos & 82 \\
\hline
\end{tabular}

No que se refere à pesquisa, em 2013 foram aprovados 394 projetos, pelo comitê de ética em pesquisa. Os principais produtos das pesquisas são: conhecimento gerado a partir das pesquisas, formação e desenvolvimento de pesquisadores, publicações em periódicos científicos. Na Tabela 3 observa-se o número de trabalhos publicados por cada curso atendido pelo HCFMRP-USP: 
Tabela 3 - Trabalhos publicados em 2013

\begin{tabular}{|c|c|}
\hline Trabalhos publicados em periódicos & Número de Trabalhos \\
\hline $\begin{array}{l}\text { Medicina, Fisioterapia, Fonoaudiologia, Nutrição, } \\
\text { Ocupacional e Informática Biomédica }\end{array}$ & 811 \\
\hline Enfermagem (dados parciais) & 337 \\
\hline Trabalhos publicados anais de Congressos & Número de Trabalhos \\
\hline $\begin{array}{llll}\text { Medicina, Fisioterapia, } & \text { Fonoaudiologia, Nutrição, } & \text { Terapia } \\
\text { Ocupacional e Informática Biomédica }\end{array}$ & 673 \\
\hline Enfermagem (dados parciais) & 217 \\
\hline Dissertações de Mestrado & Número de Trabalhos \\
\hline $\begin{array}{llll}\text { Medicina, Fisioterapia, Fonoaudiologia, Nutrição, Terapia } \\
\text { Ocupacional e Informática Biomédica }\end{array}$ & 150 \\
\hline Enfermagem (dados parciais) & 72 \\
\hline Teses de Doutorado & Número de Trabalhos \\
\hline $\begin{array}{llll}\text { Medicina, Fisioterapia, Fonoaudiologia, Nutrição, } & \text { Terapia } \\
\text { Ocupacional e Informática Biomédica } & & \\
\end{array}$ & 110 \\
\hline Enfermagem (dados parciais) & 57 \\
\hline
\end{tabular}

\subsubsection{Estrutura Organizacional}

A alta administração do HCFMRP-USP é constituída pelo conselho deliberativo e superintendência. O conselho deliberativo (CD) é composto por 7 membros titulares, sendo o diretor da FMRP, 5 docentes da FMRP e um representante do quadro de pessoal do hospital, todos com direito a voto nas decisões institucionais alguns outros diretores e chefes de departamento também participam, mas sem direito a voto. $\mathrm{Na}$ Figura 5 pode ser visa a estrutura organizacional do HCFMRP-USP:

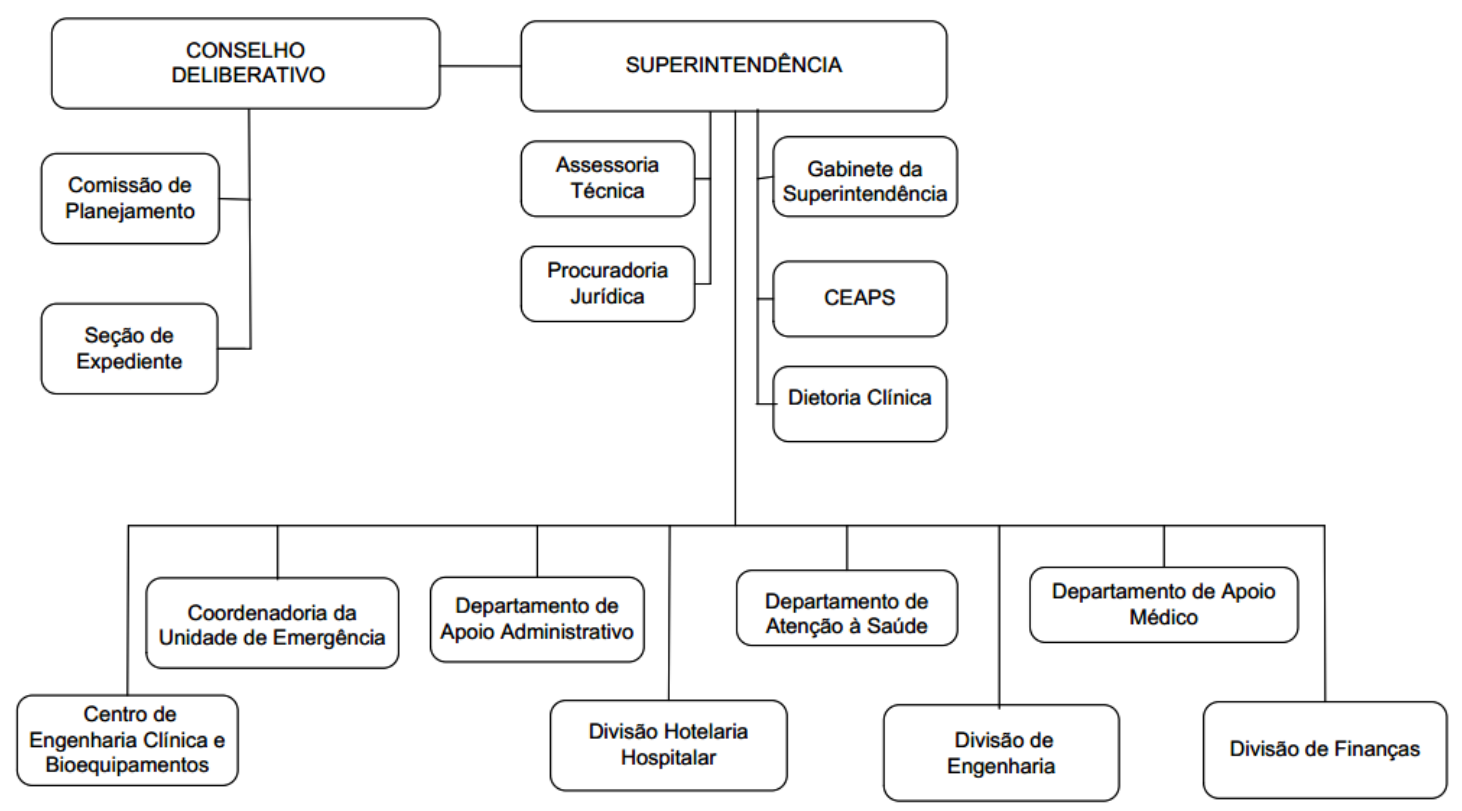

Figura 5 - Estrutura organizacional do HCFMRP-USP 


\subsubsection{Planejamento estratégico do HCFMRP-USP}

As estratégias do HCFMRP-USP são formalizadas no planejamento estratégico, geralmente elaborado com um horizonte de três anos com participação de representantes de todos os segmentos do hospital. O documento final do planejamento estratégico apresenta os planos de ação, com respectivas metas, indicadores de desempenho e cronograma para o atendimento dos objetivos traçados. Cada plano de ação conta com uma equipe e um coordenador responsável.

Esse sistema de plano de ação, metas e indicadores de desempenho utiliza o Balanced Scorecard (Kaplan; Norton, 1992) como base. Ele é dividido em cinco categorias e 17 perspectivas, sendo os objetivos ligados com cada perspectiva, como pode ser visto no Quadro 8:

Quadro 8 - Planejamento estratégico: categorias, perspectivas e objetivos

\begin{tabular}{|c|c|c|}
\hline Categoria & Perspectiva & Objetivos \\
\hline \multirow{13}{*}{ Atençãa à Saúde } & \multirow[t]{4}{*}{ Ambulatorial } & $\begin{array}{l}\text { 1. Revisar e planejar a ocupação do espaço físico dos } \\
\text { ambulatórios. }\end{array}$ \\
\hline & & $\begin{array}{l}\text { 2. Otimizar a ocupação dos espaços do Ambulatório } \\
\text { visando atender as necessidades internas e do sistema } \\
\text { de saúde, constituindo um fórum de discussão do } \\
\text { ambulatório. }\end{array}$ \\
\hline & & $\begin{array}{l}\text { 3. Melhorar os processos de atendimento no } \\
\text { Ambulatório. }\end{array}$ \\
\hline & & 4. Incrementar a relação com gestores do SUS. \\
\hline & \multirow[t]{6}{*}{ Cirúrgico } & 1. Adequar a climatização do Bloco Cirúrgico. \\
\hline & & $\begin{array}{l}\text { 2. Planejamento das atividades e estrutura física do } \\
\text { Centro Cirúrgico Ambulatorial. }\end{array}$ \\
\hline & & $\begin{array}{l}\text { 3. Priorizar os procedimentos cirúrgicos de alta } \\
\text { complexidade. }\end{array}$ \\
\hline & & 4. Reestruturar o serviço de anestesiologia. \\
\hline & & 5. Realizar e adequar a gestão da agenda cirúrgica. \\
\hline & & $\begin{array}{l}\text { 6. Adequação dos processos da patologia no centro } \\
\text { cirúrgico. }\end{array}$ \\
\hline & \multirow[t]{2}{*}{ Internação } & $\begin{array}{l}\text { 1. Criar áreas de internação com focos } \\
\text { multiprofissional e multidisciplinar (exemplo: } \\
\text { oncologia, transplantes, Moléstias Infecciosas, etc.) }\end{array}$ \\
\hline & & $\begin{array}{l}\text { 2. Otimizar a utilização dos leitos e aprimorar a } \\
\text { qualidade do atendimento }\end{array}$ \\
\hline & Urgência e Emergência & 1. Aprimorar o fluxo de pacientes de urgência e \\
\hline
\end{tabular}




\begin{tabular}{|c|c|c|}
\hline & & $\begin{array}{l}\text { emergência intra e interunidades do complexo do } \\
\text { HCFMRP-USP. }\end{array}$ \\
\hline & & $\begin{array}{l}\text { 2. Repor, ampliar e qualificar a equipe } \\
\text { multiprofissional de atendimento ao paciente de } \\
\text { Urgência e Emergência. }\end{array}$ \\
\hline & & $\begin{array}{l}\text { 3. Modernização e ampliação dos recursos de } \\
\text { diagnóstico e tratamento por imagem }\end{array}$ \\
\hline & & 4. Gerenciar a ocupação dos espaços/ enfermarias. \\
\hline & & $\begin{array}{l}\text { 5. Priorizar o atendimento, segurança e humanização da } \\
\text { Sala de Urgência da Unidade de Emergência. }\end{array}$ \\
\hline & & $\begin{array}{l}\text { 6. Criar um suporte para a regulação de pacientes em } \\
\text { seguimento com risco de intercorrências no HCFMRP- } \\
\text { USP. }\end{array}$ \\
\hline & SADT & 1. Otimizar os laudos de todas as áreas nos sistemas. \\
\hline & & $\begin{array}{l}\text { 2. Ampliação e atualização do parque tecnológico em } \\
\text { diagnostico por Imagem. }\end{array}$ \\
\hline & & $\begin{array}{l}\text { 3. Otimizar o Sistema de Coleta de Exames } \\
\text { Laboratoriais }\end{array}$ \\
\hline & CEAPS & $\begin{array}{l}\text { 1. Resgatar a vocação do CEAPS: divulgação de } \\
\text { conhecimento à comunidade interna e externa. }\end{array}$ \\
\hline & & $\begin{array}{l}\text { 2. Criar núcleo de telessaúde junto ao CEAPS, } \\
\text { integrado à FMRP-USP. }\end{array}$ \\
\hline Ensino e Pesquisa & $\begin{array}{l}\text { Residência, } \\
\text { Aprimoramento e Pós- } \\
\text { Graduação }\end{array}$ & $\begin{array}{l}\text { 1. Reforçar o papel de integração e gestão dos } \\
\text { programas de residência da Comissão de Residência } \\
\text { Médica e Comissão de Residência Multiprofissional. }\end{array}$ \\
\hline & & $\begin{array}{l}\text { 2. Regulamentação e fiscalização de profissionais sem } \\
\text { vinculo Consolidação das Leis do Trabalho atuando no } \\
\text { HCFMRP-USP. }\end{array}$ \\
\hline & & $\begin{array}{l}\text { 3. Criar mecanismos de flexibilidade para o } \\
\text { gerenciamento do financiamento das bolsas de } \\
\text { residência médica de acordo com a demanda do } \\
\text { mercado e da inserção dos programas no Complexo } \\
\text { HCFMRP-USP. }\end{array}$ \\
\hline & & $\begin{array}{l}\text { 4. Implementar novas modalidades de residência } \\
\text { multiprofissional de alta complexidade/pós graduação } \\
\text { em diversas áreas, como por exemplo: Gestão }\end{array}$ \\
\hline & & $\begin{array}{l}\text { 1. Reforçar as atividades de ensino em outros espaços } \\
\text { do Complexo HCFMRP-USP. }\end{array}$ \\
\hline & $\begin{array}{l}\text { Unidade de Pesquisa } \\
\text { Clínica }\end{array}$ & $\begin{array}{l}\text { 1. Adequação da estrutura da Unidade de Pesquisa } \\
\text { Clínica. }\end{array}$ \\
\hline & & $\begin{array}{l}2 \text { - Implantação de Núcleos Satélite de Apoio de } \\
\text { Pesquisa Clínica no complexo Hospitalar. }\end{array}$ \\
\hline & & 3- Ampliar a captação de projetos de pesquisa. \\
\hline & $\begin{array}{l}\text { Faculdade de Medicina } \\
\text { de Ribeirão Preto }\end{array}$ & $\begin{array}{l}01 \text { - Articulação das pesquisas das áreas básicas e } \\
\text { clínicas visando o aumento na captação de recursos } \\
\text { através de projetos institucionais e interinstitucionais, } \\
\text { ligados ao SUS. }\end{array}$ \\
\hline Comunid & des e Clientes & $\begin{array}{l}\text { 1. Ampliar as ações ambientais desenvolvidas no } \\
\text { HCFMRP-USP e disponibilizar para demais unidades } \\
\text { do Complexo. }\end{array}$ \\
\hline & & 2. Estabelecer comunicação eficaz com a comunidade. \\
\hline & & $\begin{array}{l}\text { 3. Articular a integração deste Hospital com as diversas } \\
\text { associações e grupos de apoio visando a divulgação de } \\
\text { informações e reintegração do paciente à sociedade. }\end{array}$ \\
\hline & & 4. Campanhas educativas de prevenção. \\
\hline & & $\begin{array}{l}\text { 5. Criar serviço de acolhimento ao paciente no ato da } \\
\text { internação n a Unidade Campus. }\end{array}$ \\
\hline
\end{tabular}




\begin{tabular}{|c|c|c|}
\hline & $\begin{array}{l}\text { 6. Melhorar a orientação do paciente que utiliza os } \\
\text { serviços do HCFMRP-USP. }\end{array}$ \\
\hline & & 7. Melhoria da infraestrutura ambulatorial. \\
\hline \multirow[t]{10}{*}{ Gestão Hospitalar } & \multirow{2}{*}{$\begin{array}{l}\text { Gestão Financeira e de } \\
\text { Custos }\end{array}$} & 1. Aumentar a captação de recursos. \\
\hline & & 2. Aprimorar o gerenciamento de custos. \\
\hline & \multirow[t]{3}{*}{$\begin{array}{l}\text { Suprimentos e uso da } \\
\text { Tecnologia }\end{array}$} & $\begin{array}{l}\text { 1. Criar um sistema de controle de uso da tecnologia } \\
\text { dos laboratórios. }\end{array}$ \\
\hline & & 2. Criar um sistema de controle do uso da tecnologia. \\
\hline & & 3. Otimizar o processo de compra. \\
\hline & $\begin{array}{l}\text { Gestão Infraestrutura e } \\
\text { Equipamentos }\end{array}$ & $\begin{array}{l}\text { 1. Implantação de um Sistema de Gerenciamento de } \\
\text { Projetos na Gestão de Equipamentos e Infraestrutura. }\end{array}$ \\
\hline & \multirow[t]{2}{*}{$\begin{array}{l}\text { Informática, Informação } \\
\text { e Sistema de Gestão }\end{array}$} & $\begin{array}{l}\text { 1. Revisar/garantir formas de segurança/ consistência } \\
\text { de dados em exames nos sistemas de informação. }\end{array}$ \\
\hline & & $\begin{array}{l}\text { 2. Criar uma estrutura para gerenciamento da } \\
\text { informação incluindo aspectos clínicos, administrativos } \\
\text { e de pesquisa. }\end{array}$ \\
\hline & \multirow{2}{*}{$\begin{array}{l}\text { Atendimento, Hotelaria, } \\
\text { Segurança e } \\
\text { Humanização }\end{array}$} & 1. Redefinição do organograma do HCFMRP-USP. \\
\hline & & $\begin{array}{l}\text { 2. Redefinição e reestruturação da Divisão de } \\
\text { Hotelaria do Hospital Campus e Unidade de } \\
\text { Emergência. }\end{array}$ \\
\hline \multirow[t]{11}{*}{ Gestão de Pessoas } & \multirow[t]{5}{*}{ Sistema de Trabalho } & $\begin{array}{l}\text { 1. Atualizar o regulamento do Hospital de forma a } \\
\text { atender as necessidades atuais. }\end{array}$ \\
\hline & & $\begin{array}{l}\text { 2. Instituir um programa de avaliação de desempenho } \\
\text { dos funcionários. }\end{array}$ \\
\hline & & 3. Capacitação das chefias. \\
\hline & & 4. Diminuir o índice de absenteísmo. \\
\hline & & 5. Aprimorar o processo seletivo externo e interno. \\
\hline & \multirow{4}{*}{$\begin{array}{c}\text { Gestão do } \\
\text { Conhecimento }\end{array}$} & 1. Melhorar a qualidade do atendimento ao público. \\
\hline & & 2. Implementar Gestão de conhecimento. \\
\hline & & $\begin{array}{l}\text { 3. Criar Sistema de Informação curricular e } \\
\text { aprimoramento profissional do HCFMRP-USP. }\end{array}$ \\
\hline & & 4. Aprimoramento profissional. \\
\hline & \multirow{2}{*}{$\begin{array}{l}\text { Qualidade de Vida, } \\
\text { Satisfação e Segurança } \\
\text { do Trabalho }\end{array}$} & $\begin{array}{l}\text { 1. Melhorias das ações de promoção à } \\
\text { saúde/prevenção. }\end{array}$ \\
\hline & & $\begin{array}{l}\text { 2. Melhoria do atendimento médico e odontológico } \\
\text { dos servidores. }\end{array}$ \\
\hline
\end{tabular}

Apesar de a organização afirmar que o planejamento estratégico tem como base o BSC, é possível perceber algumas inconsistências. Considerando a divisão clássica das perspectivas do BSC (financeira, cliente, processos internos e aprendizado e crescimento) (Kaplan; Norton, 1992), o que a organização chama de "categorias" (Atenção à Saúde, Ensino e Pesquisa, Comunidade e Clientes, Gestão Hospitalar e Gestão de Pessoas) seriam as perspectivas e as partes listadas como "perspectivas" seriam, na verdade, algo semelhante à subperspectivas. 
Essas "categorias" nas quais é dividido o planejamento estratégico são muito semelhantes às categorias da ADO na instituição, como pode ser visto no Quadro 9, contudo não são iguais.

Quadro 9 - Planejamento x avaliação

\begin{tabular}{|l|l|}
\hline Categorias Planejamento Estratégico & Categorias Avaliação de Desempenho \\
\hline Atenção à Saúde & Atenção à Saúde \\
\hline Ensino e Pesquisa & Ensino e Pesquisa \\
\hline Gestão Hospitalar & Gestão Hospitalar \\
\hline Comunidade e Clientes & Comunidade e Humanização \\
\hline Gestão de Pessoas & \\
\hline
\end{tabular}

Sendo os elementos básicos do processo de gestão estratégica desenvolver uma missão, análisar a situação da empresa, formar uma estratégia competitiva, implementar a estratégia e monitorar o desempenho (OLSON; SLATER, 2002), essa escolha de categorias é inconsistente com as afirmações da insituição quanto à relação entre planejamento estratégico e ADO.

Esperava-se que as categorias (dimensões ou módulos) estivessem alinhadas, de modo que fosse possível alinhar também os indicadores de desempenho. Segundo o entrevistado, o planejamento estratégico do HCFMRP-USP é formulado por outro grupo, com membros da alta administração. O profissional responsável pela assessoria técnica e dirigente do GAD (Grupo de Avaliação de Desempenho) participa da elaboração do planejamento estratégico. Por isso essa inconsistência no alinhamento entre avaliação e planejamento é ainda mais crítica. Se o mesmo profissional da alta administração participa de ambos os processos, esperava-se que eles estivessem alinhados.

Considerando que umas das principais razões fazer a avaliação de desempenho organizacional é gerir o desempenho (LEBAS, 1995). Se uma organização mensura eventos diferentes em seu planejamento e na ADO, se torna muito difícil gerir o desempenho organizacional. 


\subsection{A avaliação de desempenho organizacional no HCFMRP-USP}

Para compreensão da avaliação de desempenho organizacional no HCFMRP-USP foi realizada uma pesquisa documental e uma entrevista. Foi entrevistado um dos profissionais do Grupo de Avaliação de Desempenho (GAD) do Hospital das Clínicas da Faculdade de Medicina de Ribeirão Preto. O profissional é formado em administração, com 32 anos de experiência no ramo hospitalar e 25 anos com avaliação de desempenho no HCFMRP-USP.

O GAD é composto por 6 funcionários e está sob a responsabilidade do dirigente da assessoria técnica do HCFMRP-USP, que também é responsável por outras áreas. O GAD tem como função gerenciar todas as informações e indicadores de desempenho do hospital. Ele divulga os indicadores de desempenho, elabora os relatórios anuais de atividades e os relatórios de gestão. Estas informações são encaminhadas para todas as unidades do hospital e outros órgãos dos governos estadual e municipal, disponibilizadas no website do HCFMRP-USP e em cópias físicas.

Segundo o entrevistado, quando o HCFMRP-USP decidiu implantar a avaliação de desempenho organizacional, tiveram o apoio da Associação Brasileira de Hospitais Universitários e de Ensino (Abrahue). A Abrahue é uma associação que tem por missão "Congregar e representar os interesses dos hospitais de ensino, promovendo ações para o desenvolvimento da excelência no ensino, pesquisa, assistência e gestão". A Abrahue auxilia os seus associados em diversas áreas como cooperar com órgãos e entidades educacionais e de saúde, promover o aperfeiçoamento operacional de seus associados e o intercâmbio de informações e experiências. Além de promover eventos para os associados.

A Abrahue forneceu um modelo base e os indicadores, utilizando esse modelo como referência à equipe do hospital elaborou a estrutura do modelo e selecionou os indicadores que considerava mais adequados.

O sistema atual de ADO é uma combinação entre o modelo da Abrahue e o BSC, adaptado à realidade do HCFMRP-USP. Mas nele podem-se perceber características de outros sistemas, como o uso de pontuação para mensurar o desempenho final da 
organização, que é uma característica de modelos como o MADE-O (CORRÊA, 1986). As dimensões (categorias) e pontuações da avaliação de desempenho podem ser vistas na Tabela 4:

Tabela 4 - Dimensões e pontuações da avaliação de desempenho no HCFMRP-USP

\begin{tabular}{|l|c|}
\hline DIMENSÃO / CATEGORIA & PONTOS \\
\hline 1 - Atenção à Saúde & $\mathbf{4 0 0}$ \\
\hline A) Ambulatório & 185 \\
\hline B) Internação & 50 \\
\hline C) Exames & 50 \\
\hline D) Cirurgias & 70 \\
\hline E) Urgência & 45 \\
\hline - Ensino e Pesquisa & $\mathbf{1 5 5}$ \\
\hline 3 - Gestão Hospitalar & $\mathbf{1 9 5}$ \\
\hline - Comunidade e Humanização & $\mathbf{2 5 0}$ \\
\hline TOTAL & $\mathbf{1 0 0 0}$ \\
\hline
\end{tabular}

Durante a pesquisa não foi possível identificar os critérios utilizados para chegar a essas pontuações. Considerando que pontuação atribuída a cada uma das categorias é diferente, quanto maior o peso de cada categoria, maior seu impacto no resultado final da avaliação de desempenho. Nesse caso, é possível assumir que a categoria com maior peso, no caso Atenção à saúde, seja prioridade para a gestão do HCFMRP-USP e para o SUS.

A avaliação de desempenho do HCFMRP-USP está ligada diretamente ao pacto (contrato) com o Sistema Único de Saúde (SUS), esse contrato determina os valores que serão repassados pelo governo e as condições para o recebimento. Quadrimestralmente é realizada uma reunião da Comissão Permanente de Acompanhamento do Contrato (CPAC), que possui representantes do HCFMRP-USP, dos gestores estadual e municipal.

Nessas reuniões são analisados os resultados de 31 indicadores-chave de desempenho, os quais serão discutidos em detalhe nas próximas seções. Conforme os indicadores alcançam ou não as metas estabelecidas são adicionadas as respectivas pontuações para o HCFMRP-USP. Nesse processo existe uma regra quanto aos repasses financeiros do SUS, o hospital independente dos resultados da ADO recebe $85 \%$ dos repasses que se 
destinam a ele. Os outros $15 \%$ estão diretamente vinculados ao resultado da ADO. As fontes de recursos do HCFMRP-USP podem ser vitos na Tabela 5:

Tabela 5 - Fontes de recursos do HCFMRP -USP

\begin{tabular}{|c|c|c|c|c|c|}
\hline Fonte de Recurso / Ano & $\mathbf{2 0 0 9}$ & $\mathbf{2 0 1 0}$ & $\mathbf{2 0 1 1}$ & $\mathbf{2 0 1 2}$ & $\mathbf{2 0 1 3}$ \\
\hline Tesouro do Estado & 239.566 .273 & 251.488 .540 & 279.545 .959 & 319.183 .870 & 414.694 .765 \\
\hline Recurso Federal & 724.710 & - & 873.423 & 187.728 & 414.223 \\
\hline Faturamento SUS & 119.757 .367 & 126.700 .000 & 141.625 .532 & 142.058 .645 & 148.367 .978 \\
\hline $\begin{array}{c}\text { Secretaria de Estado } \\
\text { da Saúde - Termo } \\
\text { Aditivo/Incentivo SUS }\end{array}$ & 21.502 .804 & 7.900 .000 & 9.000 .000 & 9.903 .814 & 2.545 .200 \\
\hline $\begin{array}{c}\text { FAEPA - Clínica } \\
\text { Civil/Convênios }\end{array}$ & 14.373 .469 & 16.500 .000 & 19.000 .000 & 24.699 .003 & 27.608 .373 \\
\hline Total & 395.924 .623 & 402.588 .540 & 450.044 .914 & 496.033 .060 & 593.630 .539 \\
\hline
\end{tabular}

O Faturamento SUS (Faturamento SUS e Termo de Aditivo/Incentivo) correspondeu à 150.913.178 reais no ano de 2013, 25,42\% do faturamento total do hospital. Ainda que não seja a maior parcela da receita total, tem um grande impacto financeiro.

Dos 1000 pontos possíveis, mostrados na Tabela 4, o HCFMRP-USP deve atingir no mínimo 900 pontos para receber o valor total desses repasses SUS. Ou seja, os resultados da ADO se refletem diretamente nos resultados financeiros da instituição.

Todo o ano é realizado um novo contrato, ou prorrogado o contrato atual, nessas ocasiões ocorre a revisão dos indicadores-chave e decide-se se haverá ou não mudanças. Os indicadores podem ser excluídos, inseridos ou desmembrados. Nessas reuniões da CPAC também são discutidos os resultados e as metas dos indicadores.

Devido à importância dos resultados dessa avaliação para o HCFMRP-USP, são feitas mensalmente reuniões internas para acompanhar o andamento dos indicadores-chave. Essas reuniões têm como objetivo monitorar os indicadores-chave de modo que, caso exista alguma não conformidade, seja possível corrigi-la antes das reuniões quadrimestrais. Os participantes dessas reuniões mensais são uma equipe técnica formada por representantes de diversos setores, como recursos humanos, enfermagem, centro integrado da qualidade, ambulatório, etc. 
Outra prática de gestão relativa à análise do desempenho institucional são as reuniões com os departamentos clínicos e a administração, representada pela assessoria técnica. Nessas ocasiões são apresentados os resultados assistenciais e os referenciais institucionais. Essas reuniões acontecem uma vez ao ano, desde 2006, são convidados os docentes da Faculdade de Medicina de Ribeirão Preto, os médicos assistentes e a equipe de saúde. O objetivo é incentivar a equipe de saúde a olhar para os resultados, acompanhar as atividades e analisar o desempenho das especialidades, o qual é demonstrado em indicadores de produtividade e qualidade.

Segundo o entrevistado, o ato de mensurar os resultados auxilia os gestores a tomarem decisões mais conscientes, não depender de "palpites". Uma das vantagens de utilizar a ADO no hospital é ver onde são necessárias ou podem ser feitas melhorias.

A unidade de emergência do hospital, por exemplo, já foi premiada com o Urso de Diamante da 3M. Esse prêmio faz parte do Programa Soluções Integradas para a Saúde da 3M, que visa premiar instituições boas práticas nos procedimentos e tecnologias (3M, 2014). A categoria na qual o hospital foi premiado é a de Certificação em Prevenção de Lesões de Pele. O hospital foi premiado por diminuir o índice de úlcera de pressão nos pacientes.

Segundo o entrevistado foi possível atingir esses resultados somente após a criação e uso de um indicador relacionado à ocorrência de úlceras de pressão, ao conhecer os resultados foi possível criar ações para melhoria. Quanto a possíveis melhorias na ADO, foi mencionado pelo entrevistado melhores ferramentas de sistema de informação como uma possível alternativa, principalmente em relação à coleta de dados e retorno por parte dos setores do HCFMRP-USP.

Ao ser questionado sobre dificuldades que a ADO enfrenta na instituição, o entrevistado afirma que no início da implantação houve alguma resistência por parte dos funcionários do HCFMRP-USP. Muitos dos funcionários tinham dificuldade em entender a necessidade de coletar os dados. A equipe médica inicialmente não foi muito receptiva a $\mathrm{ADO}$, o entrevistado afirma que houve alguns problemas, sendo que o foco maior dos médicos durante as reuniões era cobrar mais recursos, como equipamentos e 
pessoal. Mas atualmente durante essas reuniões os participantes discutem e solicitam mais informações sobre indicadores e resultados.

\subsection{Indicadores-chave de avaliação de desempenho}

A avaliação de desempenho do HCFMRP-USP, em um nível estratégico, é feita utilizando 31 indicadores-chave. Como citado anteriormente eles são apresentados e discutidos nas reuniões quadrimestrais da CPAC. No caso de prorrogação ou renovação do contrato com o SUS, os indicadores-chave podem ser excluídos, inseridos ou desmembrados.

Os 31 indicadores-chave estão divididos em 4 categorias, uma delas com 5 subcategorias, como pode ser visto na Tabela 6:

Tabela 6 - Categorias e número de indicadores

\begin{tabular}{|l|c|}
\hline CATEGORIA & $\mathbf{N}^{\mathbf{0}}$ de Indicadores \\
\hline 1 - Atenção à Saúde: & $\mathbf{1 6}$ \\
\hline A) Ambulatório: & 8 \\
\hline B) Internação: & 2 \\
\hline C) Exames: & 1 \\
\hline D) Cirurgias: & 3 \\
\hline E) Urgência: & 2 \\
\hline 2 - Ensino e Pesquisa & $\mathbf{4}$ \\
\hline 3 - Gestão Hospitalar & $\mathbf{6}$ \\
\hline 4 - Comunidade e Humanização & $\mathbf{5}$ \\
\hline TOTAL & $\mathbf{3 1}$ \\
\hline
\end{tabular}

Aproximadamente 51,6\% (16) desses indicadores apresentam metas numéricas a serem cumpridas (o " $\mathrm{X}$ " representa o resultado de cada indicador no período), os outros $48,4 \%$ (15) têm metas não numéricas, como a apresentação da informação, disponibilizar o relatório etc., ou seja, o indicador deve necessariamente ser mensurado, mas não possui um valor de referência com o qual seu resultado será comparado.

Segundo o entrevistado no HCFMRP-USP existe a prática de que indicadores recémcriados, durante seu primeiro ano, precisam apenas apresentar a informação de seus resultados. No ano seguinte, utilizando o histórico do indicador, se possível será criada uma meta numérica. 
Dentre os indicadores estratégicos, 16 indicadores e 400 pontos estão na categoria atenção à saúde. Eles representam aproximadamente 51,6\% dos indicadores-chave e $40 \%$ dos pontos da avaliação. Pode-se perceber que todos são indicadores de caráter geral e demonstram resultados da assistência do HCFMRP-USP como um todo.

$\mathrm{Na}$ categoria ensino e pesquisa existem 4 indicadores e 155 pontos. Eles representam aproximadamente $13 \%$ dos indicadores-chave e $15,5 \%$ dos pontos da avaliação. Contudo apesar de estarem na categoria ensino e pesquisa, 2 desses indicadores (registro de horas/homem/treinamento e percentual de funcionários treinados) têm uma relação maior com gestão hospitalar ou gestão de recursos humanos do que com ensino e pesquisa.

Sendo uma das funções dos HUs prover treinamento universitário na área de saúde (MEDICI, 2001). Esperava-se o uso de indicadores relacionados ao ensino universitário, como número de alunos de residência ou número de estágios oferecidos. Informações as quais o HCFMRP-USP possui registradas, como demonstrado anteriormente, mas não são utilizadas na avaliação de desempenho.

A categoria gestão hospitalar tem 6 indicadores e 195 pontos. Eles representam aproximadamente 19,4\% dos indicadores-chave e 19,5\% dos pontos da avaliação. Dentre estes 4 indicadores são de natureza financeira (faturamento hospitalar, faturamento ambulatorial, valor médio (por especialidade) das AIH's apresentadas. Dois relacionam-se fortemente com gestão de pessoas (pesquisa de clima organizacional e índice de absenteísmo de servidores). O último indicador representa a apresentação de atas de comissões.

A categoria comunidade e humanização tem 5 indicadores e 250 pontos. Representa aproximadamente $16 \%$ dos indicadores-chave e $25 \%$ dos pontos da avaliação. Dentre os indicadores 2 são relativos a pesquisas de satisfação do usuário (paciente). Dois indicadores representam a apresentação de relatório, do Programa de Humanização do HCFMRP-USP e o Relatório de Ações Ambientais. Por fim um indicador representa a taxa de resposta da ouvidoria. 


\subsection{Indicadores de desempenho no nível operacional}

No nível operacional o HCFMRP-USP possui atualmente 211 indicadores divididos em 3 categorias nos 93 setores do hospital:

- Atenção à saúde: 144 indicadores;

- Ensino e pesquisa: 1 indicador;

- Gestão hospitalar: 66 indicadores.

Diferente dos indicadores-chave, os indicadores operacionais não possuem peso ou pontuação, eles são acompanhados pelos próprios setores e discutidos nas reuniões anuais dos departamentos clínicos e de administração.

É possível perceber que no nível operacional existe um número muito maior de indicadores relacionados à atenção à saúde, $68 \%$ dos indicadores. Uma das explicações para isso é o fato dos indicadores de atenção à saúde estarem divididos por setor do hospital. Então muitos indicadores se repetem, eles mensuram a mesma ocorrência em setores diferentes do HCFMRP-USP.

Essa repetição também ocorre nos indicadores de gestão hospitalar, do mesmo modo que os indicadores de atenção à saúde, os indicadores de gestão hospitalar são setoriais, por isso eles se repetem por existirem em vários setores diferentes. Esses fatos são consistentes com a literatura de $\mathrm{ADO}$, onde o objetivo de indicadores em nível operacional é serem específicos de determinada situação/ocorrência em um setor (MIKUŠOVÁ; JANEČKOVÁ, 2010).

Essa repetição não ocorre na categoria ensino e pesquisa, pois existe apenas um indicador. Contudo o indicador de ensino e pesquisa, no nível operacional, é um indicador de pesquisa de satisfação dos usuários (pacientes) internados nas enfermarias do HCFMRP-USP Campus. Ele aparentemente não apresenta nenhuma relação direta com a função de ensino e pesquisa de um hospital universitário. 
O termo "pesquisa" em um HU deveria referir-se às pesquisas de natureza científica e ao avanço do conhecimento, sendo linhas de pesquisa de interesse do SUS, de acordo com a legislação dos HUs, e/ou, segundo Medici (2001), atividades de ensino e pesquisa relacionadas ao tipo de atendimento médico fornece.

No Quadro 11 podem ser vistos três exemplos, um de cada categoria, dos indicadores operacionais do HCFMRP-USP:

Quadro 10 - Exemplos de indicadores operacionais do HCFMRP-USP

\begin{tabular}{|c|c|c|c|}
\hline $\mathbf{N}^{0}$ Reg. & 5 & 24 & 198 \\
\hline Área: & $\begin{array}{l}\text { Assistência Técnica do } \\
\text { Centro de Recursos } \\
\text { Humanos }\end{array}$ & $\begin{array}{l}\text { Serviço de } \\
\text { Gerenciamento da } \\
\text { Qualidade }\end{array}$ & $\begin{array}{l}\text { Comissão de Controle de } \\
\text { Infecção Hospitalar }\end{array}$ \\
\hline Andar & Andar do setor & Andar do setor & Andar do setor \\
\hline Responsável & Nome do Profissional & Nome do Profissional & Nome do Profissional \\
\hline Ramal: & $\mathrm{N}^{\circ}$ do Ramal & $\mathrm{N}^{\circ}$ do Ramal & $\mathrm{N}^{\circ}$ do Ramal \\
\hline E-mail & E-mail do responsável & E-mail do responsável & E-mail do responsável \\
\hline $\begin{array}{l}\text { Atribuições } \\
\text { da Área }\end{array}$ & $\begin{array}{l}\text { Planejamento e Controle } \\
\text { de Recursos Humanos, no } \\
\text { âmbito da Instituição. }\end{array}$ & $\begin{array}{l}\text { Disseminar a política de } \\
\text { qualidade do Programa } \\
\text { de Qualidade CQH } \\
\text { (Compromisso com a } \\
\text { Qualidade Hospitalar); } \\
\text { Acompanhamento dos } \\
\text { trabalhos realizados pelos } \\
\text { Subcomitês da Qualidade } \\
\text { - Campus e U.E.; } \\
\text { Implantação e } \\
\text { monitoramento das ações } \\
\text { institucionais em } \\
\text { atendimento às } \\
\text { legislações vigentes. }\end{array}$ & $\begin{array}{l}\text { Promover treinamento em } \\
\text { infecção hospitalar dos novos } \\
\text { colaboradores junto ao RH; } \\
\text { Elaborar indicadores de } \\
\text { infecção hospitalar; Fazer } \\
\text { vigilância epidemiológica das } \\
\text { infecções hospitalares; } \\
\text { Disponibilizar na } \\
\text { INTRANET os manuais da } \\
\text { CCIH; Investigar e controlar } \\
\text { surtos de infecção hospitalar } \\
\text { no HC Campus; Treinar } \\
\text { novos colaboradores da } \\
\text { CCIH; Oferecer atualização } \\
\text { em controle de infecção } \\
\text { hospitalar. }\end{array}$ \\
\hline $\begin{array}{l}\text { Objetivo do } \\
\text { Indicador }\end{array}$ & $\begin{array}{l}\text { Analisar a rotatividade de } \\
\text { pessoal do HCFMRP- } \\
\text { USP. }\end{array}$ & $\begin{array}{l}\text { Mensurar a taxa de } \\
\text { devolução da pesquisa de } \\
\text { satisfação nas } \\
\text { enfermarias do HCFMRP } \\
\text { USP Campus. }\end{array}$ & $\begin{array}{l}\text { Promover a qualidade na } \\
\text { assistência em saúde; } \\
\text { Minimizar o risco de infecção } \\
\text { hospitalar. }\end{array}$ \\
\hline Indicador & $\begin{array}{l}\text { Taxa de rotatividade dos } \\
\text { funcionários - HCFMRP- } \\
\text { USP }\end{array}$ & $\begin{array}{l}\text { Pesquisa de Satisfação } \\
\text { dos usuários. }\end{array}$ & $\begin{array}{l}\text { Taxa Global de infecção } \\
\text { hospitalar - HC Campus }\end{array}$ \\
\hline Fórmula & $\begin{array}{l}\left(\mathrm{N}^{\circ} \text { de desligamentos } / \mathrm{n}^{\circ}\right. \\
\text { total de servidores no } \\
\text { quadro de pessoal }) \times 100\end{array}$ & $\begin{array}{l}\mathrm{N}^{\circ} \text { pesquisas } \\
\text { devolvidas } / \mathrm{N}^{\circ} \text { de altas no } \\
\text { mês. }\end{array}$ & $\begin{array}{l}\left(\mathrm{N}^{\circ} \text { total de infecções }\right. \\
\text { hospitalares / egressos) x } 100\end{array}$ \\
\hline Periodicidade & Mensal & Mensal & Mensal \\
\hline Meta & HCFMRP-USP $=0,5 \%$ & $30 \%$ & $\begin{array}{l}\text { Manter a taxa global de } \\
\text { infecção hospitalar igual ou } \\
\text { inferior a 5\% }\end{array}$ \\
\hline
\end{tabular}




\begin{tabular}{|c|c|c|c|}
\hline Ações: & $\begin{array}{l}\text { Incentivar o servidor com } \\
\text { intenção a aposentadoria a } \\
\text { participar do curso "Vida } \\
\text { Ativa" }\end{array}$ & $\begin{array}{l}\text { Ampla divulgação na } \\
\text { instituição sobre a } \\
\text { importância da pesquisa } \\
\text { de satisfação dos } \\
\text { pacientes internados nas } \\
\text { enfermarias do } \\
\text { HCFMRP-USP Campus; } \\
\text { Acompanhar } \\
\text { semanalmente a } \\
\text { quantidade de retorno de } \\
\text { pesquisas respondidas } \\
\text { pelos } \\
\text { pacientes/acompanhantes; } \\
\text { Identificar áreas com } \\
\text { retorno inferior a } 30 \% \text {, } \\
\text { buscando alternativas que } \\
\text { favoreçam a adesão e } \\
\text { assim aumentar a } \\
\text { porcentagem. }\end{array}$ & $\begin{array}{l}\text { Treinamento dos } \\
\text { colaboradores recém- } \\
\text { admitidos; Oferecer a } \\
\text { Disciplina RCG } 312 \text {, no mês } \\
\text { de novembro, para os alunos } \\
\text { do } 2^{\circ} \text { ano de medicina da } \\
\text { FMRP-USP; Gerenciamento } \\
\text { dos leitos de isolamento; } \\
\text { Controle de antimicrobianos; } \\
\text { projeto higiene das mãos, }\end{array}$ \\
\hline $\begin{array}{l}\text { Áreas de } \\
\text { Interface }\end{array}$ & $\begin{array}{l}\text { FAEPA, Centro de } \\
\text { Recursos Humanos, } \\
\text { Gabinete da } \\
\text { Superintendência, } \\
\text { Superintendência e } \\
\text { CEAPS. }\end{array}$ & Divisão de Enfermagem & $\begin{array}{l}\text { CECEn, Divisão de } \\
\text { Enfermagem, Farmácia e } \\
\text { Laboratório de Microbiologia }\end{array}$ \\
\hline Categoria & Gestão Hospitalar & Ensino e Pesquisa & Atenção à Saúde \\
\hline
\end{tabular}

É possível perceber que existe um desalinhamento na escolha de alguns indicadores e na alocação deles nas categorias. Esse fato se torna evidente em alguns momentos, como o indicador operacional de pesquisa de satisfação dos usuários de enfermarias estar na categoria operacional ensino e pesquisa, o que como citado anteriormente, pode ser considerado uma imprecisão. Também pelo fato de que os indicadores estratégicos (indicadores-chave) relacionados à pesquisa de satisfação dos usuários estão alocados na categoria comunidade e humanização. Ou seja, indicadores muito semelhantes, que mensuram ocorrências muito parecidas, são alocados em categorias diferentes.

Sendo a escolha dos indicadores de desempenho uma decisão crítica para a ADO (DENTON, 2005) e que deve ajudar a fornecer a informação necessária para o processo de tomada de decisão (MIKUŠOVÁ; JANEČKOVÁ,2010), espera-se que no mínino o indicador mensure o que se propõe. O que nesse caso, acaba por não ocorrer, pois inda que o indicador mensure corretamente o evento, ele está alocado incorretamente em termos de categoria, então não mede o que a categoria ensino e pesquisa exige, se comparado com a missão do hospital. 
Apesar desse problema, os outros indicadores no nível operacional apresentam características consideradas desejáveis para um indicador de desempenho, como definição suficientemente detalhada, clara e compreensível, ser útil, destinar-se a facilitar a obtenção da informação necessária para o processo de tomada de decisão (MIKUŠOVÁ; JANEČKOVÁ, 2010). Inclusive esses indicadores têm áreas e profissionais responsáveis por eles e ações detalhadas para atingir a meta estabelecida.

No nível operacional do HCFMRP-USP existe também um programa de avaliação de desempenho chamado "Gestão à Vista", iniciado em 2007. O qual tem dois objetivos principais: trabalhar os indicadores de desempenho setorialmente e divulgar para os setores os resultados de dois indicadores - taxa de ocupação e média de permanência.

Esse programa permite as áreas executarem uma tarefa de cocriação de indicadores de desempenho para o acompanhamento de suas atividades. Na rede de computadores do HCFMRP-USP existe um arquivo com o modelo de proposta de indicador. Toda a vez que um setor deseja criar um novo indicador ou modificar um já existente ele deve preencher essa proposta e enviar ao GAD. O novo indicador ou mudança é discutido entre o setor proponente e o GAD. Se o indicador proposto for aprovado o setor passará a alimentar o indicador de acordo com a periodicidade acordada. Então caberá ao GAD e ao próprio setor acompanharem os resultados do indicador. $\mathrm{O}$ documento utilizado também fornece um histórico dos resultados do indicador e acompanha-se a meta de cada indicador.

Quanto à divulgação de taxa de ocupação e média de permanência, em cada setor existe um mural que contém o nome do programa (Gestão à Vista), missão, visão, valores do hospital e os resultados dos indicadores de taxa de ocupação e média de permanência, atualizados a cada três meses. Segundo o entrevistado os resultados desses indicadores sofrem influência das ações de diversas áreas do hospital, por exemplo, se a engenharia/manutenção demora em efetuar a manutenção em um berço ou equipamento o paciente ficará mais tempo internado do que necessário, gerando custos extras para o HCFMRP-USP. Por isso o programa atua em todos os setores do hospital. 


\subsection{Metas da avaliação de desempenho organizacional}

Para a criação de metas para os indicadores de ADO são utilizadas três fontes de dados: o histórico de cada indicador, informações do Sistema de Avaliação de Hospitais de Ensino - SAHE da SES-SP e do sistema de avaliação do Programa Compromisso com a Qualidade Hospitalar - CQH. Para os indicadores-chave as metas também são discutidas nas reuniões CPAC.

Contudo a série histórica de cada indicador é a referência principal para o estabelecimento de metas. Tanto que quanto um indicador novo é criado, em seu primeiro ano de uso, a meta é apenas apresentar as informações de resultado do indicador. A meta numérica é criada normalmente no início do segundo ano de uso do indicador.

\subsection{Comparação dos resultados da avaliação com outras instituições}

O HCFMRP-USP utiliza duas fontes de informações para comparar seu desempenho, o SAHE da e o sistema de avaliação- $\mathrm{CQH}$.

No SAHE é possível comparar os resultados da instituição com os outros HUs do Estado de São Paulo. O HCFMRP-USP informa em planilhas online dados de diversas naturezas como: financeiros, de recursos humanos, satisfação do usuário, infecção hospitalar, produtividade, resultado perinatal, assistenciais de enfermagem, etc. Posteriormente o hospital tem acesso aos resultados dos indicadores informados de outros hospitais de ensino do Estado de São Paulo.

Já no CQH o hospital envia os resultados dos indicadores mensalmente e o CQH devolve as medianas dos resultados dos indicadores dos demais hospitais selados. Sendo possível para o HCFMRP-USP fazer a comparação dos resultados. 
O HCFMRP-USP compara com o CQH 65 indicadores, como pode ser visto na Tabela 7:

Tabela 7 - Indicadores CQH

\begin{tabular}{|l|c|}
\hline Tipo de indicador & Quantidade de indicadores \\
\hline Relacionados à assistência & 47 \\
\hline Satisfação do usuário internado & 10 \\
\hline Gestão de pessoas & 7 \\
\hline Custos & 1 \\
\hline Total & 65 \\
\hline
\end{tabular}

Sendo o CQH um programa para a melhoria da qualidade hospitalar (CQH, 2014), é possível perceber que a grande maioria dos indicadores está relacionada diretamente com a assistência. Isso faz com que seja inviável para o HCFMRP-USP comparar seus resultados em outras áreas.

Além de que essa comparação com o CQH é útil, porém tem limitações significativas, como a possibilidade de comparar apenas alguns dos indicadores - geralmente relacionados à assistência - e a dificuldade de comparar o HCFMRP-USP devido à suas particularidades de hospital de ensino com as demais instituições seladas. Por isso é necessário o uso de outras fontes de dados como o SAHE e sua própria série histórica de indicadores. 


\section{CONCLUSÕES}

Nesta parte do trabalho estão sintetizados os resultados do trabalho, as conclusões do pesquisador, a proposta de modelo preliminar para avaliação de desempenho em hospitais universitários públicos e as limitações do estudo.

\subsection{Conclusões}

Considerando que este trabalho teve como objetivos: verificar se existe um sistema de avaliação de desempenho organizacional no hospital universitário estudado; identificar as características da avaliação de desempenho organizacional; identificar os benefícios trazidos pelo uso de avaliação de desempenho organizacional; identificar as dificuldades enfrentadas pela avaliação de desempenho organizacional.

Ao analisar os resultados da pesquisa é possível perceber que existe um sistema de avaliação de desempenho organizacional na instituição estudada, o qual apresenta muitas das características recomendadas na literatura. Como evidências desta situação, pode-se citar:

- Uso de indicadores-chave;

- Uso de indicadores no nível operacional;

- Uso de metas para os indicadores-chave e operacionais;

- Participação da alta administração na ADO;

- Participação dos setores na criação e revisão de indicadores;

- Feedback dos resultados da ADO;

- Comparação dos resultados com outras instituições;

- Uso de vários tipos de indicadores (de processo, resultado, financeiros, não financeiros, nível operacional e estratégico);

Também durante a pesquisa não foram relatadas pelo entrevistado grandes dificuldades para a realização da avaliação de desempenho. Sendo que os principais problemas estavam relacionados principalmente à resistência dos setores em participar e fornecer 
informações. Dificuldades as quais foram mais intensas no início do processo de implantação da avaliação de desempenho. O único problema ainda recorrente, segundo o entrevistado, é a necessidade de melhores ferramentas de sistema de informação para auxiliar na coleta de dados.

Contudo, ainda existem alguns problemas que podem ser considerados críticos no processo de ADO do HCFMRP-USP. Principalmente relacionados com os propósitos da realização da avaliação de desempenho que puderam ser constatados durante a análise dos resultados.

Quanto à relação entre a ADO e o planejamento estratégico da instituição pode-se citar dois problemas principais:

$1^{\circ} \mathrm{O}$ aparente desalinhamento entre o planejamento estratégico e a avaliação de desempenho em termos de categorias/perspectivas. As categorias / perspectivas nas quais é dividido o planejamento estratégico são muito semelhantes às categorias da ADO na instituição, porém não são iguais. Essas escolhas de categorias são inconsistentes com as afirmações da insituição quanto à relação entre planejamento estratégico e ADO. Esperava-se que as categorias estivessem alinhadas, de modo que fosse possível alinhar também os indicadores de desempenho. Principalmente, porque apesar da $\mathrm{ADO}$ e o planejamento serem realizados em setores o mesmo profissional da alta administração participa de ambos os processos.

$2^{\circ}$ Os indicadores-chave da avaliação e os objetivos do planejamento estratégico também não são compatíveis. A maior parte dos objetivos organizacionais declarados no planejamento, apesar de estarem alinhados com a missão do hospital, aparentemente não apresenta nenhuma relação com os indicadores-chave da ADO.

Quanto a problemas dentro das categorias de ADO, também é possível citar dois aspectos importantes:

$1^{\circ}$ Escolha dos indicadores de ADO na categoria Ensino e Pesquisa, nos níveis operacional e estratégico. O único indicador utilizado por essa categoria - no nível operacional - é o de pesquisa de satisfação dos usuários (pacientes) internados nas 
enfermarias do HCFMRP-USP Campus. O qual não tem nenhuma relação direta com a missão de Ensino e Pesquisa de um hospital universitário. O mesmo problema ocorre no nível estratégico nesta categoria, 50\% dos indicadores de Ensino e Pesquisa são indicadores de gestão hospitalar ou gestão de recursos humanos, ou seja, também não possuem relação direta com ensino e/ou pesquisa. Esperava-se que fossem utilizados indicadores relacionados ao ensino universitário, como número de alunos de residência ou número de estágios oferecidos. Informações as quais a instituição possui registradas, como demonstrado anteriormente, mas não são utilizadas na avaliação de desempenho.

$2^{\circ}$ Desalinhamento na alocação de indicadores. No nível operacional de o indicador de Pesquisa de Satisfação dos Usuários de Enfermarias, que se encontra na categoria Ensino e Pesquisa, mas no nível estratégico os indicadores (indicadores-chave) relacionados à pesquisa de satisfação dos usuários estão alocados na categoria Comunidade e Humanização.

Ao observar esses resultados é possível levantar algumas prováveis causas para esses problemas:

Quanto ao desalinhamento entre planejamento estratégico e a ADO. Considerando que a avaliação de desempenho no nível estratégico do HCFMRP-USP está ligada ao contrato/repasses do SUS e a incompatibilidade entre os objetivos organizacionais e os indicadores-chave. É possível supor que talvez se a realização da ADO na instituição tem como função principal atender a demanda das reuniões do CPAC e não gerenciar ou melhorar o desempenho. Já que os indicadores utilizados não são capazes de mensurar os objetivos organizacionais declarados, mas são adequados para atender a demanda das reuniões.

Quanto a problemas dentro das categorias de ADO, é possível que tenha havido uma confusão do termo "ensino" com o termo "treinamento", já que ambos relacionam-se à aquisição de conhecimento. Por isso indicadores que mensurem os treinamentos tenham sido alocados na categoria Ensino e Pesquisa. 


\subsection{Limitações do estudo}

Este trabalho apresenta algumas limitações, relacionadas principalmente a impossibilidade de generalizar os resultados encontrados. Já que foi estudada apenas uma instituição. Seriam necessárias outras pesquisas para um retrato mais fiel da avaliação de desempenho nos hospitais universitários públicos no Brasil.

\subsection{Recomendações para a avaliação de desempenho para hospitais universitários públicos}

Como contribuição adicional deste trabalho foram elaboradas algumas recomendações sobre a a avaliação de desempenho para hospitais universitários públicos. Para a elaboração dessas recomendações foram utilizados conceitos provenientes da literatura, principalmente de modelos de avaliação voltados para organizações públicas e para a saúde, e também os resultados encontrados na pesquisa de campo.

$1^{\circ}$ Alinhamento entre o planejamento estratégico / estratégia e a avaliação de desempenho: a escolha das categorias / perspectivas / módulos para a avaliação de desempenho deve ter como base a estratégia organizacional.

$2^{\circ}$ Alinhamento entre os indicadores-chave e os objetivos organizacionais: para alinhar a estratégia e a avaliação de desempenho é necessário que os indicadores-chave (indicadores estratégicos) sejam derivados dos objetivos organizacionais. Tornando possível para a ADO mensurar o quanto esses objetivos estão sendo atingidos.

$3^{\text {o }}$ Abrangência da avaliação: sendo uma organização que possui três grandes funções, ensino, pesquisa e assistência, a ADO em um hospital universitário abranger esses três aspectos da instituição. Não deve se concentrar apenas na assistência. 


\subsection{Recomendações para estudos futuros}

Como recomendações para estudos futuros é possível fazer algumas sugestões como:

- Estudar a avaliação de desempenho em hospitais universitários de todo o Brasil, por meio de uma abordagem quantitativa;

- Estudar a avaliação de desempenho em outros hospitais universitários e comparar os resultados entre eles, por meio de estudos multicaso;

- Utilizar abordagens como a análise envoltória de dados para estudar a eficiência em hospitais universitários;

- Realizar pesquisas similares a essa em outros tipos de hospitais públicos.

- Verificar a aplicabilidade do modelo preliminar proposto neste estudo. 


\section{REFERÊNCIAS}

3M Brasil. Soluções integradas para a saúde. Disponível em: 〈http://solutions.3m.com.br/wps/portal/pt_BR/3M/Country-LA/>. Acesso em: $13 / 09 / 2014$.

ADAMS, Chris. NEELY, Andy. The performance prism to boost M\&A sucess. Measuring Business Excellence. v. 4, n. 3, p. 19-23, 2000.

BALLARD, David J. Indicators to improve clinical quality across an integrated health care system. International Journal for Quality in Health Care. v. 15, Supplement 1: p. i13-i23, 2003.

BARATA, Luiz Roberto Barradas; MENDES, José Dínio Vaz; BITTAR, José Dínio Vaz. Hospitais de ensino e o sistema Único de saúde. RAS. v. 12, n. 46, p. 7-14, JanMar, 2010.

BARDIN, Laurence. Análise de Conteúdo. 2ed. Lisboa: Edições 70, 1977.

BARRADOS, Maria; BLAIN, J. S. Improving program results through the use of predictive operational performance indicators : a canadian case study. American Journal of Evaluation. v. 34, n. 1, p. 45-56, 2013.

BARRADOS, Maria; BLAIN, J. S. Indicators: a canadian case study improving program results through the use of predictive operational performance. American Journal of Evaluation. p. 34- 45, 2013.

BEAMON, Benita M. Measuring supply chain performance. International Journal of Operations \& Production Management. v. 19 , n. 3, p. 275 - 292, 1999.

BEHN, Robert D. Why Measure Performance? Different Purposes Require Different Measures. Public Administration Review. v. 63, n. 5, p. 586-606, September/October 2003.

BESSIRE, Dominique; BAKER, C. Richard. The French Tableau de bord and the American Balanced Scorecard: a critical analysis. Critical Perspectives on Accounting. v. 16, p. 645-664, 2005.

BHATTI, Ishaq; AWAN, Hayat M.; RAZAQ, Zahid. The key performance indicators (KPIs) and their impact on overall organizational performance. Quality \& Quantity, 2013.

BIRD, Sheila M.; Sir David Cox; Vern T. Farewell; Harvey Goldstein; Tim Holt; Peter C. Smith. Performance indicators : good, bad, and ugly. Journal of Royal Statistical Society. p. 1-27, 2005.

BONACIM, Carlos Alberto Grespan; ARAUJO, Adriana Maria Procópio. Avaliação de desempenho econômico-financeiro dos serviços de saúde: os reflexos das políticas operacionais no setor hospitalar. Ciência \& Saúde Coletiva. v. 16(Supl. 1), p. 10551068, 2011. 
BONACIM, Carlos Alberto Grespan; ARAUJO, Adriana Maria Procópio. Gestão de custos aplicada a hospitais universitários públicos: a experiência do Hospital das Clínicas da Faculdade de Medicina de Ribeirão Preto da USP. RAP. Rio de Janeiro, v. 44, n. 4, p. 903-931, Jul./Ago. 2010.

BONACIM, Carlos Alberto Grespan; ARAUJO, Adriana Maria Procópio. Valor econômico agregado por Hospitais Universitários Públicos. RAE. v. 49, n. 4, p. 419433, Out./Dez. 2009.

BOURGUIGNON, Annick; MALLERET, Véronique; NØRREKLIT, Hanne. 2004. The American balanced scorecard versus the French tableau de bord: the ideological dimension. Management Accounting Research. v. 15, p.107-134, 2004.

BOURNE, Mike; MILLS, John; WOLCOX, Mark; NELLY, Andy; PLATTS, Ken. Designing, implementing and updating performance measurement systems. International Journal of Operations \& Production Management. v. 20, n. 7, p. 754$771,2000$.

BRASIL. Decreto No 7.802, de 27 de Janeiro de 2010. Casa Civil. Subchefia para Assuntos Jurídicos.

BRASIL. Lei $\mathbf{N}^{\mathbf{1}}$ 12.550, de 15 de Dezembro de 2011. Casa Civil. Subchefia para Assuntos Jurídicos.

BRASIL. Portaria Interministerial $\mathbf{N}^{\mathbf{0}} \mathbf{8 8 3}$, de 5 de julho de 2010. Ministério da Educação/Ministério da Saúde/Ministério do Planejamento.

BUTLER, Alan; LETZA, Steve R.; NEALE, Bill. Linking the balanced scorecard to strategy. Long Range Planning. v. 30, n. 2, p. 242-253, 1997.

CASTELli, Adriana; DAWSON, Daiane; GRAVELLE, Hugh; STREET, Andrew. Improving measurement of heal system output growth. Health Economics. v.16. p.1091-1107, 2007.

CERVO, Amado Luiz; BERVIAN, Pedro Alcin. Metodologia científica. São Paulo: Makron Books, 1996.

CHEN, Xiao-yun; Kazunobu Yamauchi; Ken Kato; Akio Nishimura and Katuski Ito. Using the balanced scorecard to measure Chinese and Japanese hospital performance. International Journal of Health Care Quality Assurance. v. 19 n. 4, p. 339-350, 2006.

CHEN, Hsueh-Fen; HOU, Ying-Hui; CHANG, Ray-E. Application of the balanced scorecard to an academic medical center in Taiwan: the effect of warning systems on improvement of hospital performance. Journal of the Chinese Medical Association. v. 75, p. 530-535, 2012.

CHENHALL, Robert H.; LANGFIELD-SMITH, Kim. Multiple Perspectives of Performance Measures. European Management Journal. v. 25, n. 4, p. 266-282, 2007. 
CHIZZOTTI, Antonio. Pesquisa qualitativa em ciências sociais. Pretrópolis - RJ: Vozes, 2006.

CNES. Secretaria de atenção a saúde. DATASUS. Disponível em $<$ http://cnes.datasus.gov.br>. Acesso em 18/04/2014.

Conselho Federal de Medicina (CFM). Disponível em: <http://portal.cfm.org.br/2014>. Acesso em 20/05/2014.

COOPER, Donald R.; SCHINDLER, Pamela S. Métodos de pesquisa em administração. Porto Alegre: Bookman, 2003.

CORREAA, Hamilton Luiz. Modelo de avaliação de desempenho organizacional: MADE-O: como conhecer o verdadeiro desempenho de uma organização. Notas de aula da disciplina de EAD 5948 - Avaliação de Desempenho Global. Faculdade de Economia, Administração e Contabilidade da Universidade de São Paulo. São Paulo, 2012.

CORRÊA, Hamilton Luiz. O estado da arte da avaliação de empresas estatais. Tese (Doutorado em Administração de empresas). Faculdade de Economia, Administração e Contabilidade da Universidade de São Paulo - Universidade de São Paulo, São Paulo, 1986.

CQH - Compromisso com a qualidade hospitalar, 2014. Disponível em: <http://www.cqh.org.br/portal/pag/inicial.php>. Acesso em: 08 de Setembro de 2014.

CRESWELL, John W. Projeto de pesquisa: métodos qualitativo, quantitativo e misto. Porto Alegre: Artmed, 2007.

CRISPIM, Sergio Feliciano; LUGOBONI, Leonardo Fabris. Modelos de Avaliação de Desempenho Organizacional nas Instituições de Ensino Superior da Região Metropolitana de São Paulo. Revista Portuguesa e Brasileira de Gestão. v.11 n.1, p.42-54, jan/mar 2012.

CUNHA, Julio Araujo Carneiro. Avaliação de desempenho e eficiência em organizações de saúde: um estudo em hospitais filantrópicos. 2011. Tese (Doutorado em Administração). Faculdade de Economia, Administração e Contabilidade, Universidade de São Paulo, São Paulo, 2011.

CUNHA, Julio Araujo Carneiro da; CORREA, Hamilton Luiz. Avaliação de desempenho organizacional: um estudo aplicado em hospitais filantrópicos. Rev. adm. empres. [online], v. 53, n. 5, p. 485-499, 2013.

DAVIES, Huw Talfryn Oakley; LAMPEL, Joseph. Trust in performance indicators? Quality in Health Care. v. 7, p. 159-162, 1998.

DENIS, Jean-Louis; LANGLEY, Ann; LUXEAU, Daniel. Formal strategy in public hospitals. Long Range Planning. v. 24, n. 1, p. 71-82, 1991. 
DENTON, D. Keith. Measuring relevant things. International Journal of Productivity and Performance Management. v. 54 n. 4, p. 278-287, 2005.

DENZIN, Norman K.; LINCOLN, Yvonna S. (Editores). Collecting and interpreting qualitative materials. 3ed. Sage Publications, 2008.

DONABEDIAN, Avedis. The seven pillars of quality. Archieves of Pathology \& Laboratory Medicine. v. 114, n. 11, p. 1115-1118, Nov. 1990.

EBSERSH. Empresa Brasileira de Serviços Hospitalares. Disponível em: <http://ebserh.mec.gov.br/>. Acesso em 25 de Março de 2014.

ECCLES, Robert G. The Performance Measurement Manifesto. Harvard Business Review. January-February, p. 131-137, 1991.

EDDY, D. M. Performance measurement: problems and solutions. Health Affairs. v. 17, n.4, p. 7-25, 1998.

EDENBURG, Leslie; HERMALIN, Benjamin E.; WEISBACH , Michael S.; WOSINSKA, Marta. Governance, performance objectives and organizational form: evidence from hospitals. Journal of Corporate Finance. v.10, n.4, p. 527-548, 2004.

EDVINSSON, Leif. Developing intellectual capital at skandia. Long Range Planning. v. 30, n. 3, p. 366-373, 1997

EDVINSSON, Leif; MALONE, Michel S. Capital intelectual: descobrindo o valor real de sua empresa pela identificação de seus valores internos. São Paulo: Makron Books, 1998.

EMERSON, Rebecca A.; HENDRY, David. An Evaluation of Forecasting Using Leading Indicators. Journal of Forecasting. v.15, p.271-291, 1996.

EPSTEIN, Marc J. Strategy : from tableaux de bord to balanced scorecards. European Management Journal. v. 16, n. 2, p. 190-203, April 1998.

FORTUIN, Leonard. Performance indicators - Why, where and how? European Journal of Operational Research. v. 34, n.1, p. 1-9, 1988.

FUNDAÇÃO DE APIO AO ENSINO, PESQUISA E ASSITÊNCIA DO HCFMRPUSP. Disponível em: 〈http://www.faepa.br/Html/Default.asp >. Acesso em: 15/03/2014.

FERREIRA, Aldonio; OTLEY, David. Exploring inter and intra-relationship between the design and use of management control system. Working Paper. SSRN, 2007.

FIORIN, José Luiz. Internacionalização da produção científica: a publicação de trabalhos de Ciências Humanas e Sociais em periódicos internacionais. R B P G. v. 4, n. 8, p. 263-281, Dezembro de 2007.

FPNQ - Fundação para Prêmio Nacional da Qualidade. Critérios de excelência 2010: avaliação e diagnóstico da gestão organizacional. 2010. 
FPNQ - Fundação para Prêmio Nacional da Qualidade. Prêmio nacional de qualidade, 2002. Disponível em: <http://www.fnq.org.br>. Acesso em 15/01/2013.

FRAME, J. Davison. Quantitative Indicators for Evaluation of Basic Research Programs/Projects. IEEE Transactions on engineering management. v. 30, n. 3, p. 106-112, August 1983.

FRANCO-SANTOS, Monica; KENNERLEY, Mike; MICHELI, Pietro; MARTINEZ, Veronica; MASON, Steve; MARR, Bernard; GRAY, Dina, NEELY, Andrew. Towards a definition of a business performance measurement system. International Journal of Operations \& Production Management. v. 27 n. 8, p. 784-801, 2007.

GALVÃO, Henrique Martins; CORRÊA, Hamilton Luiz; ALVES, José Luiz. Modelo de avaliação de desempenho Global para instituição de ensino superior. Revista de Administração da Universidade Federal de Santa Maria. v. 4, n. 3, p. 425-441, Set./Dez., 2011.

GAPENSKI, Louis C.; PINK, George H. Understanding healthcare financial management. 5th ed. Health Administration Press: Chicago, Illinois, 2010.

GEISLER, Eliezer. Key Output Indicators in performance evaluation of Research and Development organizations. Technological Forecasting and Social Change. V. 47, n.2, p.189203, 1994.

GIL, Antonio Carlos. Métodos e técnicas de pesquisa social. São Paulo Atla, 1999.

GODOI, Christiane Kleinübing; BANDEIRA-DE-MELO, Rodrigo; SILVA, Anielson Barbosa. Org. Pesquisa qualitativa em estudos organizacionas: paradigmas, estratégias e métodos. São Paulo: Saraiva, 2006.

GOMES, Carlos F.; YASIN, Mahmoud M.; LISBOA, João V. Key performance factors of manufacturing effective performance: The impact of customers and employees. The TQM Magazine. v. 18, n. 4, p. 323-340, 2006.

GOMES, Carlos F.; YASIN, Mahmoud M.; LISBOA, João V. Performance measurement practices in manufacturing firms revisited. International Journal of Operations \& Production Management. v. 3, n. 11, 5-30, 2011.

GONÇALVES, Antonio C.; NORONHA, Cláudio P.; LINS, MARCOS P.E.; ALMEIDA, Renan M.V.R. Análise Envoltória de Dados na avaliação de hospitais públicos nas capitais brasileiras. Revista de Saúde Pública. v. 41, n. 3, p. 427-35, 20007.

GOSSELIN, Maurice. An empirical study of performance measurement in manufacturing firms. International Journal of Productivity and Performance Management. v. 54, n. 5/6, p. 419-437, 2005.

GRIGOROUDIS, E. ; ORFANOUDAKI, E. ; ZOPOUNIDIS, Constantinos. Strategic performance measurement in a healthcare organisation: a multiple criteria approach based on balanced scorecard. Omega. v. 40, p.104-119, 2012. 
GROSSKOPF, Shawna; MARFARITIS, Dimitri; VALDMANIS, Vivian. The effects of teaching on hospital productivity. Socio-Economic Planning Sciences. v. 35, p.189204, 2001.

GUERRA, Mariana. Análise de desempenho de organizações hospitalares. 2011. Dissertação (Mestrado em Contabilidade e Controladoria). Faculdade de Ciências Econômicas, Universidade Federal de Minas Gerais. Belo Horizonte, 2011.

HALACHMI, Arie. Performance measurement and government productivity. Work Study. v. 51, n. 2, p. 63-73, 2002.

HALACHMI, Arie. Performance measurement is only one way of managing performance. International Journal of Productivity and Performance Management. v. 54 n. 7, p. 502-516, 2005.

HILL, Manuela Magalhães; HILL, Andrew. Investigação por questionário. Lisboa: Sílabo, 2008.

HOURNEAUX JR., Flávio. Avaliação de desempenho organizacional: estudo de casos de empresas do setor químico. 2005. Dissertação (Mestrado em Administração). Faculdade de Economia, Administração e Contabilidade da Universidade de São Paulo, Universidade de São Paulo, São Paulo.

HOURNEAUX JR., Flávio. Relações entre as partes interessadas (stakeholders) e os sistemas de mensuração de desempenho organizacional. 2010. Tese (Doutorado em Administração). Faculdade de Economia, Administração e Contabilidade da Universidade de São Paulo, Universidade de São Paulo, São Paulo.

HOSPITAL DAS CLÍNICAS DA FACULDADE DE MEDICINA DE RIBEIRÃO PRETO - USP. Relatório de atividades 2013. Disponível em: $<$ http://www.hcrp.fmrp.usp.br/sitehc/informacao.aspx?id=130\&ref=1\&refV=1>.

Acesso em 20/02/2014.

HOSPITAL DAS CLÍNICAS DA FACULDADE DE MEDICINA DE RIBEIRÃO PRETO - USP. Disponível em: <http://www.hcrp.fmrp.usp.br/>. Acesso em 20/02/2014.

INTERNATIONAL SOCIETY FOR QUALITY IN HEALTH CARE (ISQua). ISQua's 4th International Summit on Indicators, Buenos Aires, October 2001. International Journal for Quality in Health Care. v. 15, Supplement 1: p. i13-i23, 2003.

IOAN, Barliba; NESTIAN, Andrei Stefan; TIţă, Silviu-Mihail. Relevance of Key Performance Indicators (KPIs) in a Hospital Performance Management Model. Journal of Eastern Europe Research in Business \& Economics. p. 1-15, 2012.

JARRAR, Yasar; SCHIUMA, Giovanni. Measuring performance in the public sector: challenges and trends. Measuring Business Excellence. v. 11, n. 4, p.4-8, 2007. 
KAPLAN, Robert S. Conceptual Foundations of the Balanced Scorecard. Handbook of Management Accounting Research. v. 3, p. 1253-1269, 2009.

KAPLAN, Robert S.; NORTON, David P. The balanced scorecard - measures that drive performance. Harvard Business Review. Boston, v. 70, n. 1, p. 71-79, JanuaryFebruary, 1992.

KAPLAN, Robert S. Strategic Performance Measurement and Management in Nonprofit Organizations. Nonprofit Management \& Leadership. v. 11, n. 3, Spring 2001.

KAPLAN, Robert S.; NORTON, David P. Using a Balanced Scorecard as a Strategic Management System. Harvard Business Review. Boston, v. 74, n. 1, p. 75-85, January- February, 1996.

KRUK, Margaret Elizabeth; FREEDMAN, Lynn P. Assessing health system performance in developing countries: A review of the literature. Health Policy. v. 85 p. 263-276, 2008.

LI, L. X.; BENTON, W. C. Performance measurement criteria in health care organizations: Review and future research directions. European Journal of Operational Research. v. 93, p. 449-468, 1996.

LAVIERI, Carlos Amorim. Sistema de avaliação de desempenho aplicados em redes de franquias. 2008. Dissertação (Mestrado em Administração). Faculdade de Economia, Administração e Contabilidade, Universidade de São Paulo. São Paulo, 2008.

LEBAS, Michel J. Performance measurement and performance management. Int. J. Production Economics. v. 41, p. 23-35, 1995.

LOBO, Maria Stella de Castro; LINS, Marcos Pereira Estellita; SILVA, Angela Cristina Moreira da; FISZMAN, Roberto. Avaliação de desempenho e integração docenteassistencial nos hospitais universitários. Revista de Saúde Pública. v. 44, n. 4, p. 581$590,2010$.

LUEDY, Almerinda; MENDES, Vera Lúcia Peixoto S.; RIBEIRO JÚNIOR, Hugo Ribeiro. Gestão pública por resultados: contrato de gestão como indutor de melhorias em um hospital universitário. Organizações \& Sociedade. v. 19, n. 63, p. 641-659, 2012.

LUGOBONI, Leonardo Fabris. Modelos de avaliação de desempenho organizacional em instituições de ensino superior na Grande São Paulo. 2010. Dissertação (Mestrado em Administração de Empresas). Universidade Municipal de São Caetano do Sul. São Paulo, 2010.

LUIJSTERBURG, Jan; HAM, Marcel van; BROUWERS, Evelien; SMITS, Martin. Towards Performance Indicators for the Health Care Sector. 21th Bled eConference eCollaboration: Overcoming Boundaries Through Multi-Channel Interaction. Bled, Slovenia, June 15 - 18, 2008. 
MACHADO, Sérgio Pinto; KUCHENBECKER, Ricardo. Desafios e perspectivas futuras dos hospitais universitários no Brasil. Ciência \& Saúde Coletiva. v. 12, n. 4, p. 871-877, 2007.

MAINZ, Jan. Defining and classifying clinical indicators for quality improvement. International Journal for Quality in Health Care. v. 15, n. 6, p. 523-530, 2003.

MARINHO, Alexandre. Hospitais Universitários: indicadores de utilização e análise de eficiência. Rio de Janeiro: IPEA Instituto de Pesquisa Econômica Aplicada, Texto para Discussão n. 833, 2001 b.

MCDONALD, Bob. Review of the Use of the Balanced Scorecard in Healthcare. B M c D C on s u l t i n g. April, 2012.

MEDICI, A. C. Hospitais universitários: passado, presente e futuro. Revista da Associação Médica Brasileira. v. 47, n. 2, p. 149-156, 2001.

MEIJER, R. F.; MOED, H. F.; RAAN, A. F. J. V. A. N. Research performance indicators for university departments: a study of an agricultural university. Scientometrics. v. 27, n. 2, p. 157-178, 1993.

MIKUŠOVÁ, Marie; JANEČKOVÁ, Viktorie. Developing and Implementing Successful Key Performance Indicators. World Academy of Science, Engineering and Technology. v. 42, p. 969-981, 2010.

MINISTÉRIO DA SAÚDE, 2014. Disponível em: <http://portalsaude.saude.gov.br/>. Acesso em de Março 2014.

NAJMI, Manoochehr; ETEBARI, Mohammad; EMAMI, Samin. A framework to review Performance Prism. International Journal of Operations \& Production Management. v. 32 n. 10, p. 1124-1146, 2012.

NEELEY, Andy; GREGORY, Mike; PLATTS, Ken. Performance measurement system design: A literature review and research agenda. International Journal of Operations \& Production Management. v. 25 n. 12, p. 1228-1263, 2005.

NEELY, Andy. Performance measurement system design - third phase. Performance Measurement System Design Workbook. April, 1994.

NEELY, Andy; MILLS, John; PLATTS, Ken; RICHARDS, Huw; GREGORY, Mike; BOURNE, Mike; KENNERLEY, Mike. Performance measurement system design: developing and testing a process-based approach. International Journal of Operations \& Production Management. v. 20 n. 10, p. 1119-1145, 2000.

NELLY, Andy; ADAMS, Chris; CROWE, Paul. The performance prism in pratice. Measuring Business Excellence. v. 5, n. 2, p.6-12, 2001.

NORREKLIT, Hanne. The balance on the balanced scorecard a critical analysis of some of its assumptions. Management Accounting Research. v. 11, n. 1, p. 65-88, 2000. 
OLSON, Eric M.; SLATER, Stanley F. The balanced scorecard, competitive strategy, and performance. Business Horizons. v. 45, n. 3, p. 11-16, May/June, 2002.

ONDATEGUI-PARRA, Silvia; BHAGWAT, Jui G.; GILL, Ileana Eric; NATHANSON, Steven; SELTZER, S.; ROS, Pablo R. Essential Practice Performance Measurement. Journal of the American College of Radiology. v. 1 n. 8 , p. 559-566, August 2004.

OZCAN, Yasar A.; Marcos E. Lins; Maria Stella C. Lobo; Angela Cristina M. da Silva; Roberto Fiszman; Basilio B. Pereira. Evaluating the performance of Brazilian university hospitals. Annals of Operations Research. v. 178, n.1, 247-261, 2010.

OZCAN, Yasar A.; SMITH, Peter. Towards a science of the management of health care. Health Care Management Science. v.1, n.1, p. 1-4, 1998.

PERERA, Roshan; DOWELL, Tony; CRAMPTON, Peter; KEARNS, Robin. Panning for gold: An evidence-based tool for assessment of performance indicators in primary health care. Health Policy. v. 80, 314-327, 2007.

PHILLIMORE, A. J. University research performance indicators in practice: The University Grants. Committee's evaluation of British universities. Research Policy, v. 18, p.255-271, 1989.

PINK, George H.; DANIEL, Imtiaz; HALL, Linda McGuillis; MCKILLOP, Ian. Selection of Key Financial Indicators: A literature, panel and survey approach. Healthcare Quarterly. v. 10, n. 1, p. 87-98, 2007.

PLATAFORMA BRASIL. Disponível em: <http://aplicacao.saude.gov.br/plataformabrasil/login.jsf>. Acesso em 25/06/2014.

PURBEY, Shankar; MUKHERJEE, Kampan; BHAR, Chandan. Performance measurement system for healthcare processes. International Journal of Productivity and Performance Management. v. 56, n. 3, p. 241-251, 2007.

REDE INTERAGENCIAL DE INFORMAÇÃO PARA A SAÚDE. Indicadores básicos para a saúde no Brasil: conceitos e aplicações. 2. ed. - Brasília: Organização Pan-Americana da Saúde, 2008.

RICHARDSON, Roberto Jarry. Pesquisa social: métodos e técnicas. São Paulo: Atlas, 1999.

ROOS, Goran; ROOS, Johan. Measuring your company's intellectual performance. Long Range Planning. v. 30, n. 3, p. 413-426, 1997.

ROTTA, Carmen Silvia Gabriel. Utilização de indicadores de desempenho hospitalar como instrumento gerencial. Tese (Doutorado em Prática de Saúde Pública). Faculdade de Saúde Pública, Universidade de São Paulo. São Paulo, 2004. 
RUBIN Haya R.; PRONOVOST Peter; DIETTE, Gregory B. The advantages and disadvantages of process-based measures of health care quality. International Journal for Quality in Health Care. v. 13, n. 6, p. 469-474, 2001.

SAMPIERI, Roberto Hernández; COLLADO, Carlos Fernández; LUCIO, Pilar Baptista. Metodologia de Pesquisa. 3 ed. São Paulo: McGraw-Hill, 2006.

SCHOLTEN, G.R.M.; VAN DER GRITEN, T.E.D. Between physician and manager: new co-operation models in Dutch hospitals. Journal of Management in Medicine. v. 12, n.1, p. 33-43, 1998.

SELF, James. Metrics and management: applying the results of the balanced scorecard. Performance Measurement and Metrics. v. 5, n. 3, p. 101-105, 2004.

SERAFIM, Ricardo Conrado; GAZOLA, Gerson; ZAVITOSKI, Leandro; ALMEIDA, Adriano Henrique; CARVALHO, Larissa Moreira Izarelli de; BITTAR, Olímpio José Nogueira Viana, ALMEIDA, André Luiz de; BORGES NETO, Benedicto Accacio; TACHINARD, Umberto; PISA, Ivan Torres. Sistema de Avaliação de Hospitais Universitários SAHU da Secretaria de Estado da Saúde de São Paulo SES-SP. X CBIS - X Congresso Brasileiro de Informática em Saúde - Informática em Saúde de Cidadania - 14-18 de Outubro de 2006.

SHAW, Charles D. How can hospital performance be measured and monitored? WHO Regional Office for Europe Health Evidence Network report. Copenhagen, 2003.

SILVA, Ligia Maria V. da; FORMIGLI, Vera Lúcia A. Avaliação em saúde: limites e perspectivas. Caderno de Saúde Pública. Rio de Janeiro, v.10, n.1, p. 80-91, jan/mar, 1994.

SILVA, Ubaldina Souza. Indicadores de qualidade e produtividade: um estudo nos hospitais de Santa Maria/RS. Dissertação de Mestrado. Escola de Administração de Empresas de São Paulo. São Paulo, 1998.

SIM, Khim Ling; KOH, Hian Chye. Balanced scorecard: a rising trend in strategic performance measurement. Measuring Business Excellence. v. 5, n. 2, p. 18-26, 2001.

SISTEMA DE AVALIAÇÃO DOS HOSPITAIS DE ENSINO (SAHE). Editorial 2009. Disponível em: 〈http://sistema4.saude.sp.gov.br/sahe/>. Acesso em 25 de Março de 2014.

SISTEMA DE AVALIAÇÃO DOS HOSPITAIS DE ENSINO (SAHE). Disponível em: <http://sistema4.saude.sp.gov.br/>. Acesso em 25 de Março de 2014.

SISTEMA DE AVALIAÇÃO DOS HOSPITAIS DE ENSINO (SAHE). Editorial 2013. Disponível em: <http://sistema4.saude.sp.gov.br/sahe/>. Acesso em 25 de Março de 2014.

Sistema de Avaliação dos Hospitais de Ensino (SAHE). Editorial 2009. Disponível em: <http://sistema4.saude.sp.gov.br/sahe/documento/editorial_2009.pdf>. Acesso em: 15/05/2014. 
SORENSEN, James E.; ZELMAN, William; HANBERY, Glyn W.; KUCIC, A. Ronald. Managing mental health organizations with 25 key performance indicators. Evaluation and Program Planning. v.10, n.3, p.239-247, 1987.

SOUZA, Antônio Artur de; GUERRA, Mariana; LARA, Cynthia Oliveira; GOMIDE, Pedro Lúcio Rodrigues; PEREIRA,Carolina Moreira; FREITAS, Deyse Aguilar. Controle de gestão em organizações hospitalares. Revista de Gestão USP. São Paulo, v. 16, n. 3, p. 15-29, julho-setembro 2009.

SOUZA, Antônio Artur De; RODRIGUES, Ludmila Teixeira; LARA, Cynthia Oliveira; GUERRA, Mariana; PEREIRA, Carolina Moreira. Indicadores de desempenho econômico-financeiro para hospitais: um estudo teórico. RAHIS - Revista de Administração Hospitalar e Inovação em Saúde. jul./dez. 2009.

STEWART, Louis J.; BESTOR, William E. Applying a Balanced Scorecard to Health Care Organizations. Journal of Corporate Accounting \& Finance. v.11, n. 3, p. 7582, March/April, 2000.

STEWART. T. A. Capital Intelectual: a nova riqueza das organizações. Lisboa: Edições Sílabo, 1999.

TANGEN, Stefan. Insights from research improving the performance of a performance measure. Measuring Business Excellence. v. 9, n. 2, p.4-11, 2005.

THE SIGMA PROJECT. The sigma guidelines: putting sustainable development into pratice - a guide for organizations, 2003. Disponível em: < http://www.projectsigma.co.uk/>. Acesso em: 15/10/2012.

TOOR, Shamas-ur-Rehman; OGUNLANA, Stephen O. Beyond the "iron triangle": Stakeholder perception of key performance indicators (KPIs) for large-scale public sector development projects. International Journal of Project Management. v. 28, n.3, p. 228-236, 2010.

TRIVIÑOS, Augusto Nibaldo Silva. Introdução à pesquisa em ciências sociais: a pesquisa qualitativa em educação. São Paulo: Atlas, 2008.

URRUTIA, Ignacio; ERIKSEN, S. D. Application of the Balanced Scorecard in Spanish private health-care management. Measuring Business Excellence. v. 9, n. 4, p.16-26, 2005.

VAN PEURSEM, K.A.; PRATT, M. J.; LAWRENCE, S. R. Health management performance a review of measures and indicators. Accounting, Auditing \& Accountability Journal. v. 8, n.5, p. 34-70, 1995.

VOELKER, Kathleen E.; RAKICH, Jonathon S.; FRENCH, G. Richard. The balanced scorecard in healthcare organizations: a performance measurement and strategic planning methodology. Hospital Topics: Research and Perspectives on Healthcare. v. 79, n. 3, summer 2001 . 
WACHTEL, T. L.; HARTFORD, C. E.; HUGHES, J. A. Building a balanced scorecard for a burn center. Burns: Journal of the International Society for Burn Injuries. v. 25, p. 431-437, 1999.

WATTS, Ted; MCNAIR-CONNOLLY, Carol J. New performance measurement and management control systems. Journal of Applied Accounting Research. v. 13, n.3, p. 226-241, 2012.

World Health Organization - WHO. Measuring hospital performance to improve the quality of care in Europe: a need for clarifying the concepts and defining the mais dimensions. Report on a WHO Workshop. Barcelona, Spain, 10-11 January 2003.

YIN, ROBERT, K. Estudo de caso: planejamento e métodos. 4 ed. Porto Alegre: Bookman, 2010.

YOKOMIZO, Cesar Akira. Avaliação de desempenho organizacional: um estudo exploratório em empresas brasileiras de desenvolvimento de software. 2009. Dissertação (Mestrado em Administração). Faculdade de Economia, Administração e Contabilidade, Universidade de São Paulo. São Paulo, 2009.

YU, Fusheng; ZHANG, Lin. Does Intelletual Capital Really Create Value? A Test Based on Ohlson Model and Skandia Navigator System. Wireless Communications, Networking and Mobile Computing, 2008. WiCOM '08. 4th International Conference on. Date 12-14 Oct. 2008

ZELMAN, William N.; PINK, George H.; MATTHIAS, Catherine B. Use of the balanced scorecard in health care. Journal of Health Care Finance. v. 29, n. 4, p.1-16, 2003.

ZHONGHUA, Cai; YE, Wang. Research Frontiers in Public Sector Performance Measurement. Physics Procedia. v. 25, p. 793-799, 2012.

ZUCCHI, Paola; BITTAR, Olímpio J. N. V. Funcionários por leito: estudo em alguns hospitais públicos e privados. Revista de Administração em Saúde. v. 4, n.14, janmar, 2002.

\title{
APÊNDICE 1 - INSTRUMENTO DE COLETA DE DADOS Roteiro de entrevista
}

\author{
Cargo Ocupado \\ Área de atuação dentro da \\ organização (ensino, pesquisa, \\ assistência) \\ Tempo no Setor \\ Curso de Graduação
}


\begin{tabular}{|l|l|l|l|l|l|}
\hline Escolaridade & Graduação & Pós-graduação & Mestre & Doutor & Pós-doutor
\end{tabular}

\section{Tema 1 - Avaliação de desempenho organizacional}

1. Existe algum sistema de avaliação de desempenho organizacional no hospital?

a. ( ) SIM ( ) NÃO

2. Se não, que meio o hospital usa para medir seu desempenho?

3. Quando foi iniciada a implantação deste sistema?

4. Se sim, ele abrange todas as áreas do Hospital Universitário?

a. ( ) SIM ( ) NÃO

5. Quais setores fazem parte e quais não?

6. Nos setores que são avaliados como essa avaliação é realizada?

7. Eles recebem feedback de seus resultados na avaliação?

a. ( ) SIM ( ) NÃO

8. Como é realizado esse feedback?

9. O sistema de avaliação de desempenho é revisado?

a. ( ) SIM ( ) NÃO

10. Se sim, como é feita essa revisão? Com que frequência?

11. Se não, porque não são revisados?

12. Como a avaliação de desempenho organizacional e o planejamento estratégico da organização estão relacionados?

13. Os resultados da avaliação são utilizados para o planejamento estratégico?
a. ( ) SIM ( ) NÃO

14. Se não, no que o hospital se baseia para realizar o planejamento estratégico?

15. As áreas de ensino, pesquisa, extensão e assistência são avaliadas em conjunto ou separadamente?

a. ( ) CONJUNTO ( ) SEPARADAS

16. Se em conjunto, como a avaliação é feita?

17. Se separadamente, como é feita em cada uma delas?

18. O hospital compara seus resultados com os de outras instituições?

a. ( ) SIM ( ) NÃO

19. Em ensino? Na pesquisa? Na assistência?

20. Se sim, como? Por qual meio?

21. Quais os critérios de comparação?

Tema 2 - Benefícios e problemas da avaliação de desempenho organizacional

22. Você considera que o uso de avaliação de desempenho traz benefícios para o Hospital?

a. ( ) SIM ( ) NÃO 
23. Se sim, quais os principais benefícios?

24. Você considera que o sistema de avaliação de desempenho poderia melhorar?

a. ( ) SIM ( ) NÃO

25. Se sim, quais seriam essas oportunidades de melhoria?

26. Você considera que a avaliação enfrenta alguma dificuldade ou encontra barreiras para seu uso na organização?

a. ( ) SIM ( ) NÃO

27. Se sim, quais seriam essas dificuldades ou barreiras?

Tema 3 - Indicadores de avaliação de desempenho organizacional

28. O Hospital Universitário utiliza algum indicador de avaliação de desempenho organizacional?

a. ( ) SIM ( ) NÃO

29. Se sim, quais são os principais indicadores de desempenho (os mais importantes) utilizados pelo hospital universitário?

30. Se, não que meios o hospital utiliza?

31. Os indicadores de desempenho são revisados?

a. ( ) SIM ( ) NÃO

32. Se sim, como é feita essa revisão? Com que frequência?

33. Se não, porque não são revisados?

34. Você considera que os indicadores de avaliação de desempenho entre os objetivos organizacionais estão alinhados?

a. ( ) SIM ( ) NÃO

35. Por quê? Dê um exemplo.

36. Existem indicadores diretamente relacionados a cada objetivo organizacional?

a. ( ) SIM ( ) NÃO

37. Se sim, cite alguns.

38. O Hospital Universitário já utilizava algum tipo de indicador antes do início da implantação do sistema de avaliação de desempenho organizacional?

39. Existem metas para os indicadores de avaliação de desempenho organizacional?

a. ( ) SIM ( ) NÃO

40. Os setores do HU participam na elaboração e revisão de suas metas de avaliação de desempenho?

a. ( ) SIM ( ) NÃO

41. Como é essa participação?

42. Qual sua impressão geral sobre a avaliação de desempenho organizacional realizada no HU? 


\section{APÊNDICE 2 - TERMO DE CONSENTIMENTO}

\section{Termo de Consentimento Livre e Esclarecido}

Esta pesquisa faz parte do estudo realizado por Joice Chiareto, acadêmica do Programa de Pós-Graduação em Administração da Faculdade de Economia, Administração e Contabilidade da Universidade de São Paulo - PPGA - FEAUSP, para a obtenção do título de Mestre em Ciências - Administração. O projeto de pesquisa possui o título "Avaliação de desempenho organizacional - um estudo em hospitais universitários públicos" e tem como objetivo analisar o sistema de avaliação de desempenho organizacional dos hospitais universitários.

Destaco que sua identidade permanecerá anônima, nos trabalhos decorrentes desta pesquisa serão divulgados somente nível administrativo e a área à qual o entrevistado pertence (exemplo: Pesquisa - alta administração). Os dados recolhidos serão publicados em uma dissertação de mestrado e em artigos decorrentes da dissertação. Se o entrevistado desejar poderá ter acesso aos resultados da pesquisa. Esta será uma entrevista semiestruturada com duração entre 20 e 30 minutos. O entrevistado é livre para recusar-se a participar da pesquisa ou retirar seu consentimento em qualquer fase da pesquisa sem penalização alguma.

No caso de interesse pelos resultados, preencha o campo "e-mail para contato" para receber um resumo com os resultados da pesquisa.

Agradeço sua colaboração.

Responsável pela pesquisa: Joice Chiareto

Acadêmica do Mestrado em Administração - Programa de Pós-Graduação em Administração da Faculdade de Economia, Administração e Contabilidade da Universidade de São Paulo - PPGA - FEAUSP.

Contato da Pesquisadora: E-mail: joice.chiareto@usp.br ; Tel.: 11 - 96261-7665.

Programa de Pós-Graduação em Administração - PPGA - FEAUSP. Av. Prof. Luciano Gualberto, 908 - Cid. Universitária - SP CEP: 05508-010 - Horário de Atendimento: De $2^{a}$ a $6^{a}$ das 9:00h às 17:00h. Telefones: (011) 3091-5805 Fax: (011) 3818-4003. Email:ppgafea@usp.br

Joice Chiareto

Entrevistado 
Pesquisadora: Joice Chiareto - Mestrado em Administração - PPGA - FEAUSP.

Contatos: E-mail: joice.chiareto@usp.br ; Tel.: 11 - 96261-7665.

\section{Responsável pela pesquisa}

\section{Joice Chiareto}

Acadêmica do Mestrado em Administração - Programa de Pós-Graduação em Administração da Faculdade de Economia, Administração e Contabilidade da Universidade de São Paulo - PPGA - FEAUSP.

Contato da Pesquisadora: E-mail: joice.chiareto@usp.br ; Tel.: 11 - 96261-7665.

\section{Dados de Identificação do Participante da Pesquisa}

Nome do participante:

$\mathrm{N}^{\mathrm{o}}$ do documento de identidade:

Sexo:

Data de nascimento:

Endereço:

Telefone:

E-mail para contato:

Local e Data: de de 2014.

\section{Entrevistado}

Declaro que, após convenientemente esclarecido pelo pesquisador e ter entendido o que me foi explicado, aceito participar do presente Projeto de Pesquisa. 
Pesquisadora: Joice Chiareto - Mestrado em Administração - PPGA - FEAUSP.

Contatos: E-mail: joice.chiareto@usp.br ; Tel.: 11 - 96261-7665. 
ANEXO 1 - AUTORIZAÇÃO DO COMITÊ DE ÉTICA HU-USP

HOSPITAL UNIVERSITÁRIO DA
UNIVERSIDADE DE SÃO
PAULO - HU/USP

\section{PARECER CONSUBSTANCIADO DO CEP}

\section{DADOS DO PROJETO DE PESQUISA}

Título da Pesquisa: Avaliação de desempenho organizacional - um estudo em hospitais universitários públicos.

Pesquisador: Joice Chiareto

Área Temática:

Versão: 2

CAAE: 30938314.6 .0000 .0076

Instituição Proponente:UNIVERSIDADE DE SAO PAULO

Patrocinador Principal: Financiamento Próprio

DADOS DO PARECER

Número do Parecer: 706.377

Data da Relatoria: $27 / 06 / 2014$

Apresentação do Projeto:

Avaliação de desempenho organizacional - um estudo em hospitais universitários públicos.

Pesquisador: Joice Chiareto

\section{Objetivo da Pesquisa:}

Objetivo Primário: Compreender como é realizada a avaliação de desempenho organizacional nos hospitais universitários públicos. Objetivo Secundário: Identificar a existência de sistemas de avaliação de desempenho organizacional nos hospitais universitários. Identificar as características da avaliação de desempenho organizacional nos hospitais universitários. Identificar os beneficios trazidos pelo uso de avaliação de desempenho

organizacional nos hospitais universitários. Identificar as dificuldades enfrentadas pela avaliação de desempenho organizacional nos hospitais universitários. É uma pesquisa qualitativa do tipo exploratória, que usa objetivos de pesquisa no lugar de hipóteses.

\section{Avaliação dos Riscos e Benefícios:}

Poderá contribuir no melhor desempenho organizacional, mas não se pode garantir á priori que isto ocorrerá. O risco de participação é nulo

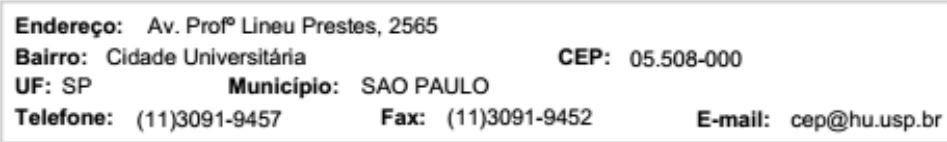




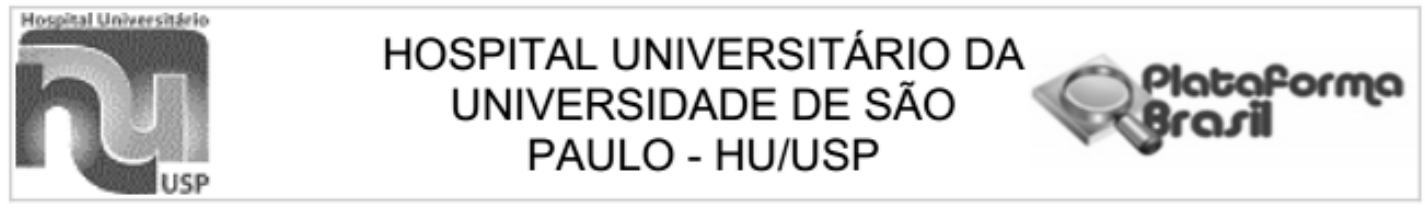

Continuaçăo do Parecer: 706.377

\section{Comentários e Considerações sobre a Pesquisa:}

De grande interesse. Já fora aprovada pelo colegiado em 23/5/2014

Considerações sobre os Termos de apresentação obrigatória:

De fácil compreensão

\section{Recomendações:}

Não existem

Conclusões ou Pendências e Lista de Inadequações:

Não existem

Situação do Parecer:

Aprovado

Necessita Apreciação da CONEP:

Não

Considerações Finais a critério do CEP:

Este projeto já fora apresentado e aprovado anteriormente em 23 de maio de 2014. A emenda feita pela pesquisadora é a carta de anuência da UNIFESP

SAO PAULO, 02 de Julho de 2014

Assinado por:

Mauricio Seckler

(Coordenador)

Endereço: Av. Prof Lineu Prestes, 2565

Bairro: Cidade Universitária

CEP: $05.508-000$

UF: SP

Municipio: SAO PAULO

Telefone: (11)3091-9457

Fax: (11)3091-9452

E-mail: cep@hu.usp.br 


\title{
ANEXO 2 - AUTORIZAÇÃO DO COMITÊ DE ÉTICA HCFMRP-USP
}

\author{
HOSPITAL DAS CLINICAS DA FACULDADE DE MEDICINA \\ DE RIBEIRÃO PRETO DA UNIVERSIDADE DE SÃO PAULO
}

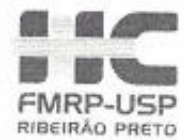

Ribeirão Preto, 13 de Junho de 2014

Projeto de pesquisa: "AVALIAÇÃO DE DESEMPENHO ORGANIZACIONAL UM ESTUDO EM HOSPITAIS UNIVERSITÁRIOS PÚBLICOS”

Pesquisador responsável: Joice Chiareto

Instituição Proponente: Faculdade de Economia, Administração e Contabilidade da Universidade de São Paulo.

"O CEP do HC e da FMRP-USP concorda com o parecer ético emitido pelo CEP da Instituiçāo Proponente, que cumpre as Resoluçōes Éticas Brasileiras, em especial a Resolução CNS 466/12. Diante disso, o HCFMRP-USP, como instituição coparticipante do referido projeto de pesquisa, está ciente de suas coresponsabilidades e de seu compromisso no resguardo da segurança e bem-estar

Ciente e de acordo:

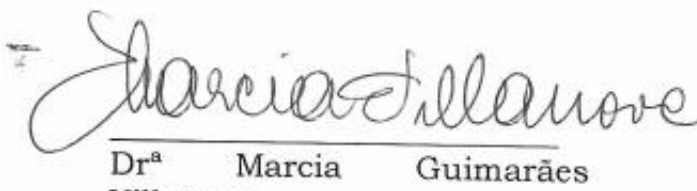

Villanova

Coordenadora do Comitē de Ética em Pesquisa - HCFMRPUSP

Prof. Dr. José Alexandre de Souza Crippa

Coordenador Técnico Cientifico da Unidade de Pesquisa Clínica HCFMRP-USP
Campus Universitário - Monte Alegre 14048-900 Ribeiräo Preto SP
Comité de Ética em Pesquisa do HCRP e FMRP-USP FWA-00002733: IRB-00002185 e Registro Plataforma Brasil/CONEP $n^{\circ} 5440$ (016) $3602-2228$ 
ANEXO 3 - INDICADORES-CHAVE DO HCFMRP-USP

\begin{tabular}{|c|c|c|c|c|}
\hline Indicador/Categoria & Fórmula & O que mede & Pontuação & Pontos \\
\hline \multicolumn{5}{|l|}{1 - Atenção à Saúde } \\
\hline \multicolumn{5}{|l|}{ A) Ambulatório } \\
\hline $\begin{array}{l}\text { Porcentagem de vagas } \\
\text { disponibilizadas de } 1^{\mathrm{a}} \mathrm{s} \\
\text { Consultas da Rede }\end{array}$ & $\begin{array}{l}\left(\mathrm{N}^{\circ} \text { de vagas }\right. \\
\text { novas } \\
\text { disponibilizadas } \\
/ \mathrm{N}^{\circ} \text { de } \\
\text { consultas } \\
\text { realizadas }) * \\
100\end{array}$ & $\begin{array}{l}\text { O nível de } \\
\text { abertura de novas } \\
\text { vagas } \\
\text { ambulatoriais } \\
\text { para a rede. }\end{array}$ & $\begin{array}{l}X>=10,0 \%-25 \\
\text { pontos } \\
9,0 \%<=X<10,0- \\
20 \text { pontos } \\
8,0<=X<9,0 \%-15 \\
\text { pontos } \\
X<8,0 \% \text { - não } \\
\text { pontua }\end{array}$ & 25 \\
\hline $\begin{array}{l}\text { Porcentagem de Consultas } \\
\text { de Pacientes Novos }\end{array}$ & $\begin{array}{l}\mathrm{N}^{\mathrm{o}} \text { de Consultas } \\
\text { de } 1^{\mathrm{a}} \text { vez da } \\
\text { rede }\end{array}$ & $\begin{array}{l}\text { O nível de } \\
\text { abertura de novos } \\
\text { pacientes } \\
\text { advindos da rede. }\end{array}$ & $\begin{array}{l}\text { Apresentou } \\
\text { informação - pontua } \\
\text { Não apresentou - não } \\
\text { pontua }\end{array}$ & 20 \\
\hline $\begin{array}{l}\text { Taxa de Agendamento das } \\
\text { Vagas Disponibilizadas } \\
\text { para DRS }\end{array}$ & $\begin{array}{l}\left(\mathrm{N}^{\circ} \text { de }\right. \\
\text { agendamentos } \\
\text { realizados pelas } \\
\text { DRS nas vagas } \\
\text { novas } \\
\text { disponibilizadas } \\
\text { / } \mathrm{N}^{\circ} \text { de vagas } \\
\text { disponibilizadas } \\
\text { para as DRS }) * \\
100\end{array}$ & $\begin{array}{l}\text { O funcionamento } \\
\text { do sistema de } \\
\text { agendamento. }\end{array}$ & $\begin{array}{l}X>=73,3 \%-25 \\
\text { pontos } \\
71,5 \%<=X<73,3- \\
15 \text { pontos } \\
70,0 \%<=X<71,5 \%- \\
10 \text { pontos } \\
X<70,0 \% \text { - não } \\
\text { pontua }\end{array}$ & 25 \\
\hline $\begin{array}{l}\text { Média de Consultas } \\
\text { Médicas agendadas por } \\
\text { consultório/dia útil }\end{array}$ & $\begin{array}{l}\left(\mathrm{N}^{\circ} \text { de }\right. \\
\text { Consultas } \\
\text { agendadas por } \\
\text { dia útil / } \\
\text { número de } \\
\text { consultórios) }\end{array}$ & $\begin{array}{l}\text { O nível de } \\
\text { utilização da } \\
\text { capacidade } \\
\text { disponibilizada } \\
\text { no ambulatório. }\end{array}$ & $\begin{array}{l}X>=10-20 \text { pontos } \\
8,5<=X<10-15 \\
\text { pontos } \\
7<=X<8,5-10 \\
\text { pontos } \\
X<7 \text { - não pontua }\end{array}$ & 20 \\
\hline $\begin{array}{l}\text { Elaboração dos Protocolos } \\
\text { de referência }\end{array}$ & Sim/Não & $\begin{array}{l}\text { O funcionamento } \\
\text { e organização da } \\
\text { rede }\end{array}$ & $\begin{array}{l}\text { Apresentou } \\
\text { informação - pontua } \\
\text { Não apresentou - não } \\
\text { pontua }\end{array}$ & 25 \\
\hline $\begin{array}{l}\text { Elaboração do Plano de } \\
\text { Contrarreferência }\end{array}$ & Sim/Não & $\begin{array}{l}\text { O funcionamento } \\
\text { e organização da } \\
\text { rede }\end{array}$ & $\begin{array}{l}\text { Apresentou } \\
\text { informação - pontua } \\
\text { Não apresentou - não } \\
\text { pontua }\end{array}$ & 20 \\
\hline $\begin{array}{l}\text { Taxa de alta do paciente em } \\
\text { seguimento }\end{array}$ & $\begin{array}{l}\left(\mathrm{N}^{\circ} \text { de altas } / \mathrm{n}^{\circ}\right. \\
\text { de pacientes em } \\
\text { seguimento })\end{array}$ & $\begin{array}{l}\text { Avalia a } \\
\text { qualidade do } \\
\text { encaminhamento } \\
\text { médico no HC }\end{array}$ & $\begin{array}{l}X>=1,5-25 \text { pontos } \\
1,4<=X<1,5-20 \\
\text { pontos } \\
1,2<=X<1,4-15 \\
\text { pontos } \\
X<1,2 \text { - não pontua }\end{array}$ & 25 \\
\hline $\begin{array}{l}\text { Índice de absenteísmo de } \\
\text { pacientes agendados no } \\
\text { período (em seguimento) }\end{array}$ & $\begin{array}{l}\left(\mathrm{N}^{\circ} \text { de faltas / }\right. \\
\mathrm{n}^{\circ} \text { de consultas } \\
\text { agendadas })\end{array}$ & $\begin{array}{l}\text { O nível de } \\
\text { utilização da } \\
\text { capacidade } \\
\text { disponibilizada } \\
\text { no ambulatório. }\end{array}$ & $\begin{array}{l}\text { Apresentou } \\
\text { informação - pontua } \\
\text { Não apresentou - não } \\
\text { pontua }\end{array}$ & 25 \\
\hline \multicolumn{5}{|l|}{ B) Internação } \\
\hline $\begin{array}{l}\text { Taxa de Ocupação } \\
\text { Operacional }\end{array}$ & $\begin{array}{l}\left(\mathrm{N}^{\mathrm{o}} \text { de diárias } /\right. \\
\left.\mathrm{n}^{\mathrm{o}} \text { de leitos-dia }\right) \\
* 100\end{array}$ & $\begin{array}{l}\text { O nível de } \\
\text { utilização dos } \\
\text { leitos hospitalares } \\
\text { disponíveis, } \\
\text { cadastrados no } \\
\text { SUS. }\end{array}$ & $\begin{array}{l}X>100,0 \%-20 \\
\text { pontos } \\
85,1 \%<=X<=100,0 \%- \\
25 \text { ptos } \\
80,0 \%<=X<85,1 \% \\
-20 \text { pontos } \\
75,5 \%<=X<80,0 \%-\end{array}$ & 25 \\
\hline
\end{tabular}




\begin{tabular}{|c|c|c|c|c|}
\hline & & & $\begin{array}{l}15 \text { pontos } \\
X<75,5 \% \text { - não } \\
\text { pontua }\end{array}$ & \\
\hline $\begin{array}{l}\text { Média de Permanência } \\
\text { (dias) }\end{array}$ & $\begin{array}{l}\left(\mathrm{N}^{\mathrm{o}} \text { de diárias / }\right. \\
\left.\mathrm{n}^{\mathrm{o}} \text { de altas }\right)^{*} \\
100\end{array}$ & $\begin{array}{l}\text { O tempo médio } \\
\text { que um paciente } \\
\text { permanece } \\
\text { internado no } \\
\text { hospital. }\end{array}$ & $\begin{array}{l}X<=6,7-25 \text { pontos } \\
6,7<X<=7,0-20 \\
\text { pontos } \\
7,0<X<=7,5-15 \\
\text { pontos } \\
X>7,5 \text { - não pontua }\end{array}$ & 25 \\
\hline \multicolumn{5}{|l|}{ C) Exames } \\
\hline $\begin{array}{l}\text { Percentual de exames } \\
\text { ofertados como SADT } \\
\text { externo efetivamente } \\
\text { realizado }\end{array}$ & $\begin{array}{l}\text { ( } \mathrm{N}^{\circ} \text { de exames } \\
\text { SADT } \\
\text { realizado para } \\
\text { paciente } \\
\text { externo/ } \mathrm{N}^{\circ} \text { de } \\
\text { Exames SADT } \\
\text { ofertado p/ } \\
\text { paciente } \\
\text { externo }\end{array}$ & $\begin{array}{l}\text { O nível de } \\
\text { utilização dos } \\
\text { exames ofertados } \\
\text { para paciente } \\
\text { externo }\end{array}$ & $\begin{array}{l}\text { Apresentou } \\
\text { informação - pontua } \\
\text { Não apresentou - não } \\
\text { pontua }\end{array}$ & 50 \\
\hline \multicolumn{5}{|l|}{ D) Cirurgias } \\
\hline $\begin{array}{l}\text { Média mensal de cirurgias } \\
\text { por sala }\end{array}$ & $\begin{array}{l}\mathrm{N}^{\circ} \text { de cirurgias } \\
\text { realizadas / } \mathrm{N}^{\mathrm{o}} \\
\text { de salas } \\
\text { funcionando }\end{array}$ & $\begin{array}{l}\text { A utilização das } \\
\text { salas cirúrgicas } \\
\text { disponíveis, } \\
\text { excluindo-se as } \\
\text { bloqueados por } \\
\text { reforma. }\end{array}$ & $\begin{array}{l}X>=57-25 \text { pontos } \\
54<=X<57-20 \\
\text { pontos } \\
50<=X<54-15 \\
\text { pontos } \\
X<50 \text { - não pontua }\end{array}$ & 25 \\
\hline $\begin{array}{l}\text { Taxa de Ocupação das } \\
\text { Salas Cirúrgicas (Campus) }\end{array}$ & $\begin{array}{l}\left(\mathrm{N}^{\mathrm{o}} \text { de horas }\right. \\
\text { utilizadas / } \mathrm{N}^{\mathrm{o}} \\
\text { de horas } \\
\text { disponíveis }) \\
* 100\end{array}$ & $\begin{array}{l}\text { A utilização das } \\
\text { salas cirúrgicas } \\
\text { disponíveis. }\end{array}$ & $\begin{array}{l}X>=82,0 \%-25 \\
\text { pontos } \\
80,0 \%<X<82,0 \%- \\
20 \text { pontos } \\
78,0 \%<=X<=80,0 \% \\
-15 \text { pontos } \\
X<78,0 \% \text { - não } \\
\text { pontua }\end{array}$ & 25 \\
\hline $\begin{array}{l}\text { Taxa de Infecção por } \\
\text { cirurgia limpa }\end{array}$ & $\begin{array}{l}\left(\mathrm{N}^{\circ} \text { de }\right. \\
\text { Episódios de } \\
\text { Infecção de } \\
\text { cirurgia limpa/ } \\
\mathrm{n}^{\circ} \text { de Cirurgias } \\
\text { limpas }) * 100\end{array}$ & $\begin{array}{l}\text { O Índice de } \\
\text { Infecção } \\
\text { Hospitalar em } \\
\text { pacientes } \\
\text { submetidos à } \\
\text { cirurgia limpa. }\end{array}$ & $\begin{array}{l}X<=3,0-20 \text { pontos } \\
3,0 \%<X<=4,0 \%- \\
15 \text { pontos } \\
4,0 \%<X<=5,0 \%- \\
10 \text { pontos } \\
X>5,0 \% \text { - não pontua }\end{array}$ & 20 \\
\hline \multicolumn{5}{|l|}{ E) Urgência } \\
\hline $\begin{array}{l}\text { Porcentagem de paciente } \\
\text { regulado para U.E. }\end{array}$ & $\begin{array}{l}\left(\mathrm{N}^{\mathrm{o}} \text { de }\right. \\
\text { pacientes } \\
\text { regulados/ } \mathrm{N}^{\mathrm{o}} \\
\text { de } \\
\text { atendimentos }) \\
* 100\end{array}$ & $\begin{array}{l}\mathrm{N}^{\mathrm{o}} \text { de pacientes } \\
\text { novos } \\
\text { encaminhados } \mathrm{p} / \\
\text { U.E. }\end{array}$ & $\begin{array}{l}X>=72,2 \%-25 \\
\text { pontos } \\
70,0 \%<=X<72,2 \%- \\
20 \text { pontos } \\
67,0 \%<=X<70,0 \% \\
-15 \text { pontos } \\
X<67,0 \% \text { - não } \\
\text { pontua }\end{array}$ & 25 \\
\hline Taxa de Internação da U.E. & $\begin{array}{l}\left(\mathrm{N}^{\circ} \text { de }\right. \\
\text { pacientes } \\
\text { internados no } \\
\text { P.S / }{ }^{\circ} \text { de } \\
\text { pacientes } \\
\text { atendidos no } \\
\text { PS }) * 100\end{array}$ & $\begin{array}{l}\mathrm{N}^{\circ} \text { de internações } \\
\text { em relação aos } \\
\text { pacientes } \\
\text { atendidos na UE. } \\
\text { Obs.: Exceto } \\
\text { oftalmologia. }\end{array}$ & $\begin{array}{l}X>=64,3 \%-20 \\
\text { pontos } \\
62,0 \%<=X<64,3 \%- \\
15 \text { pontos } \\
60,0 \%<=X<62,0 \%- \\
10 \text { pontos } \\
X<60,0 \% \text { - não pontua }\end{array}$ & 20 \\
\hline \multicolumn{5}{|l|}{2 - Ensino e Pesquisa } \\
\hline $\begin{array}{l}\text { Registro de } \\
\text { Horas/Homem/Treinamento }\end{array}$ & Sim/Não & $\begin{array}{l}\text { O interesse da } \\
\text { Instituição na } \\
\text { Capacitação de }\end{array}$ & $\begin{array}{l}\text { Treinamento } \\
\text { realizado - pontua } \\
\text { Não apresentou - não }\end{array}$ & 30 \\
\hline
\end{tabular}




\begin{tabular}{|c|c|c|c|c|}
\hline & & $\begin{array}{l}\text { Recursos } \\
\text { Humanos }\end{array}$ & pontua & \\
\hline $\begin{array}{l}\text { Percentual de Funcionários } \\
\text { Treinados }\end{array}$ & Sim/Não & $\begin{array}{l}\text { O interesse da } \\
\text { Instituição na } \\
\text { Capacitação de } \\
\text { Recursos } \\
\text { Humanos }\end{array}$ & $\begin{array}{l}\text { Apresentou } \\
\text { informação - pontua } \\
\text { Não apresentou - não } \\
\text { pontua }\end{array}$ & 25 \\
\hline $\begin{array}{l}\mathbf{N}^{\circ} \text { de Projetos apresentados } \\
\text { ao Comitê de Ética em } \\
\text { Pesquisa }\end{array}$ & Sim/Não & $\begin{array}{l}\text { O interesse da } \\
\text { Instituição na } \\
\text { pesquisa }\end{array}$ & $\begin{array}{l}\text { Apresentou } \\
\text { informação - pontua } \\
\text { Não apresentou - não } \\
\text { pontua }\end{array}$ & 50 \\
\hline $\begin{array}{l}\mathbf{N}^{0} \text { de Auxílios Faepa para } \\
\text { Projetos de Pesquisa }\end{array}$ & Sim/Não & $\begin{array}{l}\text { O interesse da } \\
\text { Instituição na } \\
\text { pesquisa }\end{array}$ & $\begin{array}{l}\text { Apresentou } \\
\text { informação - pontua } \\
\text { Não apresentou - não } \\
\text { pontua }\end{array}$ & 50 \\
\hline \multicolumn{5}{|l|}{3 - Gestão Hospitalar } \\
\hline Faturamento Hospitalar & $\begin{array}{l}\text { Valor do } \\
\text { contrato } x \\
\text { faturamento }\end{array}$ & $\begin{array}{l}\text { Acompanhamento } \\
\text { no processo de } \\
\text { Faturamento } \\
\text { Hospitalar }\end{array}$ & $\begin{array}{l}X>95,0 \%-30 \text { pontos } \\
85,0 \%<X<=95,0 \%- \\
20 \text { pontos } \\
80,0 \%<=X<=85,0 \% \\
-10 \text { pontos } \\
X<80,0 \% \text { - não } \\
\text { pontua }\end{array}$ & 30 \\
\hline Faturamento Ambulatorial & $\begin{array}{l}\text { Valor do } \\
\text { contrato } x \\
\text { faturamento }\end{array}$ & $\begin{array}{l}\text { Acompanhamento } \\
\text { no processo de } \\
\text { Faturamento } \\
\text { Ambulatorial }\end{array}$ & $\begin{array}{l}X>90,0 \%-30 \\
\text { pontos } \\
80,0 \%<=X<=90,0 \% \\
-20 \text { pontos } \\
70,0 \%<=X<80,0 \%- \\
10 \text { ptos } \\
X<70,0 \% \text { - não } \\
\text { pontua }\end{array}$ & 30 \\
\hline $\begin{array}{l}\text { Valor médio (por } \\
\text { especialidade) das AIH's } \\
\text { apresentadas. }\end{array}$ & Sim/Não & $\begin{array}{l}\text { Acompanhamento } \\
\text { mensal do } \\
\text { processo de } \\
\text { Faturamento } \\
\text { Hospitalar - } \\
\text { SIH/SUS com } \\
\text { referências } \\
\text { anuais. }\end{array}$ & $\begin{array}{l}\text { Apresentou } \\
\text { informação - pontua } \\
\text { Não apresentou - não } \\
\text { pontua }\end{array}$ & 30 \\
\hline $\begin{array}{l}\text { Pesquisa de Clima } \\
\text { Organizacional }\end{array}$ & Sim/Não & $\begin{array}{l}\text { O nível de } \\
\text { satisfação dos } \\
\text { servidores, } \\
\text { através de } \\
\text { questionários } \\
\text { aplicados. }\end{array}$ & $\begin{array}{l}\text { Apresentou } \\
\text { informação - pontua } \\
\text { Não apresentou - não } \\
\text { pontua }\end{array}$ & 25 \\
\hline $\begin{array}{l}\text { Índice de Absenteísmo dos } \\
\text { Servidores }\end{array}$ & $\begin{array}{l}\left(\mathrm{N}^{\mathrm{o}} \text { de dias }\right. \\
\text { faltantes } / \mathrm{n}^{\text {o de }} \\
\text { servidores/dia) } \\
* 100\end{array}$ & $\begin{array}{l}\text { O absenteísmo } \\
\text { dos servidores. }\end{array}$ & $\begin{array}{l}X<=5,8 \%-30 \\
\text { pontos } \\
5,8 \%<X<=6,7 \%- \\
20 \text { pontos } \\
6,7 \%<X<=7,0 \%- \\
10 \text { pontos } \\
X>7,0 \% \text { - não } \\
\text { pontua }\end{array}$ & 30 \\
\hline
\end{tabular}




\begin{tabular}{|c|c|c|c|c|}
\hline $\begin{array}{l}\text { Atas de: Comissão de } \\
\text { Análise de Prontuário e } \\
\text { Óbitos; Bloco Cirúrgico; } \\
\text { Comissão de Oncologia; } \\
\text { Conselho Deliberativo; } \\
\text { Comissão de Farmácia e } \\
\text { Terapêutica; Comitê de } \\
\text { Mortalidade Materna; } \\
\text { Comissão de Ética Médica; } \\
\text { Comitê Assessor de } \\
\text { Materiais; Comissão de } \\
\text { Ética em Pesquisa; Reunião } \\
\text { de Diretores/Financeira; } \\
\text { CCIH; Equipe de } \\
\text { Planejamento U.E. } \\
\text { Comissão Intra-hospitalar } \\
\text { de Transplantes }\end{array}$ & $\begin{array}{l}\text { Para cada } \\
\text { comissão que } \\
\text { apresentar } \\
\text { Atas/Relatório } \\
\text { do Trimestre } \\
\text { será computado } \\
5 \text { pontos. }\end{array}$ & $\begin{array}{l}\text { Demonstrar que a } \\
\text { Instituição possui } \\
\text { Comissões } \\
\text { formalizadas e } \\
\text { organizadas. }\end{array}$ & $\begin{array}{l}\text { Para cada comissão } \\
\text { que apresentar } \\
\text { Atas/Relatório do } \\
\text { Trimestre será } \\
\text { computado } 05 \text { pontos. } \\
\text { Pontuação máxima } 50 \\
\text { pontos. }\end{array}$ & 50 \\
\hline \multicolumn{5}{|l|}{4 - Comunidade e Humanização } \\
\hline $\begin{array}{l}\text { Pesquisa de Satisfação do } \\
\text { Ambulatório }\end{array}$ & Sim/Não & $\begin{array}{l}\text { O nível de } \\
\text { satisfação dos } \\
\text { pacientes, através } \\
\text { de questionários } \\
\text { aplicados. }\end{array}$ & $\begin{array}{l}\text { Apresentou } \\
\text { informação - pontua } \\
\text { Não apresentou - não } \\
\text { pontua }\end{array}$ & 50 \\
\hline $\begin{array}{l}\text { Pesquisa de Satisfação das } \\
\text { Enfermarias (Campus e } \\
\text { U.E.) }\end{array}$ & Sim/Não & $\begin{array}{l}\text { O nível de } \\
\text { satisfação dos } \\
\text { pacientes, através } \\
\text { de questionários } \\
\text { aplicados. }\end{array}$ & $\begin{array}{l}X>=25,0 \%-50 \\
\text { pontos } \\
23,0 \%<=X<25,0 \%- \\
40 \text { pontos } \\
21,0 \%<=X<23,0 \%- \\
30 \text { pontos } \\
X<21,0 \% \text { - não } \\
\text { pontua }\end{array}$ & 50 \\
\hline $\begin{array}{l}\text { Apresentar relatório de } \\
\text { ações ambientais }\end{array}$ & Sim/Não & $\begin{array}{l}\text { A } \\
\text { sustentabilidade } \\
\text { institucional. }\end{array}$ & $\begin{array}{l}\text { Apresentou } \\
\text { informação - pontua } \\
\text { Não apresentou - não } \\
\text { pontua }\end{array}$ & 50 \\
\hline $\begin{array}{l}\text { Programa de Humanização } \\
\text { e o Público Atendido }\end{array}$ & Sim/Não & $\begin{array}{l}\text { O interesse da } \\
\text { Instituição em } \\
\text { atender os } \\
\text { clientes, pautada } \\
\text { no respeito à vida } \\
\text { humana. }\end{array}$ & $\begin{array}{l}\text { Apresentou } \\
\text { informação - pontua } \\
\text { Não apresentou - não } \\
\text { pontua }\end{array}$ & 50 \\
\hline $\begin{array}{l}\text { Taxa de Resposta da } \\
\text { Ouvidoria }\end{array}$ & Sim/Não & $\begin{array}{l}\text { Demonstrar que a } \\
\text { Instituição se } \\
\text { preocupa com } \\
\text { seus clientes. }\end{array}$ & $\begin{array}{l}X>=95,0 \%-50 \\
\text { pontos } \\
90,0 \%<=X<95,0 \%- \\
40 \text { pontos } \\
85,0 \%<=X<90,0 \%- \\
30 \text { pontos } \\
X<85,0 \% \text { - não } \\
\text { pontua }\end{array}$ & 50 \\
\hline
\end{tabular}


ANEXO 4 - INDICADORES OPERACIONAIS DO HCFMRP-USP

\begin{tabular}{|c|c|c|c|c|c|}
\hline $\mathbf{N}^{0}$ & Indicador & Fórmula & Periodicidade & Meta & Categoria \\
\hline 1 & $\begin{array}{l}\text { Incidência de } \\
\text { flebite em acesso } \\
\text { venoso periférico } \\
\text { nas enfermarias de } \\
\text { Cl.Part. E } \\
\text { Convênios }\end{array}$ & $\begin{array}{l}\text { ( } \mathrm{N}^{\circ} \text { de flebites no } \\
\text { período / } \mathrm{N}^{\circ} \text { de } \\
\text { pacientes/dia com } \\
\text { acesso venoso } \\
\text { periférico no período) X } \\
100\end{array}$ & Mensal & Indice $<1,25 \%$ & $\begin{array}{l}\text { Atenção a } \\
\text { Saúde }\end{array}$ \\
\hline 2 & $\begin{array}{l}\text { Incidência de } \\
\text { quedas nos } \\
\text { pacientes nas } \\
\text { enfermarias de } \\
\text { Cl.Part. E } \\
\text { Convênios }\end{array}$ & $\begin{array}{l}\left(\mathrm{N}^{\circ} \text { de quedas no }\right. \\
\text { período / } \mathrm{N}^{\circ} \text { de } \\
\text { pacientes/dia no } \\
\text { período) X } 100\end{array}$ & Mensal & Índice $<0,43 \%$ & $\begin{array}{l}\text { Atenção a } \\
\text { Saúde }\end{array}$ \\
\hline 3 & $\begin{array}{l}\text { Taxa de resposta da } \\
\text { caixa de sugestões }\end{array}$ & $\begin{array}{l}\left(\mathrm{N}^{\circ} \text { de respostas das }\right. \\
\text { áreas/ Total de } \\
\text { reclamações/sugestões) } \\
\text { X } 100\end{array}$ & Mensal & $85 \%$ & $\begin{array}{l}\text { Gestão } \\
\text { Hos } \\
\text { pitalar }\end{array}$ \\
\hline 4 & $\begin{array}{l}\text { Tempo médio de } \\
\text { execução das } \\
\text { atividades } \\
\text { p/aplicação de } \\
\text { medidas } \\
\text { disciplinares }\end{array}$ & $\begin{array}{l}\text { Somatória de dias para } \\
\text { execução das } \\
\text { atividades/ } \mathrm{N}^{\circ} \text { de me } \\
\text { didas disciplinares. }\end{array}$ & Mensal & 15 dias & $\begin{array}{l}\text { Gestão } \\
\text { Hos } \\
\text { pitalar }\end{array}$ \\
\hline 5 & $\begin{array}{l}\text { Taxa de } \\
\text { rotatividade dos } \\
\text { funcionários - } \\
\text { HCRP }\end{array}$ & $\begin{array}{l}\left(\mathrm{N}^{\circ} \text { de desligamentos }\right. \\
/ \mathrm{n}^{\circ} \text { total de servidores } \\
\text { no quadro de pessoal) } \mathrm{x} \\
100\end{array}$ & Mensal & $\mathrm{HCRP}=0,5 \%$ & $\begin{array}{l}\text { Gestão } \\
\text { Hospitalar }\end{array}$ \\
\hline 6 & $\begin{array}{l}\text { Taxa de } \\
\text { rotatividade dos } \\
\text { funcionários - } \\
\text { FAEPA }\end{array}$ & $\begin{array}{l}\left(\mathrm{n}^{\circ} \text { de desligamentos / }\right. \\
\mathrm{n}^{\circ} \text { total de servidores no } \\
\text { quadro de pessoal) } \mathrm{x} \\
100\end{array}$ & Mensal & $\mathrm{FAEPA}=1,6 \%$ & $\begin{array}{l}\text { Gestão } \\
\text { Hospitalar }\end{array}$ \\
\hline 7 & $\begin{array}{l}\text { Tempo médio de } \\
\text { preenchimento de } \\
\text { vagas (Global) }\end{array}$ & $\begin{array}{l}\text { Quantidade de vagas } \\
\text { preenchidas/ Tempo } \\
\text { para preenchimento } \\
\text { (dias) }\end{array}$ & Mensal & $\begin{array}{l}90 \text { dias com abertu } \\
\text { ra de processo sele } \\
\text { tivo. }\end{array}$ & $\begin{array}{l}\text { Gestão } \\
\text { Hospitalar }\end{array}$ \\
\hline 8 & $\begin{array}{l}\text { Tempo Médio de } \\
\text { preenchimento de } \\
\text { vagas FAEPA - } \\
\text { C/Abert.Proc.Selet. }\end{array}$ & $\begin{array}{l}\text { Quantidade de vagas } \\
\text { preenchidas/ Tempo } \\
\text { para preenchimento } \\
\text { (dias) }\end{array}$ & Mensal & $\begin{array}{l}80 \text { dias com abertu } \\
\text { ra de processo sele } \\
\text { tivo. }\end{array}$ & $\begin{array}{l}\text { Gestão } \\
\text { Hospitalar }\end{array}$ \\
\hline 9 & $\begin{array}{l}\text { Tempo Médio de } \\
\text { preenchimento de } \\
\text { vagas HCRP - Sem } \\
\text { Abert.Proc.Selet. }\end{array}$ & $\begin{array}{l}\text { Quantidade de vagas } \\
\text { preenchidas/ Tempo } \\
\text { para preenchimento } \\
\text { (dias) }\end{array}$ & Mensal & $\begin{array}{l}50 \text { dias com abertu } \\
\text { ra de processo sele } \\
\text { tivo. }\end{array}$ & $\begin{array}{l}\text { Gestão } \\
\text { Hospitalar }\end{array}$ \\
\hline 10 & $\begin{array}{l}\text { Tempo Médio de } \\
\text { preenchimento de } \\
\text { vagas FAEPA - } \\
\text { Sem } \\
\text { Abert.Proc.Selet. }\end{array}$ & $\begin{array}{l}\text { Quantidade de vagas } \\
\text { preenchidas/ Tempo } \\
\text { para preenchimento } \\
\text { (dias) }\end{array}$ & Mensal & $\begin{array}{l}45 \text { dias com abertu } \\
\text { ra de processo sele } \\
\text { tivo. }\end{array}$ & $\begin{array}{l}\text { Gestão } \\
\text { Hospitalar }\end{array}$ \\
\hline 11 & $\begin{array}{l}\text { Tempo médio para } \\
\text { elaboração de cada } \\
\text { certidão. }\end{array}$ & $\begin{array}{l}\text { Somatório de dias para } \\
\text { elaboração de cada } \\
\text { certidão / } \mathrm{n}^{\circ} \text { de } \\
\text { certidões elaboradas/ } \\
\text { mês. }\end{array}$ & Mensal & 5,17 dias & $\begin{array}{l}\text { Gestão } \\
\text { Hospitalar }\end{array}$ \\
\hline 12 & $\begin{array}{l}\text { Tempo médio para } \\
\text { elaboração de cada } \\
\text { rescisão contrato. }\end{array}$ & $\begin{array}{l}\text { somatório de dias para } \\
\text { elaboração de cada } \\
\text { recisão / no de rescisões } \\
\text { contratuais }\end{array}$ & Mensal & 3,52 dias & $\begin{array}{l}\text { Gestão } \\
\text { Hospitalar }\end{array}$ \\
\hline
\end{tabular}




\begin{tabular}{|c|c|c|c|c|c|}
\hline & & elaboradas/mês & & & \\
\hline 13 & $\begin{array}{l}\text { Tempo médio para } \\
\text { elaboração do } \\
\text { Contrato de } \\
\text { Trabalho. }\end{array}$ & $\begin{array}{l}\text { Somatório de dias para } \\
\text { elaboração de cada } \\
\text { contrato / } \mathrm{n}^{\circ} \text { de contrato } \\
\text { de trabalho elaborados } \\
\text { no período. }\end{array}$ & Mensal & 0,83 dia & $\begin{array}{l}\text { Gestão } \\
\text { Hospitalar }\end{array}$ \\
\hline 14 & $\begin{array}{l}\text { Tempo Médio para } \\
\text { elaboração de } \\
\text { declara ções }\end{array}$ & $\begin{array}{l}\text { (somatório de dias para } \\
\text { elaboração de cada } \\
\text { declaração / no de } \\
\text { delcarações elaboradas } \\
\text { no período) }\end{array}$ & Mensal & 1,31 dias & $\begin{array}{l}\text { Gestão } \\
\text { Hospitalar }\end{array}$ \\
\hline 18 & $\begin{array}{l}\text { \% de indicadores } \\
\text { atualizados no } \\
\text { Programa Gestão à } \\
\text { Vista }\end{array}$ & $\begin{array}{l}\left(\mathrm{N}^{\circ} \text { de indicadores }\right. \\
\text { atualizados / } \mathrm{N}^{\circ} \text { total de } \\
\text { indicadores do } \\
\text { Programa) } \times 100\end{array}$ & Trimestral & $\begin{array}{l}\text { Obter } 85 \% \text { de } \\
\text { atualização dos } \\
\text { indicadores. }\end{array}$ & $\begin{array}{l}\text { Gestão } \\
\text { Hospitalar }\end{array}$ \\
\hline 19 & $\begin{array}{l}\text { Tempo médio de } \\
\text { atendimento em } \\
\text { dias (Suporte } \\
\text { Técnico) }\end{array}$ & $\begin{array}{l}\text { Mediana do Tempo de } \\
\text { Atendimento de Cada } \\
\text { Ordem de Serviço. }\end{array}$ & Mensal & 1 dia & $\begin{array}{l}\text { Gestão } \\
\text { Hospitalar }\end{array}$ \\
\hline 20 & $\begin{array}{l}\text { Taxa de } \\
\text { manutenções } \\
\text { corretivas dos } \\
\text { sistemas }\end{array}$ & $\begin{array}{l}\text { ( } \mathrm{N}^{\circ} \text { de manutenções } \\
\text { corretivas / } \mathrm{N}^{\circ} \text { total de } \\
\text { solicitadas no mês ) } \mathrm{X} \\
100\end{array}$ & Mensal & $10 \%$ & $\begin{array}{l}\text { Gestão } \\
\text { Hospitalar }\end{array}$ \\
\hline 21 & $\begin{array}{l}\text { Percentual de Erros } \\
\text { identificados no } \\
\text { Processo de Teste. }\end{array}$ & $\begin{array}{l}\text { (Total de erros } \\
\text { encontrados / Total de } \\
\text { testes realizados) X } 100\end{array}$ & Mensal & $20 \%$ & $\begin{array}{l}\text { Gestão } \\
\text { Hospitalar }\end{array}$ \\
\hline 22 & $\begin{array}{l}\mathrm{N}^{\circ} \text { de notificações } \\
\text { de Eventos } \\
\text { adversos } \\
\text { relacionados à } \\
\text { Assistência ao } \\
\text { Paciente recebidas } \\
\text { pelo GR. }\end{array}$ & Número de notificações & Mensal & $\begin{array}{l}\geq 140 \text { notificações } \\
\text { mensais }\end{array}$ & $\begin{array}{l}\text { Gestão } \\
\text { Hospitalar }\end{array}$ \\
\hline 23 & $\begin{array}{l}\mathrm{N}^{\circ} \text { de notificações } \\
\text { relacionadas às } \\
\text { Tecno logias de } \\
\text { Saúde recebi das } \\
\text { pelo Serviço de } \\
\text { Gerenciamento de } \\
\text { Risco por mês. }\end{array}$ & Número de notificações & Mensal & $\begin{array}{l}\mathrm{N}^{\circ} \text { de notificações } \\
\text { mensais } \geq 102\end{array}$ & $\begin{array}{l}\text { Gestão } \\
\text { Hospitalar }\end{array}$ \\
\hline 25 & $\begin{array}{l}\text { Percentual de falta } \\
\text { de materiais em } \\
\text { estoque. }\end{array}$ & $\begin{array}{l}\text { (Quantidade de itens } \\
\text { que faltaram durante o } \\
\text { mês / Total de Itens de } \\
\text { estoque) X } 100\end{array}$ & Mensal & $\begin{array}{l}\text { Manter em } 5 \% \text { o } \\
\text { Índice de falta de } \\
\text { materiais de esto } \\
\text { que. }\end{array}$ & $\begin{array}{l}\text { Gestão } \\
\text { Hospitalar }\end{array}$ \\
\hline 26 & $\begin{array}{l}\text { Percentual de } \\
\text { entregas em atraso }\end{array}$ & $\begin{array}{l}\left(\mathrm{N}^{\circ} \text { de itens recebidos }\right. \\
\text { em atraso / total de itens } \\
\text { recebidos) x } 100\end{array}$ & Mensal & $\begin{array}{l}15 \% \text { de entregas } \\
\text { com atraso }\end{array}$ & $\begin{array}{l}\text { Gestão } \\
\text { Hospitalar }\end{array}$ \\
\hline 27 & $\begin{array}{l}\text { Percentual de } \\
\text { resolutividade das } \\
\text { faltas. }\end{array}$ & $\begin{array}{l}\text { (quantidade de itens que } \\
\text { faltaram durante o mês } \\
\text { - quantidade de itens } \\
\text { em falta não resolvidos } \\
\text { no final do mês / } \\
\text { quantidade de itens que } \\
\text { faltaram durante o mês) } \\
\text { X } 100\end{array}$ & Mensal & Atingir $80 \%$. & $\begin{array}{l}\text { Gestão } \\
\text { Hospitalar }\end{array}$ \\
\hline
\end{tabular}




\begin{tabular}{|c|c|c|c|c|c|}
\hline 28 & $\begin{array}{l}\text { Percentual da } \\
\text { variação de preços } \\
\text { no período. }\end{array}$ & $\begin{array}{l}\text { (Valor total contrata do } \\
\text { - Valor total nego ciado } \\
\text { / Valor total contratado) } \\
\text { X } 100\end{array}$ & Mensal & $\begin{array}{l}\text { Atingir índice > } \\
\text { zero. }\end{array}$ & $\begin{array}{l}\text { Gestão } \\
\text { Hospitalar }\end{array}$ \\
\hline 29 & $\begin{array}{l}\text { Índice de não } \\
\text { conformi dade no } \\
\text { Inventário do } \\
\text { Almoxarifado }\end{array}$ & $\begin{array}{l}\left(\mathrm{N}^{\circ} \text { de itens em não }\right. \\
\text { conformidade / total de } \\
\text { itens inventaria dos) } \mathrm{X} \\
100\end{array}$ & Mensal & Atingir $8,95 \%$ & $\begin{array}{l}\text { Gestão } \\
\text { Hospitalar }\end{array}$ \\
\hline 30 & $\begin{array}{l}\text { Avaliação dos } \\
\text { serviços prestados - } \\
\text { Campus - ( } \mathrm{N}^{\mathrm{o}} \text { de } \\
\text { não conformidades) }\end{array}$ & $\begin{array}{l}\text { Quantidade de não } \\
\text { conformidades }\end{array}$ & Mensal & $\begin{array}{l}\text { máximo de } 30 \text { não } \\
\text { conformidades por } \\
\text { mês. }\end{array}$ & $\begin{array}{l}\text { Gestão } \\
\text { Hospitalar }\end{array}$ \\
\hline 31 & $\begin{array}{l}\text { Número de } \\
\text { Solicitações de } \\
\text { Urgência pelas Uni } \\
\text { dades Usuárias do } \\
\text { HC-Campus }\end{array}$ & $\begin{array}{l}\text { Quantidade de soli } \\
\text { citações de urgência }\end{array}$ & Mensal & $\begin{array}{l}\text { máximo de } 30 \\
\text { solici tações de } \\
\text { urgência }\end{array}$ & $\begin{array}{l}\text { Gestão } \\
\text { Hospitalar }\end{array}$ \\
\hline 32 & $\begin{array}{l}\text { Avaliação dos } \\
\text { serviços prestados - } \\
\text { U.E. - (N }{ }^{\circ} \text { de não } \\
\text { conformidades) }\end{array}$ & $\begin{array}{l}\text { Quantidade de não } \\
\text { conformidades }\end{array}$ & Mensal & $\begin{array}{l}\text { máximo de } 30 \text { não } \\
\text { conformidades por } \\
\text { mês. }\end{array}$ & $\begin{array}{l}\text { Gestão } \\
\text { Hospitalar }\end{array}$ \\
\hline 33 & $\begin{array}{l}\text { Porcentagem de } \\
\text { devolução de peças } \\
\text { de enxoval - U.E. }\end{array}$ & $\begin{array}{l}\text { (Qtd kg roupa pro } \\
\text { cessada entregue } \\
\text { (limpa) / Qtd kg rou pas } \\
\text { recolhidas (su jas)) X } \\
100\end{array}$ & Mensal & $\begin{array}{l}\text { Índice de devolu } \\
\text { ção de roupas } \\
\text { limpas é de } 88 \%\end{array}$ & $\begin{array}{l}\text { Gestão } \\
\text { Hospitalar }\end{array}$ \\
\hline 34 & $\begin{array}{l}\text { Porcentagem de } \\
\text { devolução de peças } \\
\text { de enxoval - } \\
\text { Campus }\end{array}$ & $\begin{array}{l}\text { (Qtd kg roupa pro } \\
\text { cessada entregue } \\
\text { (limpa) / Qtd kg rou pas } \\
\text { recolhidas (su jas)) X } \\
100\end{array}$ & Mensal & $\begin{array}{l}\text { Índice de devolu } \\
\text { ção de roupas } \\
\text { limpas é de } 88 \%\end{array}$ & $\begin{array}{l}\text { Gestão } \\
\text { Hospitalar }\end{array}$ \\
\hline
\end{tabular}




\begin{tabular}{|c|c|c|c|c|c|}
\hline 35 & $\begin{array}{l}\text { Avaliação dos } \\
\text { serviços prestados } \\
\text { pela Empresa } \\
\text { Terceirizada } \\
\text { (Enfermarias) }\end{array}$ & $\begin{array}{l}\text { Média das oito avali } \\
\text { ações feitas no mês / } \\
0,50 \text {. Média do con } \\
\text { tingente operacional, } \\
\text { comparado ao esti } \\
\text { pulado em contrato. A } \\
\text { pontuação obtida / } 0,50 \text {. } \\
\text { Somar os valores } \\
\text { obtidos. }\end{array}$ & Mensal & $\begin{array}{l}\text { Atingir a } \\
\text { pontuação máxima } \\
\text { de } 674 \text { pon tos. }\end{array}$ & $\begin{array}{l}\text { Gestão } \\
\text { Hospitalar }\end{array}$ \\
\hline 36 & $\begin{array}{l}\text { Avaliação dos } \\
\text { serviços prestados } \\
\text { pelo SHL }\end{array}$ & $\begin{array}{l}\text { Média das oito avali } \\
\text { ações feitas no mês / } \\
0,50 \text {. Média do con } \\
\text { tingente operacional, } \\
\text { comparado ao estipu } \\
\text { lado em contrato. A } \\
\text { pontuação obtida / } 0,50 \text {. } \\
\text { Somar os valo res } \\
\text { obtidos. }\end{array}$ & Mensal & $\begin{array}{l}\text { Atingir a } \\
\text { pontuação máxima } \\
\text { de } 674 \text { pontos. }\end{array}$ & $\begin{array}{l}\text { Gestão } \\
\text { Hospitalar }\end{array}$ \\
\hline 37 & $\begin{array}{l}\text { Avaliação dos } \\
\text { serviços prestados - } \\
\text { Empresa } \\
\text { Terceirizada } \\
\text { (Ambulatórios) }\end{array}$ & $\begin{array}{l}\text { Média das oito avali } \\
\text { ações feitas no mês / } \\
0,50 \text {. Média do con } \\
\text { tingente operacional, } \\
\text { comparado ao estipu } \\
\text { lado em contrato. A } \\
\text { pontuação obtida / } 0,50 \text {. } \\
\text { Somar os valo res } \\
\text { obtidos. }\end{array}$ & Mensal & $\begin{array}{l}\text { Atingir a } \\
\text { pontuação máxima } \\
\text { de } 674 \text { pontos. }\end{array}$ & $\begin{array}{l}\text { Gestão } \\
\text { Hospitalar }\end{array}$ \\
\hline 38 & $\begin{array}{l}\text { Avaliação dos } \\
\text { serviços prestados - } \\
\text { Empresa } \\
\text { Terceirizada - } \\
\text { Amb/Enferm (No } \\
\text { de reclamações) }\end{array}$ & $\begin{array}{l}\text { Acompanhamento da } \\
\text { planilha básica de } \\
\text { captação de dados. }\end{array}$ & Mensal & $\begin{array}{l}\text { Acompanhamento } \\
\text { por } 6 \text { meses antes } \\
\text { de se estabelecer a } \\
\text { meta. Salientamos } \\
\text { que em janeiro de } \\
2013 \text { era } \\
\text { monitorado apenas } \\
\text { o atendi mento } \\
\text { telefônico e à } \\
\text { partir de fevereiro } \\
\text { foi implantado no } \\
\text { SHL a Central de } \\
\text { Atendi mentos de } \\
\text { BIP, o que alterou } \\
\text { o núme ro de } \\
\text { reclamações } \\
\text { recebidas. }\end{array}$ & $\begin{array}{l}\text { Gestão } \\
\text { Hospitalar }\end{array}$ \\
\hline 39 & $\begin{array}{l}\text { Avaliação dos } \\
\text { serviços prestados } \\
\text { (No de reclamações } \\
\text { - ENF/AMB - } \\
\text { SHL) }\end{array}$ & $\begin{array}{l}\text { Acompanhamento da } \\
\text { planilha básica de } \\
\text { captação de dados. }\end{array}$ & Mensal & $\begin{array}{l}\text { Máximo de } 20 \text { re } \\
\text { clamações ao mês. }\end{array}$ & $\begin{array}{l}\text { Gestão } \\
\text { Hospitalar }\end{array}$ \\
\hline 40 & $\begin{array}{l}\text { Avaliação dos } \\
\text { serviços prestados } \\
\text { pelas Empresas } \\
\text { Terceirizadas (No } \\
\text { de Reclamações) }\end{array}$ & $\begin{array}{l}\text { Número de reclama } \\
\text { ções / Mês }\end{array}$ & Mensal & $\begin{array}{l}\text { Mediante as infor } \\
\text { mações captadas, } \\
\text { mensurar a capaci } \\
\text { dade produtiva do } \\
\text { setor e realizar } \\
\text { ações pertinentes } \\
\text { para não acarretar } \\
\text { sobrecarga ou ocio } \\
\text { sidade no setor. } \leq \\
5 .\end{array}$ & $\begin{array}{l}\text { Gestão } \\
\text { Hospitalar }\end{array}$ \\
\hline
\end{tabular}




\begin{tabular}{|c|c|c|c|c|c|}
\hline 41 & $\begin{array}{l}\text { Produtividade do } \\
\text { setor PABX }\end{array}$ & $\begin{array}{l}\mathrm{N}^{\circ} \text { de ligações por } \\
\text { servidor (Quantidade } \\
\text { total de ligações } \\
\text { realizadas pelo PABX / } \\
\mathrm{N}^{\circ} \text { médio de servidores } \\
\text { ativos no mês) / } \\
\text { quantidade total de } \\
\text { ligações realizadas. }\end{array}$ & Mensal & Z 3000 ligações & $\begin{array}{l}\text { Gestão } \\
\text { Hospitalar }\end{array}$ \\
\hline 42 & $\begin{array}{l}\text { Tempo de parada } \\
\text { dos elevadores em } \\
\text { horário de } \\
\text { funcionamento }\end{array}$ & $\begin{array}{l}\text { Somatória das horas } \\
\text { paradas dos elevado res }\end{array}$ & Mensal & $\leq 20$ horas/mês & $\begin{array}{l}\text { Gestão } \\
\text { Hospitalar }\end{array}$ \\
\hline 43 & $\begin{array}{l}\text { Quantidade de ocor } \\
\text { rências de furtos no } \\
\text { Hospital. }\end{array}$ & $\begin{array}{l}\text { Somatória das ocor } \\
\text { rências de furtos e } \\
\text { outros delitos na } \\
\text { Instituição. }\end{array}$ & Mensal & $\leq 26$ & $\begin{array}{l}\text { Gestão } \\
\text { Hospitalar }\end{array}$ \\
\hline 47 & $\begin{array}{l}\text { Percentual de } \\
\text { fatura mento das } \\
\text { internações e } \\
\text { atendimentos } \\
\text { ambula toriais de } \\
\text { média e alta } \\
\text { complexidade }\end{array}$ & $\begin{array}{l}\text { Perfil das internações: } \\
\text { 1) Vr. Faturado dos } \\
\text { procedimentos de alta } \\
\text { complexidade (SIH) X } \\
\text { 100, dividido pelo total } \\
\text { faturado (somados } \\
\text { procedi mentos de Alta } \\
\text { e Média Complexidade } \\
\text { do SIH) = Percentual } \\
\text { das Internações de Alta } \\
\text { Complexidade. 2) Vr. } \\
\text { Faturado dos } \\
\text { procedimentos de } \\
\text { Média Complexidade } \\
\text { (SIH) X 100, dividido } \\
\text { pelo total Faturado } \\
\text { (somados procedi } \\
\text { mentos de Alta e Média } \\
\text { Complexidade do SIA) } \\
\text { = Percentual dos } \\
\text { atendimentos Média } \\
\text { Complexidade. }\end{array}$ & Mensal & $\begin{array}{l}\text { Apontar dados } \\
\text { para o registro de } \\
\text { infor mações e } \\
\text { otimiza ção do } \\
\text { faturamento. }\end{array}$ & $\begin{array}{l}\text { Gestão } \\
\text { Hospitalar }\end{array}$ \\
\hline 48 & $\begin{array}{l}\text { Valor Médio da } \\
\text { AIH por } \\
\text { especialidade }\end{array}$ & $\begin{array}{l}\text { Valor Médio das AIHS } \\
\text { - Valor Total do } \\
\text { Faturamento / n total } \\
\text { das AIHS apresen } \\
\text { tadas. E Valor Médio } \\
\text { das AIHS por } \\
\text { especialidade - Valor } \\
\text { faturado da } \\
\text { especialidade / } \mathrm{n}^{\circ} \text { de } \\
\text { AIHs da especialida de }\end{array}$ & Mensal & $\begin{array}{l}\text { Apontar dados } \\
\text { para o registro de } \\
\text { informa ções e } \\
\text { otimização do } \\
\text { faturamento. }\end{array}$ & $\begin{array}{l}\text { Gestão } \\
\text { Hospitalar }\end{array}$ \\
\hline 73 & $\begin{array}{l}\text { Taxa das faltas de } \\
\text { pacientes }\end{array}$ & $\begin{array}{l}\left(\mathrm{N}^{\circ} \text { de faltas } / \mathrm{N}^{\circ} \mathrm{de}\right. \\
\text { agendamentos }) \times 100\end{array}$ & Mensal & $18 \%$ & $\begin{array}{l}\text { Gestão } \\
\text { Hospitalar }\end{array}$ \\
\hline 74 & $\begin{array}{l}\mathrm{N}^{\circ} \text { de atendimento } \\
\text { ambulatorial } \\
\text { realizado no CER }\end{array}$ & $\begin{array}{l}\mathrm{N}^{\circ} \text { de atendimentos } \\
\text { ambulatoriais realizados } \\
\text { no Centro de } \\
\text { Reabilitação. }\end{array}$ & Mensal & $\begin{array}{l}12.000 \\
\text { atendimentos } \\
\text { mensais. }\end{array}$ & $\begin{array}{l}\text { Gestão } \\
\text { Hospitalar }\end{array}$ \\
\hline
\end{tabular}




\begin{tabular}{|c|c|c|c|c|c|}
\hline 99 & $\begin{array}{l}\text { Índice de perfuro } \\
\text { cortante recebido } \\
\text { na seção de } \\
\text { descontaminação. }\end{array}$ & $\begin{array}{l}\left(\mathrm{N}^{\circ} \text { de materiais }\right. \\
\text { perfuro cortantes } \\
\text { recebidos misturados } \\
\text { com instrumentais do } \\
\mathrm{CC} / \mathrm{N}^{\circ} \text { de cirurgias } \\
\text { realizadas no Centro } \\
\text { Cirúrgico e Anexo 1) X } \\
100\end{array}$ & Mensal & Índice de $0,9 \%$ & $\begin{array}{l}\text { Gestão } \\
\text { Hospitalar }\end{array}$ \\
\hline 100 & $\begin{array}{l}\text { Total de itens } \\
\text { esterilizados } \\
\text { mensalmente }\end{array}$ & $\begin{array}{l}\text { Total de itens } \\
\text { esterilizados }\end{array}$ & Mensal & $\begin{array}{l}\text { Atingir } 72.000 \\
\text { itens }\end{array}$ & $\begin{array}{l}\text { Gestão } \\
\text { Hospitalar }\end{array}$ \\
\hline 101 & $\begin{array}{l}\text { Taxa de kits } \\
\text { anestésicos } \\
\text { devolvidos com } \\
\text { sujidade }\end{array}$ & $\begin{array}{l}\left(\mathrm{N}^{\circ} \text { de Kits anestésicos }\right. \\
\text { sujos recebidos na } \\
\text { devolução / } \mathrm{N}^{\circ} \text { de Kits } \\
\text { anestésicos enviados ao } \\
\text { Bloco Cirúrgico) } \mathrm{X} \\
100\end{array}$ & Mensal & Índice 3,0\% & $\begin{array}{l}\text { Gestão } \\
\text { Hospitalar }\end{array}$ \\
\hline 102 & $\begin{array}{l}\text { Tempo médio de } \\
\text { emissão de laudos }\end{array}$ & $\begin{array}{l}\text { Média da quantidade de } \\
\text { dias de liberação do } \\
\text { exame, emitida pelo } \\
\text { Sistema HC - Laudos } \\
\text { Patologia }\end{array}$ & Mensal & $\begin{array}{l}\text { Manter os } 6 \text { dias } \\
\text { úteis para emissão } \\
\text { dos laudos de } \\
\text { patologia cirúrgica. }\end{array}$ & $\begin{array}{l}\text { Gestão } \\
\text { Hospitalar }\end{array}$ \\
\hline 103 & $\%$ necropsias & $\begin{array}{l}\left(\mathrm{N}^{\circ} \text { de necropsias } / \mathrm{n}^{\circ}\right. \\
\text { de óbitos) X } 100\end{array}$ & Mensal & $\begin{array}{l}\text { Atingir 30\% dos } \\
\text { casos de } \\
\text { falecimento de } \\
\text { pacientes do } \\
\text { Campus e U.E. }\end{array}$ & $\begin{array}{l}\text { Gestão } \\
\text { Hospitalar }\end{array}$ \\
\hline 104 & $\begin{array}{l}\text { Tempo médio de } \\
\text { emissão de laudos }\end{array}$ & $\begin{array}{l}\text { Média da quantidade de } \\
\text { dias de liberação do } \\
\text { exame, emitida pelo } \\
\text { Sistema HC - Laudos } \\
\text { Cipatologia }\end{array}$ & Mensal & $\begin{array}{l}\text { Manter os } 3 \text { dias } \\
\text { úteis para emissão } \\
\text { dos laudos de } \\
\text { citopatologia. }\end{array}$ & $\begin{array}{l}\text { Gestão } \\
\text { Hospitalar }\end{array}$ \\
\hline 105 & $\begin{array}{l}\text { Taxa de PA's } \\
\text { devolvidos após o } \\
\text { envio de cobrança. }\end{array}$ & $\begin{array}{l}\text { (Total de PA's } \\
\text { devolvidos após a } \\
\text { cobrança / Total de } \\
\text { PA's cobrados) X } 100\end{array}$ & Mensal & $\begin{array}{l}\text { Garantir a } \\
\text { devolução de } 80 \% \\
\text { dos PA's cobrados. }\end{array}$ & $\begin{array}{l}\text { Gestão } \\
\text { Hospitalar }\end{array}$ \\
\hline 106 & $\begin{array}{l}\text { Taxa de PA's } \\
\text { devolvidos }\end{array}$ & $\begin{array}{l}\text { (Total de PA's } \\
\text { devolvidos / total de } \\
\text { PA's retirados) x } 100\end{array}$ & Mensal & $\begin{array}{l}\text { Garantir a } \\
\text { devolução de } \\
\text { 100\% dos PA's } \\
\text { retirados. }\end{array}$ & $\begin{array}{l}\text { Gestão } \\
\text { Hospitalar }\end{array}$ \\
\hline 107 & $\begin{array}{l}\text { Taxa de } \\
\text { prontuários } \\
\text { devolvidos após } \\
\text { envio de cobrança. }\end{array}$ & $\begin{array}{l}\text { (Total de prontuários } \\
\text { devolvidos após a } \\
\text { cobrança / total de } \\
\text { prontuários cobrados) X } \\
100\end{array}$ & Mensal & $\begin{array}{l}\text { Garantir a } \\
\text { devolução de } 95 \% \\
\text { dos prontuários } \\
\text { cobrados. }\end{array}$ & $\begin{array}{l}\text { Gestão } \\
\text { Hospitalar }\end{array}$ \\
\hline 108 & $\begin{array}{l}\text { Taxa de } \\
\text { prontuários } \\
\text { devolvidos. }\end{array}$ & $\begin{array}{l}\text { (Total de prontuários } \\
\text { devolvidos / total de } \\
\text { prontuários retirados) x } \\
100\end{array}$ & Mensal & $\begin{array}{l}\text { Garantir a } \\
\text { devolução de } \\
100 \% \text { dos } \\
\text { prontuários } \\
\text { retirados. }\end{array}$ & $\begin{array}{l}\text { Gestão } \\
\text { Hospitalar }\end{array}$ \\
\hline 109 & $\begin{array}{l}\text { Taxa de } \\
\text { solicitações } \\
\text { atendidas no prazo } \\
\text { de } 30 \text { dias. }\end{array}$ & $\begin{array}{l}\text { (Total de solicitações } \\
\text { atendidas / Total de } \\
\text { solicitações recebidas) } \\
\text { X } 100\end{array}$ & Mensal & $\begin{array}{l}\text { Garantir o } \\
\text { atendimento de no } \\
\text { mínimo } 90 \% \text { das } \\
\text { solicitações. }\end{array}$ & $\begin{array}{l}\text { Gestão } \\
\text { Hospitalar }\end{array}$ \\
\hline 110 & $\begin{array}{l}\% \text { atendimento do } \\
\text { Serviço Social - } \\
\text { ACOI }\end{array}$ & $\begin{array}{l}\text { ( } \mathrm{N}^{\circ} \text { de atendimentos } \\
\text { efetuados pelo Serviço } \\
\text { Social / } \mathrm{N}^{\circ} \text { de consultas } \\
\text { médicas do } \\
\text { Ambulatório de Cola } \\
\text { genose Infantil - ACOI) }\end{array}$ & Mensal & $\begin{array}{l}\text { Atender } 60 \% \text { dos } \\
\text { casos agendados } \\
\text { no Ambulatório de } \\
\text { Colagenose } \\
\text { Infantil - ACOI }\end{array}$ & $\begin{array}{l}\text { Gestão } \\
\text { Hospitalar }\end{array}$ \\
\hline
\end{tabular}




\begin{tabular}{|c|c|c|c|c|c|}
\hline & & X 100 & & & \\
\hline 111 & $\begin{array}{l}\text { \% atendimento do } \\
\text { Serv. Social - } \\
\text { Ambulatório de } \\
\text { Endocrinologia } \\
\text { Obstétrica } \\
\text { (ENDOB 600) }\end{array}$ & $\begin{array}{l}\left(\mathrm{N}^{\circ} \text { de pacientes que }\right. \\
\text { participaram do grupo / } \\
\mathrm{N}^{\circ} \text { de cocnsultas } \\
\text { médicas do Ambulató } \\
\text { rio ENDOB } 600) \times 100\end{array}$ & Mensal & $\begin{array}{l}\text { Atender } 20 \% \text { das } \\
\text { pacientes } \\
\text { agendadas no } \\
\text { Ambulatório de } \\
\text { Endocrinologia } \\
\text { Obstétrica } \\
\text { (ENDOB 600) }\end{array}$ & $\begin{array}{l}\text { Gestão } \\
\text { Hospitalar }\end{array}$ \\
\hline 112 & $\begin{array}{l}\% \text { atendimento do } \\
\text { Serv. Social no } \\
\text { CTIA }\end{array}$ & $\begin{array}{l}\left(\mathrm{N}^{\circ} \text { de atendimentos }\right. \\
\text { efetuados pelo Serviço } \\
\text { Social / } \mathrm{N}^{\mathrm{o}} \text { de } \\
\text { internações do CTIA) X } \\
100\end{array}$ & Mensal & $\begin{array}{l}\text { Atender } 70 \% \text { dos } \\
\text { casos internados } \\
\text { no CTIA }\end{array}$ & $\begin{array}{l}\text { Gestão } \\
\text { Hospitalar }\end{array}$ \\
\hline 113 & $\begin{array}{l}\% \text { atendimento do } \\
\text { Serv. Social no } \\
\text { CCP }\end{array}$ & $\begin{array}{l}\text { ( } \mathrm{N}^{\mathrm{o}} \text { de atendimentos } \\
\text { efetuados pelo Serviço } \\
\text { Social / } \mathrm{N}^{\mathrm{o}} \text { de casos } \\
\text { internados na } \\
\text { Enfermaria de CCP) X } \\
100\end{array}$ & Mensal & $\begin{array}{l}\text { Atender } 50 \% \text { dos } \\
\text { casos internados. }\end{array}$ & $\begin{array}{l}\text { Gestão } \\
\text { Hospitalar }\end{array}$ \\
\hline 114 & $\begin{array}{l}\% \text { atendimento do } \\
\text { Serv. Social na } \\
\text { Gastrocirurgia }\end{array}$ & $\begin{array}{l}\text { ( } \mathrm{N}^{\circ} \text { de atendimentos } \\
\text { efetuados pelo Serviço } \\
\text { Social / } \mathrm{N}^{\circ} \text { de casos } \\
\text { internados na } \\
\text { Enfermaria de } \\
\text { Gastrocirurgia) X } 100\end{array}$ & Mensal & $\begin{array}{l}\text { Atender } 50 \% \text { dos } \\
\text { casos internados. }\end{array}$ & $\begin{array}{l}\text { Gestão } \\
\text { Hospitalar }\end{array}$ \\
\hline 190 & $\begin{array}{l}\text { Taxa de erro de } \\
\text { separação de } \\
\text { medicamento }\end{array}$ & $\begin{array}{l}\left(\mathrm{N}^{\circ} \text { de itens separados }\right. \\
\text { incorretamente / } \mathrm{n}^{\circ} \text { total } \\
\text { de itens separados) } \mathrm{X} \\
100\end{array}$ & Mensal & $\begin{array}{l}\text { A taxa de erro de } \\
\text { separação pelo } \\
\text { auxiliar } \\
\text { farmacêutico deve } \\
\text { ser menor que 5\% }\end{array}$ & $\begin{array}{l}\text { Gestão } \\
\text { Hospitalar }\end{array}$ \\
\hline 191 & $\begin{array}{l}\text { Taxa de erro de } \\
\text { inventário }\end{array}$ & $\begin{array}{l}\left(\mathrm{N}^{\circ} \text { de itens com }\right. \\
\text { divergência de } \\
\text { estoque/ } \mathrm{n}^{\circ} \text { de total de } \\
\text { itens inventariados) X } \\
100\end{array}$ & Mensal & $\begin{array}{l}\text { A taxa de erro de } \\
\text { inventário deve ser } \\
\text { menor que } 20 \% \text {. }\end{array}$ & $\begin{array}{l}\text { Gestão } \\
\text { Hospitalar }\end{array}$ \\
\hline 192 & $\begin{array}{l}\text { Giro de Estoque da } \\
\text { Farmácia }\end{array}$ & $\begin{array}{l}\text { Vr. Contábil dos } \\
\text { medicamentos } \\
\text { consumidos no mês/ } \\
\text { (vr. Contábil do estoque } \\
\text { inicial + final)/2 }\end{array}$ & Mensal & $\begin{array}{l}\text { De acordo com } \\
\text { normas da } \\
\text { Instituição: } 0,5\end{array}$ & $\begin{array}{l}\text { Gestão } \\
\text { Hospitalar }\end{array}$ \\
\hline 193 & $\begin{array}{l}\text { Taxa de tarefas } \\
\text { alteradas }\end{array}$ & $\begin{array}{l}\text { (Tarefas alteradas / } \\
\text { tarefas planejadas) X } \\
100\end{array}$ & Mensal & $\begin{array}{l}\text { Taxa menor que } \\
5 \%\end{array}$ & $\begin{array}{l}\text { Gestão } \\
\text { Hospitalar }\end{array}$ \\
\hline 194 & $\begin{array}{l}\text { Taxa de cloro não } \\
\text { conforme na água } \\
\text { potável. }\end{array}$ & $\begin{array}{l}\left(\mathrm{N}^{\circ} \text { de amostras não }\right. \\
\text { conformes } / \mathrm{n}^{\circ} \text { de } \\
\text { amostras analisadas) X } \\
100 .\end{array}$ & Mensal & $\begin{array}{l}\text { Taxa menor que } \\
5 \%\end{array}$ & $\begin{array}{l}\text { Gestão } \\
\text { Hospitalar }\end{array}$ \\
\hline 195 & $\begin{array}{l}\text { Taxa de aquisição } \\
\text { de medicamentos } \\
\text { não padronizados }\end{array}$ & $\begin{array}{l}\left(\mathrm{N}^{\circ} \text { de itens adquiridos }\right. \\
\text { não padronizados / } \mathrm{N}^{\circ} \\
\text { de itens dispensados) } \mathrm{X} \\
100\end{array}$ & Mensal & $<3 \%$ & $\begin{array}{l}\text { Gestão } \\
\text { Hospitalar }\end{array}$ \\
\hline 196 & $\begin{array}{l}\text { Taxa de falta de } \\
\text { medicamentos ao } \\
\text { paciente internado }\end{array}$ & $\begin{array}{l}\left(\mathrm{N}^{\circ} \text { de itens }\right. \\
\text { padronizados não } \\
\text { atendidos / } \mathrm{n}^{\circ} \text { de itens } \\
\text { padronizados } \\
\text { solicitados) X } 100\end{array}$ & Mensal & $\begin{array}{l}\text { Garantir a } \\
\text { integralidade do } \\
\text { tratamento } \\
\text { proposto ao } \\
\text { paciente internado }\end{array}$ & $\begin{array}{l}\text { Gestão } \\
\text { Hospitalar }\end{array}$ \\
\hline
\end{tabular}




\begin{tabular}{|c|l|l|l|l|l|}
\hline 197 & $\begin{array}{l}\text { Taxa de } \\
\text { intervenções } \\
\text { farmacêuticas - } \\
\begin{array}{l}\text { Central de } \\
\text { Quimioterapia }\end{array}\end{array}$ & $\begin{array}{l}\text { (Intervenções } \\
\text { farmacêuticas / Total de } \\
\text { prescrições analisadas) } \\
\text { X 100 }\end{array}$ & $\begin{array}{l}\text { Mensal } \\
\text { Deve ser menor } \\
\text { que 5\% }\end{array}$ & $\begin{array}{l}\text { 6\% (série } \\
\text { histórica) }\end{array}$ & $\begin{array}{l}\text { Gestão } \\
\text { Hospitalar }\end{array}$ \\
\hline $\begin{array}{l}\text { Taxa Global de } \\
\text { infecção hospitalar } \\
\text { - Unidade de } \\
\text { Emergência }\end{array}$ & $\begin{array}{l}\text { (No total de IH / } \\
\text { egressos) X 100 }\end{array}$ & Mensal & $\begin{array}{l}\text { Manter a taxa } \\
\text { global de infecção } \\
\text { hospitalar igual ou } \\
\text { inferior a 5\% }\end{array}$ & $\begin{array}{l}\text { Gestão } \\
\text { Hospitalar }\end{array}$ \\
\hline
\end{tabular}

